\title{
FAMILIES ARE FOR THRIVING, NOT JUST SURVIVING: AGED OUT FOSTER YOUTHS' EXPERIENCES OF FAMILY, HOME, AND ESTRANGEMENT
}

A Dissertation
Presented to
The Faculty of the Graduate School
At the University of Missouri-Columbia
In Partial Fulfillment
Of the Requirements for the Degree
Doctor of Philosophy
By
LESLIE R. NELSON
Dr. Colleen Colaner, Dissertation Advisor
MAY 2018


The undersigned, appointed by the dean of the Graduate School, have examined the dissertation entitled

FAMILIES ARE FOR THRIVING, NOT JUST SURVIVING: AGED OUT FOSTER

YOUTHS’ EXPERIENCES OF FAMILY, HOME, AND ESTRANGEMENT

presented by Leslie R. Nelson,

a candidate for the degree of doctor of philosophy of communication, and hereby certify that, in their opinion, it is worthy of acceptance.

Associate Professor Colleen Colaner

Assistant Professor Haley Horstman 
Associate Professor Brian Houston 
Associate Professor Clark Peters 

This dissertation is dedicated to my participants, who so graciously shared their stories with me. 


\section{ACKNOWLEDGEMENTS}

Writing and completing a dissertation takes a village. I feel so blessed for the many people that supported me throughout this journey and helped me fulfill this lifelong dream of mine. I am forever grateful for the people who made me into the scholar, teacher, and person I am today. I want to first thank my participants, for being willing to share their stories and experiences with me. In just a few short hours I learned so much about your lives, struggles, achievements, and futures. I think of you all often and am constantly reminded of the power of your narratives. I believe each and every one of you has the ability to change the world. I am so grateful for the opportunity to share bits and pieces of your lives in this work.

I also want to sincerely thank my advisor, Dr. Colleen Colaner. I do not think I will ever be able to adequately thank you for all of your support and guidance over the past six years. You were not only an advisor, but also a mentor, friend, and confidant. You challenged me in ways that made me a better researcher, teacher, and professional. When the going got tough you were always there to remind me to "work smarter, not harder." You were also always eager to celebrate my achievements and never stopped believing in me. I will sure miss having you just a few flights of stairs away, but the knowledge and advice you have provided me will guide me for years to come. Thank you, thank you, thank you! You really are the best.

I also want to express my gratitude for my dissertation committee members. Dr. Clark Peters, thank you for offering your expertise on the foster care system. You introduced me to literature that positively shaped my dissertation work and were always eager to provide thorough feedback. I am so appreciative of your guidance along the way. 
Dr. Brian Houston, thank you for pushing me to carefully consider my dissertation arguments and claims. And yes, Omaha, NE is the greatest city in the world! Dr. Haley Horstman, I could always count on you to ask insightful questions that encouraged me to carefully consider the decisions I was making throughout the dissertation process. Not only am I grateful for your insights, I am thankful for the many conversations we had about the job market, teaching, and life in general. You always provided honest advice and really engaged in perspective-taking (but seriously). You are such a positive person and I am so grateful for the time that I have gotten to work with you and converse with you over the past five years. From puppy yoga to narrative seminars - I will value the memories we have made for years to come.

I also want to sincerely thank my students. I have been so incredibly blessed to teach and mentor so many impressive, driven, and hilarious students over the years. You all have helped me realize my true passion and I will treasure the kind words of support you have offered me over the years. Thank you all for the memories, I am so proud that I got to be your teacher. I will always be here to support you and cheer you on as you go out and achieve your own dreams! I cannot wait to see all that you accomplish!

I also cannot thank my colleagues and friends enough for their support over the last six years. As we all know, that support was mostly tied to out-of-office shenanigans. From trivia to game nights to sand volleyball to dinner parties... the time spent decompressing with you all will always hold a special place in my heart. You made Columbia truly feel like home and I am so grateful to have made life-long friends throughout this journey. You all are the best! A special shout out goes to Rocio, my dissertation buddy. From writing nights at Uprise to our daily GIFs and Facebook 
convos, I always knew we had each other to get through the inevitable ups and downs of the dissertation process. You are such a dear friend to me and I cannot wait to support each other through the next stages of our careers (insert our favorite diss GIF here)!

Of course, I would not be here today if it were not for the support of my family. To my mom, you instilled in me from a young age the idea that I had the ability to achieve my dreams. You did this by showing me what it meant to be a successful, strong, and passionate woman. You are not just my mom, you are my role model, my friend, my rock, my fellow pea in the pod... I love you so much, and I cannot thank you enough for everything you have said and done to get me to this point in my life. To Mark, you taught me what it meant to be disciplined... to set my mind on something and never give up. You were always quick to say "good luck, good luck" and have celebrated my achievements every step of the way. You were always there, and I cannot thank you enough for that. I am so lucky to have you in my life and love you more than you know! To Eric, I really do not think I would be here today if I did not have the support of the best big brother in the world. You have taught me so many lessons throughout my life from how to successfully get chores done 30 minutes before Mom got home to teaching me what it means to be a genuinely good person. You are an inspiration to me and I can only hope to be half the spouse and parent you are one day. I love you, brother. To Ashton, thank you for supporting and celebrating me on this wild journey. I love how our relationship has grown closer and stronger than I ever could have imagined over the years. Our (nearly) daily conversations are something I always look forward to and I am so lucky to call you my sister. You are the epitome of what it means to be a faithful, loving, and caring person. I appreciate you and love you! To the kiddos, thank you for 
being my inspiration in so many ways. Your stories touched me and shaped me into the researcher I am today. Your hugs, calls, cards, and pictures have made me feel so loved. I am the luckiest aunt in the world and love each of you so stinkin' much! I cannot wait to continue to watch each of you grow into your own unique selves. Being your aunt is one of my favorite things in the world!

Last but certainly not least, I want to thank my little family. To Piper, where would I be without you, girl? You brought a smile to my face every single day. From ruffling the blinds to nudging my arm - you seemed to know just when I needed a break. I am the luckiest fur mom in the world and wish you could know how much it meant to me to have you here. You were my constant and I will forever remember you as being such an integral part of this life stage. I love you, Pip! To Marc, gosh... where do I even begin? I could not have dreamed of having a more thoughtful, encouraging, supportive, kind, and generous person to support me throughout this process. You never hesitated to celebrate each and every achievement along the way, big or small. From flowers to cards to trips to toasts, you always make me feel special. I am so lucky to call you my best friend and cannot wait to see how our life unfolds. Thank you for everything - your unwavering support, your goofiness, and your belief in me. I love you lotso! Adventure partners for life. 


\section{TABLE OF CONTENTS}

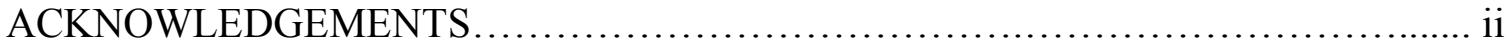

LIST OF TABLES.................................................................. viii

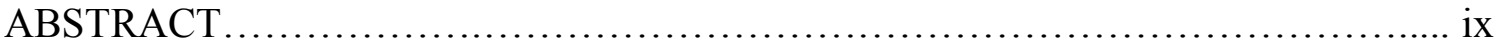

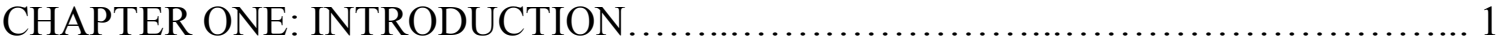

CHAPTER TWO: LITERATURE REVIEW....................................... 10

Challenges Facing Aged Out Foster Youth...................................... 11

Resilience Among Aged Out Foster Youth.................................... 15

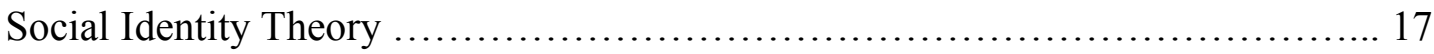

Social Construction of Family Groups........................................ 21

Engaging Family ............................................................... 34

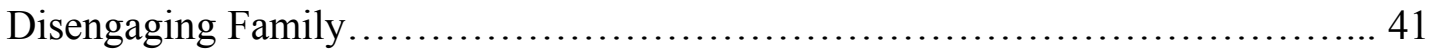

CHAPTER THREE: METHODOLOGY ........................................ 56

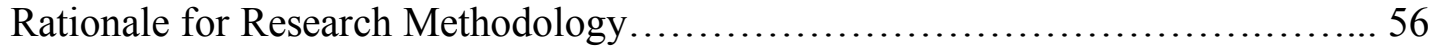

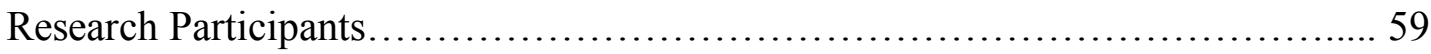

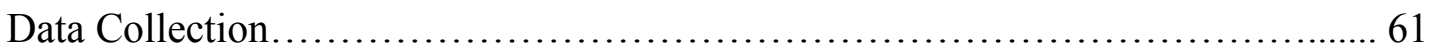

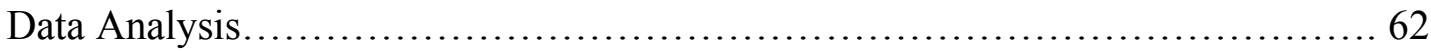

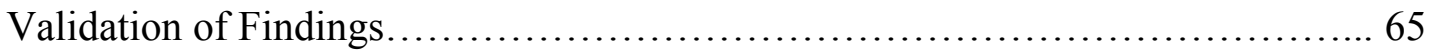

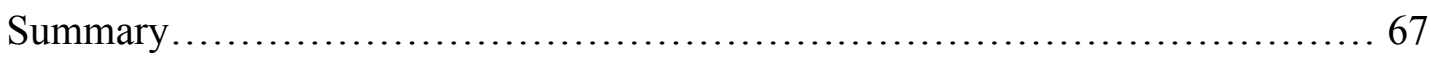

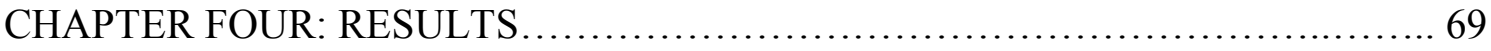

Research Question One: Defining and Categorizing "Family"........................ 69

Defining "Family" (RQ1a) ............................................ 70

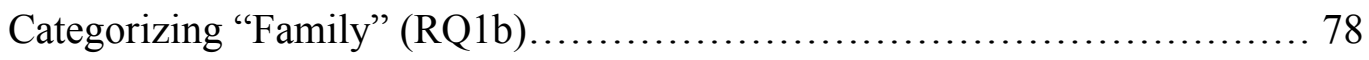

Research Question Two: Making Sense of "Home" ............................ 87

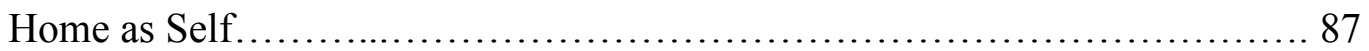

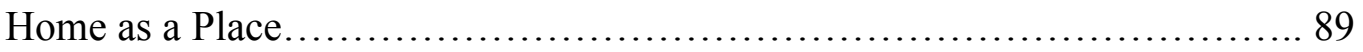

Home as Family ........................................................ 95

Research Question Three: Constructing and Maintaining Family Identity............ 97

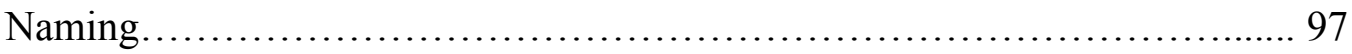

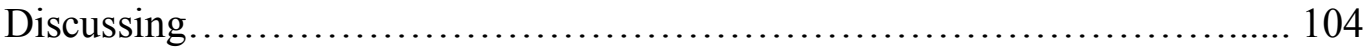

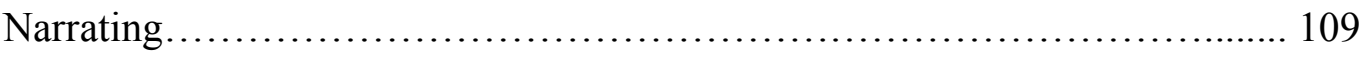




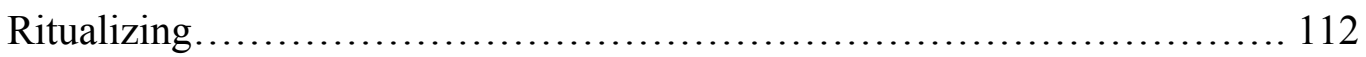

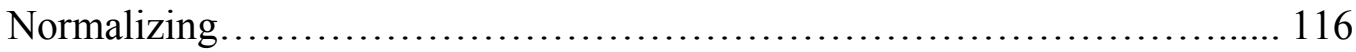

Research Question Four: The Faces of and Reasons for Family Estrangement.... 117

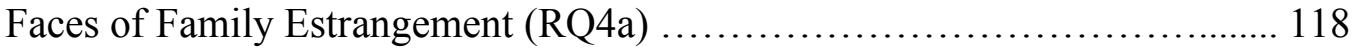

Reasons for Family Estrangement RQ4b) ................................. 121

Research Question Five: Deconstructing Family Identity........................ 125

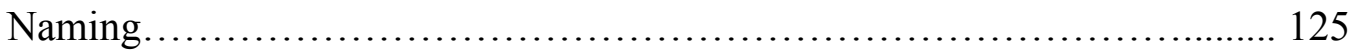

Discussing ........................................................... 133

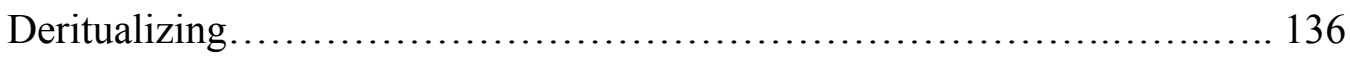

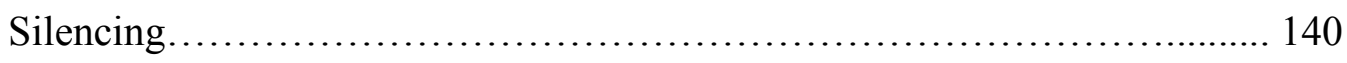



Research Question Six: Impacts of Family Estrangement......................... 147

Emotional Implications.................................................... 148

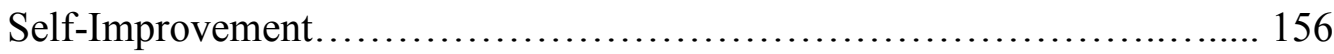

CHAPTER FIVE: DISCUSSION................................................ 164

Family Estrangement as a Potential Pathway to Self-Actualization.............. 164

Implications for Discourse-Dependence Theorizing......................... 176

Implications for Social Identity and Intergroup Theorizing................... 185

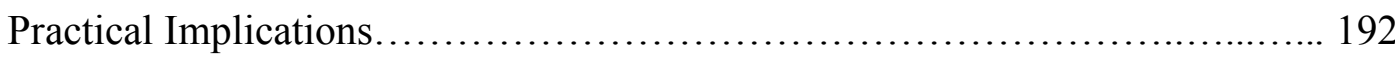

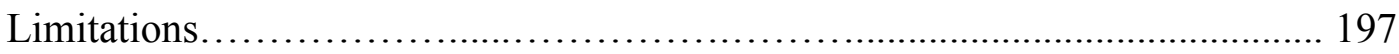

Directions for Future Research....................................... 200



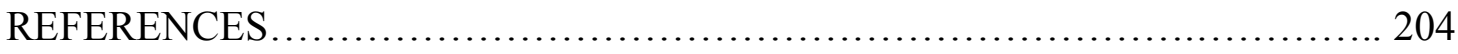

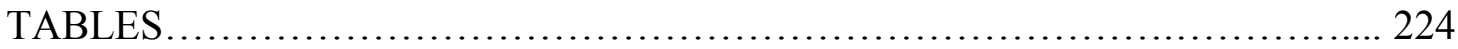

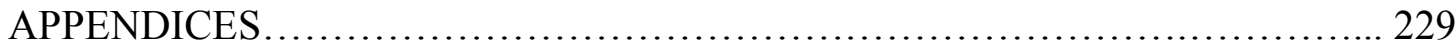

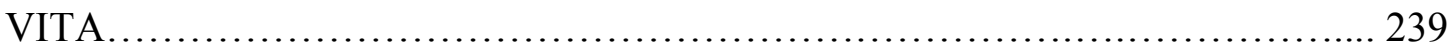




\section{LIST OF TABLES}

Table 1. Participant Demographics.......................................... 224

Table 2. Family Ingroup Members...................................... 225

Table 3. Family Outgroup Members.......................................... 226

Table 4. Liminal Group Members....................................... 227

Table 5. Estrangement Profiles.............................................. 228 


\begin{abstract}
Guided by social identity (Tajfel \& Turner, 1986), social constructionism (Berger \& Luckmann, 1967; Gergen, 1985), and discourse-dependence (Galvin, 2006; Galvin \& Braithwaite, 2014) theorizing, the present study illuminated the communicative experiences and complexities inherent to family and home life for youth who aged out of foster care. Broadly, results from 30 interviews afforded a necessary understanding of how aged out foster youth understand and process "family," "home," and family identity formation and deconstruction in conversations with others. First, findings revealed that "family" was conceptualized as those who love you unconditionally, as those who support you, and as more than blood - signifying a valuing of function (e.g., love, support) over structure (e.g., blood/legal ties) when defining "family." The criteria aged out foster youth applied to "family" informed aged out foster youths' decision-making processes about what individuals were identified as family ingroup members, family outgroup members, and liminal group members. Second, results indicated that participants drew upon their experiences before, during, and after care when making sense of home as self, home as a place, and home as family. Third, findings revealed that aged out foster youth utilized naming, discussing, narrating, ritualizing, and normalizing to build and maintain family identity with family ingroup members. Fourth, results indicated that aged out foster youth most often estranged from biological family members due to physical actions, personal attributes, and/or lack of social support. Ultimately, participants reported estranging from family members because they defied their personal standards for family relationships. In order to actively deconstruct family identity with these family members, aged out foster youth utilized the discursive strategies of naming,
\end{abstract}


discussing, deritualizing, silencing, and disassociating to deliberately defy standards of family as a way to create distance. Last, results revealed that aged out foster youth tended to focus on the positive impacts of family estrangement on the self through discussing both emotional implications (i.e., positive affect, negative affect, and mixed affect) and self-improvement implications (i.e., demonstrating empowerment, encouraging self-care, and promoting mental health).

Findings contribute to family communication and family estrangement research by illuminating how aged out foster youth accounts spoke to family estrangement as a potential pathway to self-actualization. Results also advance discourse-dependence theorizing by empirically testing Galvin and Braithwaite's (2014) proposed identity deconstruction strategies and illuminating how standards for identity-building talk have heightened. Moreover, findings contribute to social identity and intergroup theorizing through revealing how the family ingroup is being reimagined and complicating our understandings of intergroup distinctions. A host of practical implications, such as offering estrangement coaching and developing practical skills for evaluating family, also emerged. Ultimately, results from the current study pave the way for future research to continue to explore how family and home life are discussed and experienced among aged out foster youth. 


\section{Chapter 1: Introduction}

"Aging out" refers to the time when foster youth have reached legal adulthood, meaning the state no longer holds rights over foster youth as a consequence of age (Scott, 2012). In order to age out of the foster care system, the foster child must currently be in the system (i.e., not reunified with birth parent(s) or legal guardian(s); not adopted by kin or non-kin) when the state considers the foster youth a legal adult. In the past year, approximately 17,188 foster youth aged out of the United States foster care system (Adoption and Foster Care Analysis Reporting System [AFCARS], 2016).

Foster youth are vulnerable during their transition out of care and, consequently, often experience a variety of mental, behavioral, and social issues (Courtney \& HughesHeuring, 2005; Cunningham \& Diversi, 2013). These issues can be attributed, in part, to the host of challenges foster youth often face upon exiting care. Research has revealed many aged out foster youth experience high rates of educational failure (i.e., many do not graduate high school), unemployment and poverty, poor mental health (i.e., former foster youth suffer from high rates of depression and have poor psychological health overall), criminal involvement (i.e., more likely than general population to have criminal record), single parenting (i.e., more likely to have children out of wedlock), and housing instability (i.e., high rates of housing mobility and many youth do not have a place to safely reside) (Courtney et al., 2016; Courtney \& Hughes-Heuring, 2005; Courtney, Piliavin, Grogan-Kaylor, \& Nesmith, 2001; Cox, 2013; Cunningham \& Diversi, 2013; Dworsky, Napolitano, \& Courtney, 2013; Fowler, Toro, \& Miles, 2009; Leone \& Weinberg, 2010). Moreover, aged out foster youth often do not have the same social supports (e.g., familial, peer, professional) as their peers who do not age out of care. As a 
result, many aged out foster youth report feeling socially isolated upon aging out of care (Courtney \& Hughes-Heuring, 2005; Cunningham \& Diversi, 2013; Samuels, 2009).

Despite the many challenges facing aged out foster youth, research has shown they have the potential to overcome adversity under certain conditions (Jones, 2012; Legault, Anawati, \& Flynn, 2006; McWey, Acock, \& Porter, 2010). These conditions include having a strong social support network, being older at discharge, and keeping in contact with former foster connections (Legault et al., 2006; McWey et al., 2010). In fact, findings reveal maintaining a strong social network can lead to feelings of belongingness which, in turn, contributes to increases in self-esteem (Legault et al., 2006). Thus, developing and maintaining a strong social network may allow aged out foster youth to positively adapt to negative life events upon aging out of care (Jones, 2012; Legault et al., 2006). However, knowledge of how aged out foster youth may cultivate and maintain meaningful family relationships and abandon destructive family relationships has yet to be examined from a communication perspective.

Grounded in theories of social identity (Tajfel \& Turner, 1986), social constructionism (Berger \& Luckmann, 1967; Gergen, 1985), and discourse-dependence (Galvin, 2006; Galvin \& Braithwaite, 2014), the current study seeks to better understand how aged out foster youth communicatively manage their familial identities in light of their aged-out status. Specifically, the goals of the current study are: (1) to understand how aged out foster youth define "family," family ingroup members, and family outgroup members, (2) to examine how aged out foster youth make sense of home, (3) to explore the communication strategies aged out foster youth utilize to create and sustain a family identity, and (4) to illuminate the complex characteristics and communication processes 
associated with the family estrangement process (i.e., who are defined as estranged family members, reasons for family estrangement, communication strategies utilized to deconstruct family identity, and impacts of family estrangement).

\section{Study Goals}

In what follows, the four overarching goals of the study will be articulated and expanded upon: defining family, conceptualizing home, engaging family, and disengaging family.

\section{Defining Family}

The current study first seeks to shed light on how aged out foster youth define "family" as well as their own family ingroups and outgroups. In the absence of permanent familial ties, such is the case with aged out foster youth, discourse serves as the vehicle by which family connections are constructed, negotiated, and maintained (Galvin, 2006). Because identifying family is an inherently communicative process, family groups are socially constructed and communicatively defined. Therefore, by applying social constructionism (Berger \& Luckmann, 1967; Gergen, 1985) and social identity (Tajfel \& Turner, 1986) frameworks, we can better understand how aged out foster youth shape their realities and identities through their communication with others. Of particular importance is exploring how aged out foster youth define "family," family ingroup members, and family outgroup members. Beyond accounting for the ambiguity associated with not having a legal family, constructing and defining family becomes even more complex when factoring in the voluntary nature of family ties. Upon aging out, foster youth have agency in identifying and enacting familial group distinctions (i.e., who is [ingroup] and who is not [outgroup] family). Therefore, in light of family becoming 
ambiguous and voluntary upon aging out of foster care, it is important to examine how aged out foster youth define "family" as well as family ingroup and outgroup members.

\section{Conceptualizing Home}

Understanding how aged out foster youth make sense of "home" represents the second goal of the current paper. Previous research has revealed home is often related to feelings of safety, security, freedom, comfort, and love (Collier, Phillips, \& Ledema, 2015; Depres, 199; Easthope, 2004; Scharp, Paxman, \& Thomas, 2016; Somerville, 1997; Tester \& Wingfield, 2013). Although these studies demonstrate how home is conceptualized, the majority of these definitions have surfaced from research examining White, middle-class families (Despres, 1991). As a result, researchers have begun calling for understandings of home in more diverse contexts (Easthope, 2004). Because aged out foster youth often transition between homes, or placements, while in care and $18.3 \%$ of foster youth report experiencing homelessness within one year of aging out of care (Courtney et al., 2016), it is likely aged out foster youth conceive of home in unique and varying ways. Because home is socially constructed and sustained through discourse, exploring aged out foster youths' conceptions and experiences of home is worthwhile and necessary. In so doing, we can better understand how aged out foster youth may cultivate "home" before, during, and after exiting care. This knowledge could prove fruitful when attempting to establish "home" for youth aging out of the foster care system.

\section{Engaging Family}

The third goal of the study centers on assessing the specific communication strategies aged out foster youth utilize to create and sustain their family ingroup identity. Drawing from discourse-dependence theorizing (Galvin, 2006), the four internal 
boundary management strategies of naming, discussing, narrating, and ritualizing may shed light on the communication processes aged out foster youth utilize to create and sustain a family identity with family ingroup members. Beyond examining the utilization of Galvin's strategies in nurturing a family identity, it is plausible context-specific strategies may also emerge. Context-specific strategies refer to communication strategies that help to create and sustain family identity that are not accounted for in Galvin's (2006) internal boundary management theorizing (Nelson \& Colaner, 2018). In diverse family forms, context-specific strategies play a particularly important role in cultivating family ties and identity (Nelson \& Colaner, 2018). In fact, previous research has revealed context-specific strategies are prevalent in both non-neurotypical families (Hays \& Colaner, 2016) and transracial adoptive families (Nelson \& Colaner, 2018). This study answers the call by Nelson and Colaner to further investigate the prevalence of contextspecific strategies in diverse families by examining their utilization in aged out foster

youths' family identity constructions. Taken together, Galvin's (2006) internal boundary management strategies and context-specific communication strategies (Nelson \& Colaner, 2018) may help illuminate the complex process by which aged out foster youth construct and sustain a family identity in light of the voluntary and ambiguous nature of family ties upon aging out of care.

\section{Disengaging Family}

Despite the focus thus far on examining how communicative constructions and enactments of family and home may foster a strong support network and a salient family identity, the fourth goal of the paper focuses on the ways in which aged out foster youth may disengage, or estrange from, family. Several aspects of family estrangement will be 
assessed, including: who aged out foster youth identify as estranged family members, reasons for family estrangement, the communication strategies aged out foster youth utilize to deconstruct family identity, and the impacts of family estrangement.

To date, family estrangement has primarily been examined in the biological parent-child relationship (see Carr, Holman, Abetz, Koenig Kellas, \& Vagnoni, 2015; Scharp, 2014; Scharp, Thomas, \& Paxman, 2015; Scharp \& Thomas, 2016). Consequently, examining family estrangement in more complex contexts is vital to assess (Scharp, 2014; 2017). Examining reasons, enactments, and impacts of family estrangement amongst aged out foster youth represents a complex context for these youth have experienced at least two families/homes throughout their lives (e.g., biological family, foster family, residential care facility, group home, etc.). Moreover, because many foster children transition between foster families, group homes, and residential care facilities (Reilly, 2002), aged out foster youth may draw from their involvement in multiple family and/or home systems (i.e., beyond one biological and one foster family, group home, or residential care facility) to describe their family estrangement experiences. Therefore, addressing Scharp's $(2014 ; 2017)$ call to examine estrangement in more diverse contexts, family estrangement will be considered from the perspectives of aged out of foster youth.

First, in order to make sense of how aged out foster youth experience family estrangement, it is imperative to examine what family members aged out foster youth estrange from and for what reasons. By asking aged out foster youth to reflect on their family estrangement experiences, we can better understand the potentially diverse ways in which family estrangement is characterized and experienced. Second, it is critical to 
assess the communicative strategies aged out foster youth employ to deconstruct family identity - an important component of the family estrangement process (Galvin, 2014; Galvin \& Braithwaite, 2014; Scharp, 2017). Previous research has revealed family estrangement is an inherently communicative process (Galvin, 2014; Galvin \& Braithwaite, 2014; Scharp, 2014). Just as individuals utilize discourse to construct their family identity, they also use discourse to deconstruct their family identity (Galvin, 2014). Although research on family estrangement from a communicative perspective is still in its infancy, Galvin and Braithwaite (2014) set forth four potential deconstruction strategies individuals may utilize throughout the family estrangement process: naming, discussing, narrating, and deritualizing. Although vernacular parallels exist between Galvin and Braithwaite's (2014) deconstruction strategies and Galvin's (2006) internal boundary management strategies, these strategies are quite different in practice. Namely, deconstruction strategies are enacted as a means of creating distance as opposed to closeness (Galvin \& Braithwaite, 2014). Consequently, examining how aged out foster youth utilize the four deconstruction strategies, as well as context-specific strategies (see Nelson \& Colaner, 2018), to create and sustain distance from family is critical to assess. Exploring the communication tactics aged out foster youth utilize to deconstruct family identity adds to the growing body of research examining the process and characteristics of family estrangement (see Carr et al., 2015; Scharp, 2014; Scharp et al., 2015; Scharp \& Thomas, 2016; Scharp, 2017) and provides a unique contribution in terms of examining family estrangement in more diverse contexts (i.e., potentially both biological and nonbiological family relationships). In addition to examining who aged out foster youth estrange from, why foster youth estrange, and how foster youth estrange, this study adds 
to the growing body of family estrangement research by assessing what impacts aged out foster youth report experiencing as a result of family estrangement. Ultimately, gauging out foster youths' insights on how they process and respond to family estrangement provides a valuable body of knowledge for both scholars and professionals alike, who may work closely with foster youth during their transition out of care.

\section{Conclusion and Preview}

This chapter provides several justifications for the importance of examining the communicative experiences and complexities associated with transitioning out of the foster care system. This chapter first discussed common challenges aged out foster youth encounter as well as the factors that may promote positive adaptation, or resilience, for youth aging out of care. Next, the four goals of the study were set forth: defining family, conceptualizing home, engaging family, and disengaging family. Aging out often results in challenges that aged out foster youth must navigate and adapt to throughout their lives. Consequently, understanding how communication is affected by and reflected in the lived experiences of aged out foster youth may lend insight into how, why, and to what end they may go about cultivating healthy relationships and abandoning destructive relationships upon transitioning out of care.

Chapter 2 will begin with a lengthened discussion of the challenges facing aged out foster youth and the factors that may allow aged out foster youth to positively adapt upon aging out of care. Next, the theoretical foundations of the current study will be teased out with a specific focus on how "family," family ingroups, family outgroups, and home may be constituted and experienced. Third, communication behaviors that aged out foster youth may utilize to construct their family identity will be discussed. Lastly, how 
family estrangement is constituted and family identity is deconstructed by aged out foster youth will be examined. This study adds to the growing body of literature on foster family communication by examining how aged out foster youth define "family," family ingroup members, family outgroup members, and home as well as the communicative behaviors aged out foster youth utilize to construct and deconstruct family identity. This study will give voice to the complex ways familial identity is communicatively negotiated among aged out foster youth and advance current theorizing on foster family communication, discourse-dependence, social identity, and family estrangement. 


\section{Chapter 2: Literature Review}

The primary reasons children enter the foster care system are domestic violence, poverty, substance abuse, and parental incarceration in their family of origin (Patrick \& Galvin, 2012). By the time children enter into care all have experienced "threatening situations such as neglect, domestic violence, physical abuse, or sexual abuse" (Oswald, Heil, \& Goldbeck, 2010, p. 462). Consequently, prior to entering into the system, many foster children suffer from relatively mild to more serious psychological issues and are often at risk for emotional, social, and behavioral difficulties (Holtan, Ronning, Handegayrd, \& Sourander, 2005; Ryan, Herz, Hernandez, \& Marshall, 2007). Although foster care functions to promote children's well-being and healthy development (Samuels, 2009), research has shown transitioning into the foster care system poses additional challenges for foster children, including mental health issues (e.g., depression, anxiety, and low self-esteem), developmental delays, and behavioral issues (Freundlich \& Wright, 2003; Shin, 2005; Viadero, 2010).

Although foster children often face a host of challenges prior to and upon transitioning into the foster care system, so too do youth who are aging out. These challenges include but are not limited to: housing and economic instability, physical and sexual victimization, and unemployment (Cunningham \& Diversi, 2013). The common thread here lies in the fact that the majority of youth who spend time in the foster care system have experienced significant transitions, losses, challenges, and stressors (Cunningham \& Diversi, 2013; Oswald et al., 2010; Viadero, 2010). It is imperative to understand these challenges because hardships may have lasting effects on aged out foster youths' social support networks, identity formation, and well-being (see Courtney 
et al., 2001; Cunningham \& Diversi, 2012). The challenges aged out foster youth encounter likely set the foundation for the complex communication aged out foster youth must engage in when (de)constructing family and making sense of "home."

Amidst the challenges associated with aging out of care, research has also revealed foster youth may demonstrate healthy behaviors and establish meaningful relationships (Legault et al., 2006; McWey et al., 2010). Thus, examining how aged out foster youth can positively adapt to difficult life circumstances can give insight into the specific conditions that may allow aged out foster youth to flourish despite facing significant hardships (Jones, 2012; Legault et al., 2006; McWey et al., 2010). Specifically, an examination of the relationships and factors that may impact the likelihood of aged out foster youth having stable support networks and a place to call home upon aging out of care will be addressed. Below, a holistic view of the challenges facing aged out foster youth as well as the distinct factors that may allow youth to demonstrate resilience are presented.

\section{Challenges Facing Aged Out Foster Youth}

Research has revealed many foster youth experience difficulties managing the transition from adolescent to independent adult (Courtney \& Hughes-Heuring, 2005). Significant difficulties include poor physical and mental health, difficulty obtaining medical insurance, loss of social supports, and economic and housing instability (Courtney \& Hughes-Heuring, 2005; Cunningham \& Diversi, 2013; Dworsky et al., 2013). Consequently, many aged out foster youth have difficulty securing a job, lack health insurance, experience the criminal justice system, become single parents, and have trouble meeting their fundamental needs (e.g., shelter, food) (Courtney \& Hughes- 
Heuring, 2005; Courtney et al., 2001; Courtney et al., 2016; Cunningham \& Diversi, 2013). As Courtney and Hughes-Heuring (2005) put it: "the deck is stacked against them" (p. 27).

Wave 2 findings from the CalYOUTH study, a longitudinal research project aimed at evaluating the outcomes of extending foster care beyond the age of 18 , shed further light on the challenges associated with aging out of the foster care system (Courtney et al, 2016). This research has revealed that, within one year of aging out of care, $11.8 \%$ of foster youth had lived in five or more places and $18.3 \%$ reported being homeless (i.e., slept in a shelter or a place people are not meant to sleep for at least one night due to not having a place to stay) at least one time since aging out (Courtney et al., 2016). Prior research has indicated that factors leading to housing instability and homelessness include physical and sexual victimization, emotional and behavioral problems, criminal conviction, and dropping out of high school (Fowler et al., 2009). In fact, in this year-long period, $66.8 \%$ of aged out foster youth were not employed, $20.2 \%$ reported being convicted of a crime, and $19.4 \%$ of aged out foster youth were hungry but did not eat because they could not afford food (Courtney et al., 2016).

These challenges may be attributed, in part, to lower levels of educational attainment. Research indicates only $37 \%$ of youth who age out of care graduate high school, just $7 \%$ of youth who had spent at least a year in care accumulate any college credit, and only $9 \%$ of youth take college courses in the $12-18$ months after leaving care (Courtney et al., 2001). Because foster youth are more likely to repeat grades, transition into and out of different school systems, and tend to score lower on standardized tests than their non-fostered peers (Sheppard, 2012), foster youths' successes in terms of 
graduating high school, pursuing college, or securing a well-paying job are often hindered (Cox, 2013; Leone \& Weinberg, 2010). These statistics give voice to how these various challenges, when taken together, manifest into a variety of less-than-ideal conditions that may lead to poor outcomes for youth who have aged out of foster care.

Beyond educational obstacles these challenges may also be attributed, in part, to aged out foster youth not having the same social supports (e.g., family, peer, professional) as their non-fostered peers (Courtney \& Hughes-Heuring, 2005; Cunningham \& Diversi, 2013; Samuels, 2009). Lack of social supports often leads to high rates of social isolation and, consequently, the inability to depend on others in times of need (Courtney \& Hughes-Heuring, 2005). Research examining aged out foster youths' perceptions of their transition to independence has revealed many aged out foster youth report the need for more connections with those who support them before, during, and after aging out (Cunningham \& Diversi, 2013). In other words, aged out foster youth voiced a desire for more contact and communication with those who would eventually serve as their main sources of social support once they were living on their own.

Despite the desire for more social support, research has shown aged out foster youth often have difficulty trusting other people and forming relationships due to their experiences with loss and impermanence over the course of their lives (Cunningham \& Diversi, 2013). Because a lack of social support is linked to anxiety when exiting care, aged out foster youth need more guidance on how to develop, maintain, and sustain healthy relationships. Although most youth reported attempting to establish a connection with biological family members after exiting care, many came to realize these family members did not offer the support they needed (Cunningham \& Diversi, 2013). 
Moreover, regardless of whether reunifications with birth family members were generally positive or negative, research has shown these relationships often dissolve shortly after youth age out of care (Cunningham \& Diversi, 2013), further contributing to aged foster youths' experiences of social isolation.

The difficulty in creating and sustaining relationships often results in many aged out foster youth being highly self-reliant (Cunningham \& Diversi, 2013). Because foster youth experience a multitude of losses throughout their lives, many foster youth strive to be self-reliant and some avoid permanent connections (e.g., legal guardianship; adoption) in order to protect themselves from future loss (Cunningham \& Diversi, 2013). Despite desiring self-reliance, many still worried about becoming homeless, not having food to eat, and not being able to secure a well-paying job (Cunningham \& Diversi, 2013).

Ultimately, the transition to adulthood is unpredictable for foster youth and it is often the case these youth experience social support disruptions, increased stress, and struggle to hold a job, keep a roof over their head, or have food on the table (Courtney \& Hughes-Heuring, 2005; Courtney et al., 2001; Courtney et al., 2016; Cunningham \& Diversi, 2013). Although other family forms experience significant transitions (e.g., divorced families, stepfamilies, military families), the multitude of transitions (i.e., into and out of families; between homes and schools) foster youth go through, in addition to having unique health needs, brands the foster youth experience as unique and complicated. Of particular interest to the present study is examining how these challenges affect and reflect aged out foster youths' creation, maintenance, negotiation, and deconstruction of family ties. Thus, it is worth exploring how these challenges set foster children up for having complex family configurations that must be negotiated through 
communication. One way to better understand how aged out foster youth navigate the transition to adulthood is to examine the conditions that may allow them to flourish in the face of adversity.

\section{Resilience Among Aged Out Foster Youth}

Although foster youth often face severe adversity, research has revealed that nearly $75 \%$ of youth are able to establish at least one productive connection with the adult world (Jones, 2012). Therefore, despite the overwhelming challenges aged out foster youth often face, research has revealed that many aged out foster youth can persevere under the right conditions. Specifically, having a social support system, possessing independent living skills, being older at discharge, and remaining in contact with former foster connections have been shown to promote aged out foster youths' positive adaptations to life circumstances (i.e., resilience) (Jones, 2012; Luthar, Cicchetti, \& Becker, 2000).

A long line of research has confirmed that forming healthy relationships with foster parents and birth families can promote foster youths' mental and behavioral health (Ackerman \& Dozier, 2005; Legault et al., 2006; McWey et al., 2010). Specifically, foster parent involvement, support, and attachment have been associated with increases in foster youths' self-esteem and positive self-representation (Ackerman \& Dozier, 2005; Denuweleara \& Bracke, 2007; Legault et al., 2006; Luke \& Coyne, 2008). These findings suggest parents' emotional investment may allow foster youth to develop a positive sense of self and strategies to adapt to adverse life circumstances. Arguably increased selfesteem and healthy adaptation strategies would serve youth well as they transition out of care. Research has also revealed that more frequent contact with birth mothers is 
associated with lower levels of depression and less externalizing behavioral problems (McWey et al., 2010). Specifically, foster youth who had little to no contact with their birth mothers often had clinically significant behavioral issues (McWey et al., 2010). Thus, supporting frequent and consistent contact with birth family members while foster youth are in care may positively affect foster youths' transition to adulthood.

Beyond establishing healthy relationships with foster and biological parents, foster youth fare best and exhibit less aggressive behaviors when they have a group of close friends and placement stability (i.e., children not moving from home to home or into and out of foster care) (Legault et al., 2006; Mekonnen, Noonan, \& Rubin, 2009). Moreover, research has revealed youth-focused interventions, communication skills, and collaboration between individuals, families, and society in terms of placement and permanency plans may help foster youth positively adapt to challenges they may encounter when aging out of care (Scannapieco, Connell-Carrick, \& Painter, 2007).

Aged out foster youths' ability to adapt (i.e., ability to function in light of previous adversity) may also be impacted by the strength of their community (Houston, 2015; Houston, Spialek, Cox, Greenwood, \& First, 2015). In other words, the strength of the community in which aged out foster youth reside may impact their personal ability to thrive upon transitioning out of care. For example, social support is often fostered in communities and may allow those who have undergone significant traumas or stressful life events, such as aged out foster youth, to better adapt (Houston et al., 2015). In this regard, communities may promote hope, strength, and positive adaptation amongst at-risk youth, such as aged out foster youth (see Allen et al., 2016). Resiliency centered in 
communities emphasizes the human and relational nature of resiliency and may have an impact on aged out foster youths' family-life relationships upon aging out of care.

Taken together, an examination of the factors that can promote resilience among aged out foster youth provides valuable insight into the relationships that aged out foster youth may seek to maintain in order to positively adapt to the difficulties and hardships many experience upon aging out of care. Thus, when addressing aged out foster youths' communicative constructions of family, home, and estrangement, it will be particularly fruitful to examine which relationships and home conditions afford them the opportunity to thrive. In sum, although research has revealed aged out foster youth face a myriad of challenges upon exiting care, fostering healthy relationships may allow youth to positively adapt to the challenges associated with aging out of care and ultimately result in a successful transition to adulthood.

Now that a holistic picture of the aged out foster youth experience has been provided, an exploration of the important role of communication in the lives of these young adults will be presented. One way of understanding the communicative experiences of aged out foster youth is to put into perspective the ways in which group identifications and enactments shape the lives of aged out foster youth. In what follows, we turn to social identity theorizing to examine the ways in which aged out foster youth may define "family," family ingroup members, and family outgroup members in the absence of permanent, legal ties to family.

\section{Social Identity Theory}

At the personal level, individuals are interested in what makes them unique beings; at the collective level, individuals are concerned with what makes the groups they 
belong to distinctive from others (Harwood, 2006). A social identity is the portion of an individual's self-concept derived from perceived memberships in social groups (Giles, Reid, \& Harwood, 2010; Hogg \& Abrams, 2001; Tajfel \& Turner, 1986). Social identities are socially constructed, meaning our identifications with and perceptions of groups are created and negotiated through our communication (Harwood, 2006). Individuals identify the groups they feel they belong to as ingroups and the groups they do not feel they belong to as outgroups (Giles et al., 2010). Social identity serves as a means to inform us of who we are (i.e., us; ingroups) and helps us understand who we are not (i.e., them; outgroups). Thus, social identity theory reflects a collectivist approach to understanding both the self and others (Hogg \& Abrams, 2001).

Because "groups only exist to the extent that people give them meaning," identifying with some groups and not others renders the groups to which an individual belongs as meaningful (Giles et al., 2010, p. 3). Because of this, the more salient a group is to one's personal identity, the more evident group identifications will be in social interactions (Giles et al., 2010; Hornsey, 2008). Research has also demonstrated that we are motivated to maintain a positive social identity (i.e., a collective self-esteem) such that we want to belong in superior groups (Hogg \& Abrams, 2001). Consequently, when we belong to marginalized groups, we tend to seek out ways to uphold a positive social identity (Giles et al., 2010; Hogg \& Abrams, 2001). Three known tactics exist for managing negatively-regarded social identities: social mobility (i.e., leaving group in search of more positive group), social creativity (i.e., changing outlook of group to something more positive or shifting the comparison group), and social competition (i.e., advocating, protesting, or fighting for more favorable group conditions) (Giles et al., 
2010). These tactics can be engaged across a wide range of contexts such as with strangers, acquaintances, friends, and even family.

Although social identity research has often focused on non-intimate encounters (i.e., strangers) (Hogg \& Abrams, 2001), more recently social identity theorizing has been used to understand communicative dynamics in intimate encounters (i.e., families), which are often infused with and shaped by group memberships (Harwood, 2006). Across and within contexts, individuals attempt to create conditions whereby their social identities, or ingroups, will be positively regarded. Communication serves as the vehicle by which group distinctions are negotiated and families often serve as a driving force in these discussions.

\section{Family as a Social Group}

By nature, a family is a collection of social beings and thus constitutes a social group. Just like individuals, families construct identities over time and through discourse (Manning, 2006; Soliz \& Rittenour, 2012). Shared family identity refers to the way family members characterize, experience, or perceive the family as a group across interactional contexts (Manning, 2006). Perceiving a shared family identity means that an individual believes they share a common familial ingroup with at least one other person. Communication is central to this process such that establishing a sense of shared family identity hinges on discourse (Soliz \& Rittenour, 2012; Galvin, 2014). At the same time, discourse also serves as the tool by which a shared family identity is renounced (i.e., we not only rely on discourse to construct a family identity but also rely on discourse to deconstruct a family identity) (Galvin, 2014). In the absence of legal and permanent familial ties, such is the case with aged out foster youth, discourse may become even 
more pertinent for it serves as the very means by which family connections are constructed, deconstructed, negotiated, and maintained (Galvin, 2006).

Importantly, when negotiating family connections, aged out foster youth may consider certain family members to be on the boundary between family ingroup and family outgroup. In reference to the management of one's own perceived family membership, Colaner, Halliwell, \& Guignon (2014) referenced a tension known as a relational-relational gap, whereby adoptees felt as though they were not entirely connected to either their adoptive or birth families. The current study builds upon this finding to suggest individuals may feel a similar tension in reference to their perceptions of others' membership within their family, or who they feel belongs and does not belong in their family. Thus, in specific situations and with certain people, aged out foster youth may also straddle, and must reconcile, familial and non-familial identities. Who aged out foster youth perceive to be in their family ingroup and outgroup may be in flux and vary from situation to situation as well as from person to person. For example, should an aged out foster youth reunite with a biological family member, they may consider that family member to be family yet not family. The biological family member may be regarded as familial due to their shared genes. However, the biological family member may simultaneously be considered not family due to the absence of a long-term status (i.e., the youth spent time away from the biological family member while in foster care), for example. Aged out foster youth may also consider some foster family relationships to be on the boundary between groups (i.e., family ingroup and family outgroup). In this scenario, the foster family member may be regarded as familial because of the time they spent with this family member while in care, yet not family due to the absence of shared 
genes. It is plausible these distinctions may change or morph as new relationships form and take shape upon youths' transition out of care. These "marginal" identities raise questions about the legitimacy of an identity and encourage difficult ascriptions (e.g., he/she is not really a family ingroup member, or he/she is not really family outgroup member). In situations such as this, the authenticity of a social identity is questioned. For aged out foster youth, the legitimacy of others' status as "family" may be questioned in light of the societal assumptions about family (e.g., families are long-term, biologically related, and legally connected) (Floyd, Mikkelson, \& Judd, 2006). Building upon this line of research, the current study attempts to illuminate how aged out foster youth discursively make sense of family authenticity, and ultimately, their family identity.

The inherent diversity of the foster family structure highlights the importance of understanding the role communication plays in constructing, negotiating, maintaining, and potentially deconstructing family identity (Galvin, 2014; Soliz \& Rittenour, 2012). In the current study, examining how aged out foster youth make sense of and (de)construct familial group memberships through their communication is of particular interest. Identifying family is an inherently communicative process (Galvin, 2006). Thus, like all groups, family groups must be socially constructed and communicatively defined.

\section{Social Construction of Family Groups}

Berger and Luckmann (1967) introduced the theory of social constructionism with the intent to understand how knowledge, rather than communication, was socially constructed (Leeds-Hurwitz, 2006). However, today, social constructionism is rooted in communication (Leeds-Hurwitz, 2006). A social constructionist approach illuminates how people make sense of their realities (Gergen, 1985) and operates under the 
assumption that conversation is "the most important vehicle of reality-maintenance" (Berger \& Luckmann, 1967, p. 152). In other words, a social constructionist approach posits communication is the tool by which we talk our realities into being (Berger \& Luckmann, 1967; Gergen, 1985). It is through our interactions with others that our realities are shaped, identities are defined, and we begin to make sense of the social world in meaningful ways (Gergen, 2003; Leeds-Hurwitz, 2006). As such, everyday talk often creates and sustains not only our realities, but also our relationships with others (Baxter, 2004; Leeds-Hurwitz, 2006). As Baxter (2004) noted: "relationships are constituted in communication practices" such that "persons and relationships are not analytically separable from communication" (p. 3). In this regard, communication is the vehicle by which individuals and relationships exist, survive, and thrive in society (Leeds-Hurwitz, 2006). For example, "family" only exists to the extent that people define it and give it meaning. Family is constituted through language (Baxter, 2004; Leeds-Hurwitz, 2006).

A long line of family communication research has utilized the framework of social constructionism to better understand communicative decisions and dynamics inherent to diverse family forms, such as foster and adoptive families (see DocanMorgan, 2014; Suter, 2008; Suter \& Ballard, 2009; Suter, Baxter, Seurer, \& Thomas, 2014). In fact, research has demonstrated familial (Galvin, 2006; Suter, 2008) identities are constructed, maintained, repaired, and changed through our conversations with others.

Social constructionism is a particularly fruitful guiding theory for examining the communication constructions and deconstructions of family for aged out foster youth because, in addition to accounting for construction and maintenance, social constructionism takes into account the elements of repair and change (Carey, 1989). As 
Leeds-Hurwitz (2006) argues, "if we stop displaying a concept, such as a family's identity, over time, it dissipates, dissolves, ceases to be true" (p. 231). In these situations, as may be the case for aged out foster youth who have agency over family configurations, they may choose to maintain their family identity to make it relevant, repair the social construction of family to account for change, or change their social construction of family altogether. Therefore, by applying a social constructionism framework in the current study, we can better understand how aged out foster youth shape their realities and identities through family communication. One important area of inquiry is examining how aged out foster youth socially construct "family."

\section{Current Approaches to Defining Family}

Given the increasing diversity of U.S. families, a myriad of laws and practices have been adjusted to reflect the permanent whitewater we have been experiencing in terms of family definition stability (Galvin, 2003, 2006, 2012). As a result, how family communication scholars define family has important implications for research, theory, and perceptions of family both within the discipline and at the societal level (Baxter, 2014b; Floyd et al., 2006; Galvin, 2006; Turner \& West, 2015).

Far fewer modern American families reflect full blood and legal ties than in the middle of the $20^{\text {th }}$ century (Galvin, 2014). Consequently, traditional definitions and society's assumptions of family (e.g., sharing genes, having a legal connection, assumed permanence, ongoing interdependence) are often challenged in our current theorizing of and approaches to family communication research (Baxter, 2014a; Baxter \& Braithwaite, 2006; Floyd et al., 2006). Studies emerging on foster families represents just one of the many ways modern families (e.g., foster families, adoptive families, same-sex families, 
etc.) have challenged more traditional definitions and assumptions of family. Indeed, over the past few decades, how family is defined and approached in family communication scholarship has steadily evolved. Now, many more scholars are giving agency to their participants to define family for themselves (Galvin, 2004), which exemplifies how scholars are beginning to recognize the variability inherent to the modern family experience and society's changing assumptions about what constitutes family. Consequently, family communication scholars now often approach definitions of family from a transactional perspective, whereby the focus is on how individuals identify, connect, and experience family with others (Baxter, 2014a).

As Coontz (2000) put it— the nuclear family (i.e., mom, dad, and biological children) is more of a myth now than it ever was a reality. In light of this recognition and rise in diverse families, discourse-dependent families (i.e., diverse families that rely more on talk to establish family identity) are becoming the norm, not the exception (Galvin, 2006). As a result, family members enact discursive strategies to "create, maintain, reconfigure, and/or disconfirm their overall family identity and/or specific relational ties" (Galvin, 2014, p. 18). Consequently, researchers are increasingly paying more attention to the communication among family members, family functioning, and how much families feel like "family" when defining and studying family ties (Galvin, 2006; Baxter, 2014a). In so doing, more of an emphasis has been placed on the social construction of family and how families thrive through their communication (Galvin, 2014) as opposed to defining family based off of structural components (e.g., biological ties; legal connection) (Galvin, 2006; Whitchurch \& Dickson, 1999). This is indicative of the role lens (Floyd et al., 2006), whereby attachment and patterns of interaction are more salient 
to definitions of family than shared genetics and/or legal recognition (i.e., biogenetic and socio-legal lenses; Floyd et al., 2006).

As Munro \& Munro (2003) point out, arriving at a universal definition of family is nearly impossible for definitions are both time-bound and culture-specific. As such, scholars today tend to emphasize either process (i.e., interactions, communicative constructions) or form (i.e., biology, legality) in their definition of family and they will likely continue to do so for the foreseeable future. Given the current study seeks to examine how aged out foster youth communicate and experience family ties, form is acknowledged but process is emphasized. In other words, biology and legality are considered yet how aged out foster youth communicatively construct and deconstruct family is of most importance to the present study. Thus, considering an "aged out" status indicates a foster child was both not adopted and not reunited with their birth family while in care, it is likely aged out foster youth define "family," family ingroup members, and family outgroup members in varied ways.

\section{Communicating Family Ties in the Foster Context}

Family is often the first group a person belongs in and usually provides the most long-lasting group membership for individuals (Socha, 1999). In the foster care context, the word usually is especially pertinent as foster youth may: (1) never reunify with their biological families, (2) transition between foster families, group homes, or residential care facilities seldom or frequently, (3) be adopted by foster parents after birth parents' rights have been terminated, (4) run away while in care, or (5) age out of the foster care system (AFCARS, 2016). Therefore, understandings of family from current, former, and aged out foster youths' perspectives likely vary given their connections to biological 
family, foster family members, group home members, residential care workers, and/or social workers for various amounts of time throughout their lives. Although aged out foster youths' constructions of family have yet to be assessed, a growing body of research has begun to illuminate the ways in which current foster parents, current foster youth, and former foster youth define and make sense of family.

Concerning the viewpoint of foster parents, research has revealed many foster parents must confront the tension of emphasizing that biology constitutes families versus language creates families. In their study of online foster-to-adoption narratives, Suter and colleagues (2014) discovered foster parents communicatively managed the tension between the discourse of biological normativity (i.e., biology creates families) and the discourse of constitutive kinning (i.e., language creates families) when defining and making sense of family. Consequently, foster parents simultaneously accept the influence of biology yet recognize the importance of communication in establishing familial ties.

Likewise, a study examining foster entrance narratives (i.e., the story foster parents tell their child upon the child's transition into the home) revealed a similar tension when making distinctions about the foster child's place in the family (Nelson \& Horstman, 2017). Results indicated some foster parents described the child's status within the family as temporary while others indicated it was forever (Nelson \& Horstman, 2017). Foster parents who stressed the child's place in the family was temporary often discussed the child's return to the birth family whereas those who emphasized a forever status tended to view the child's place in the family as permanent, despite the likelihood of reunification (Nelson \& Horstman, 2017). In so doing, foster parents make sense of the child's place in the family in light of the child's potential return 
to birth parents and face the tension of considering the foster child as "family" or "family-like." In terms of the impact of specific communication behaviors, research has found that foster parents who exhibit high levels of conversation orientation (i.e., willing to engage in open conversations about a variety of topics with their foster child; Koerner \& Fitzpatrick, 2002) tend to view their foster child as a member of their family (Nelson \& Colaner, 2016). This research highlights the centrality of bi-directional, open communication from parent to child and child to parent in fostering family identity.

Taken together, these studies underscore the importance of communication in creating a family identity and further reveal that many foster parents feel conflicted when asked to define how and to what degree their foster child represents a member of their family. Ambiguity becomes a natural part of the foster parent experience in so far that parents must attempt to make sense of their foster child's place in the family in light of a temporary family status. The same holds true for current foster children.

Previous research has indicated adolescent foster youth who are currently in long-term foster care often have a comprehensive and open-minded outlook on family ties (Ellingsen, Stephens, \& Størksen, 2012). In fact, studies have shown current foster youth tend to perceive family in one of three ways: they see both the birth and foster family as their family, they see only the birth family as their family, or they perceive the foster family as being their only family (Andersson, 2009; Ellingsen, Shemmings, \& Størksen, 2011; Gardner, 1998).

A related line of research examining former foster youths' (i.e., individuals who were in foster care at some point throughout their life) sense-making about family revealed two discourses animated their constitutions of family: discourse of permanence 
and discourse of performance (Thomas, Jackl, \& Crowley, 2017). The discourse of permanence emphasizes biological and historical connection whereas the discourse of performance centers around role enactment, tolerance, and unconditional love (Thomas et al., 2017). Results further illuminated how these discourses, at times, interplay in former foster youths' constructions of family; for example, some participants explained that both biological connection and role performance were both important to their constitutions of family (Thomas et al., 2017).

Each of these studies give voice to the complexity of adolescent and former foster youths' sense-making around who and what constitutes family, opening the door for exploring the ways in which aged out foster youth may give voice to the discourses of permanence and/or performance when defining "family" and who they may perceive to be a part of their family ingroup and family outgroup. Importantly, the current study extends this growing body of work by examining aged out foster youth's definitions of "family," family ingroup members, and family outgroup members - which are likely different from other foster youth given aged out foster youth: (a) are not in long-term care and thus may not feel a sense of belonging or attachment to any specific family (b) have likely experienced multiple placements which impact their conceptions and experience of "family," (c) have agency over family configurations, and (d) may regard others (i.e., friends, group home workers, social workers, mentors, other aged out foster youth) beyond foster and biological family members as family. Therefore, whereas research has shown (former) foster youth's perceptions of family can be complex and multifaceted, how aged out foster youth conceive of family has yet to be explored. 
In sum, recent research has revealed current foster parents and children often feel conflicted when asked to define how and to what degree the foster child represents a member of the family (Ellingsen et al., 2012; Suter et al., 2014; Thomas et al., 2017). It is plausible aged out foster youth may experience a similar tension upon aging out of the foster care system given their numerous family options. Because research has demonstrated discourse plays an instrumental role in constructing a family identity (Galvin, 2006; Nelson \& Colaner, 2016), the current study seeks to understand how aged out foster youth define "family," family ingroup members, and family outgroup members. Defining family becomes even more complicated when factoring in the voluntary nature of family ties.

Voluntary nature of family. According to Vangelisti (2006), family relationships are often long-term and, as a result, are difficult to dissolve - even in the presence of abuse or distress. However, aged out foster youth often have a choice in whether they maintain or dissolve existing family ties to biological, foster family, group home, residential care family members and/or others due to the nature of being on their own. To this degree, family becomes voluntary in so far that there is "a mutuality of selection," meaning both parties in a given relationship are afforded a unique understanding and perspective of who is and who is not family (Braithwaite et al., 2010, p. 390). Although various other terms such as intentional families (Muraco, 2006), fictive kin (Chatters, Taylor, Jayakody, 1994), ritual kin (Ebaugh \& Curry, 2000), urban tribes (Watters, 2003), and street families (McCarthy, Hagan, \& Martin, 2002) have been used to describe family ties formed outside of blood and genes (Floyd \& Morman, 2006), the current study will utilize the term voluntary kin as a means of demonstrating what is most 
important about these relationships is how individuals make sense of them (Braithwaite et al., 2010).

A long line of research has indicated the positive aspects of voluntary kin relationships - such as promoting closeness, love, and intimacy, ensuring protection and belongingness, and serving as social supports (Ebaugh \& Curry, 2000; Johnson, 1999; McCarthy, Hagan, \& Martin, 2002; Muraco, 2006; Nelson, 2013; Weston, 1991)however, the very nature of family being voluntary to aged out foster youth is quite different because this term must be considered in light of their previous, often many, family configurations. Youth who age out of the foster care system were, at one point, removed from their biological family due to safety and well-being concerns (Oswald et al., 2010). As such, although foster youth still share genes with their biological family members, these relationships become voluntary in so far that these youth have agency in if they wish to consider biological family members as family.

Concerning previous family configurations outside of the biological family, youth who have aged out also must reconcile these individual members' role in their life as familial or forgotten. However, when considering these connections, it is often the case no legal or biological ties exist. As previous research suggests, these conditions (i.e., lack of genetic and legal connection) most often classify voluntary relationships (Nelson, 2013). Consequently, Braithwaite and colleagues (2011) voluntary kin typology provides a fruitful framework for examining aged out foster youths' understandings of family, such that if foster youth were to attempt to maintain ties with a foster connection (i.e., someone they connected with while in foster care), they may be understood in one of four ways: (1) as substitute family (i.e., foster connection replaces blood and legal family), (2) 
as supplemental family (i.e., in addition to the biological family, the foster connection is also family), (3), as convenience family (i.e., foster connection is family in a certain context or at specific times), or (4), as extended family (i.e., biological family and foster connection are part of the same family). As you can see, the voluntary nature of aged out foster youth considering foster connections as family is quite different from understandings of biological family as family. However, a commonality exists in the fact that both relationships become voluntary upon foster youths' transition out of foster care.

Aged out foster youth have agency in identifying family and enacting familial group distinctions (i.e., who is [ingroup] and who is not [outgroup] family). Because defining family is a voluntary and communicative process (Braithwaite et al., 2010; Galvin, 2006), it is vital we examine how aged out foster youth define "family," family ingroup members, and family outgroup members. Understanding how aged out foster youth make family distinctions not only contributes to the growing body of work examining family conceptualizations, but also provides a useful body of knowledge that may allow professionals to more appropriately talk about and assist in fostering familial connections for aged out foster youth during their transition out of care. With this, the first research question is posed:

RQ1a: How do aged out foster youth define "family?"

RQ1b: Who do aged out foster youth define as family ingroup and family outgroup members?

\section{Experience of Home in the Foster Context}

As youth age out of the system they not only have agency in designating familial relationships, but also how they experience and conceive of home. Although research has 
yet to examine how aged out foster youth define and experience home, previous research has indicated home can be conceived of in complex and myriad ways.

Psychologically, research has revealed home is related to feelings of security, values, and privacy (Depres, 1991). Sociologically, home is the locus for family life and a place of relaxation, safety, freedom, and self-expression (Somerville, 1997). For those nearing the end of life, home equates to being in close proximity to family members and is often regarded as a safe place (Collier, Phillips, \& Ledema, 2015). For individuals experiencing homesickness, home is often defined by feelings such as safety, love, and comfort as well as a physical space (Scharp et al., 2016). Although these studies provide a glimpse into how home is defined, previous research has revealed these lists of meanings often do not regard broader contexts, which inevitably shape the meaning of home (Tester \& Wingfield, 2013). In fact, a majority of these lists have been developed through studies that examined White, middle-class, nuclear families (Depres, 1991). As a result, researchers contend "it is important to explain the concept of 'home' as it is understood in different contexts by different people" (Easthope, 2004, p. 135) rather than trying to create one definition of home that can work in all contexts and for all people (Tester \& Wingfield, 2013). Thus, one particular context of home worth examining is that of aged out foster youth. In particular, understanding how foster youth construct home through discourse is vital for researchers to assess.

Previous research has revealed that central to former foster youths' definitions of permanence are a "real" family and "home" (Samuels, 2009). Specifically, many former foster youth emphasized a relational component of permanence over legal and physical such that relational dimensions of a permanent family tie and sense of home were viewed 
by participants as equally, if not more, important to healthy development (Samuels, 2009). In fact, many youth who aged out of the system searched for "real" family and "home" after transitioning out of care. However, many foster youth reported not receiving support in their search. Therefore, most reported a continued desire, but unmet need, to experience the relational meanings they ascribed to permanency (Samuels, 2009). Research has further indicated that foster children in long-term placements may come to consider a foster placement as home despite feeling connected to birth family members (Biehal, 2012). For these foster youth, rather than home representing a single place, their experience of home may hinge on a feeling a sense of belonging in social, psychological, or spatial domains (Blunt \& Dowling, 2006). In other words, the many transitions between birth and foster placements may disrupt old conceptions of home and establish new constructions of home in terms of belongingness (Biehal, 2012).

Although previous research has afforded an understanding of the way foster youth may experience home, the ways in which home is created and sustained through discourse has yet to be examined by family communication researchers. In light of the need for understanding home in diverse contexts (Depres, 1991; Easthope, 2004; Tester \& Wingfield, 2013) and given the fact $18.3 \%$ of aged out foster youth report being homeless within one year of aging out of care (Courtney et al., 2016), it is worth examining what "home" means to aged out foster youth. In so doing, we can better understand how aged out foster youth cultivate "home" before, during, and after aging out of care. This knowledge could prove fruitful when attempting to establish "home" for youth aging out of the foster care system. Thus, the second research question is posed:

RQ2: How do aged out foster youth make sense of "home?" 


\section{Engaging Family}

Beyond examining aged out foster youths' communicative constructions of family and home, it is vital to examine the specific communication strategies aged out foster youth utilize to construct and maintain their family identity. Discourse-dependence theorizing (Galvin, 2006) allows for an assessment of the communicative nuances associated with aged out foster youths' creation and maintenance of family ingroups.

\section{Discourse-Dependence Theorizing}

Drawing from social constructionism, Galvin (2006) articulated the critical role communication and language play in creating and sustaining family ties. Although all families rely on discursive practices to construct and manage their family identity, increased diversity (i.e., lack of legal and biological ties) within the family results in families becoming more reliant on discursive strategies to create, maintain, and negotiate family identity (Galvin, 2006, 2014). As a result, more diverse families are more “discourse-dependent" (Galvin, 2006). Aged out foster youth are discourse-dependent in that they must rely on communication to construct, maintain, and negotiate family relationships (Galvin, 2006). Because family ties are ambiguous and voluntary in this context, they must be communicatively constructed and sustained throughout the life course. For aged out foster youth, family may be constructed in myriad ways. Regardless of how aged out foster youth define family, one constant remains: they must communicatively construct and maintain their family identity for there are no legal ties, relationships are voluntary, and there may be no biological connection. Thus, the unique characteristics of aged out foster youth result in communication being the mechanism by which family identity is established and (re)affirmed. 
Internal boundary management. Given one purpose of the current study is to gauge how aged out foster youth create and sustain a family identity with family ingroup members, the internal boundary management strategies of naming, discussing, narrating, and ritualizing (Galvin, 2006) will be assessed. Each of these strategies will be discussed in turn with a specific focus on the ways in which aged out foster youth may utilize these strategies to create, negotiate, and sustain their family ingroup.

Naming. In order to establish a family status, family members often turn to the discursive practice of naming - a meaningful indicator of internal family identity (Galvin, 2006). It is often the case naming is instrumental in achieving an inclusive sense of "we" through signifying the degree of closeness between family members. However, in the context of aged out foster youth, the discursive practice of naming becomes even more complex. Although Galvin (2014) notes naming includes "choosing names/titles for persons considered as family but without blood or legal ties," the voluntary nature of aged out foster youths' familial relationships poses a unique situation whereby names may be renegotiated despite blood ties to biological family members (p. 28). In other words, the voluntary nature of those who do and do not share blood ties must be considered when examining how aged out foster youth utilize naming to sustain their family ingroup.

Research has revealed in other diverse family forms, such as adoptive families, naming provides insight into family identity dynamics. Suter (2012) examined naming practices in internationally adoptive families from the parents' perspective and found that parents often (re)named their adopted child for both pragmatic and identity purposes. Recent research has built upon this foundational work by Suter (2012) through examining 
the naming and labeling practices Korean adoptees utilize when referring to their Korean birth parents (see Docan-Morgan, 2017). Findings from this study indicated most participants addressed members of their birth family using Korean terms of address (Docan-Morgan, 2017). However, some participants used name and labels from their adopted country's language, avoided addressing birth parents, and/or used the first name of the birth parent (Docan-Morgan, 2017). Similar to Suter's (2012) findings, DocanMorgan (2017) discovered naming practices often resulted from a desire to appeal to family identity, outsiders, and/or pragmatism. Taken together, these studies underscore the important yet complicated nature of (re)naming in diverse family forms. In light of this previous work, it is important to explore the complex naming practices aged out foster youth engage to build a family identity. Understanding how aged out foster youth utilize naming can shed light on how a family identity is constructed with voluntary family members (e.g., previous foster family members, social workers, friends, mentors, etc.) as well as those that were once regarded as involuntary family members (e.g., biological family members).

Discussing. The discursive strategy of discussing refers to positive family identity-building talk (Galvin, 2006; Jones \& Hackett, 2008). A long line of research has revealed discussions in the family shape family identity (Anderson, Rueter, \& Lee, 2015; Colaner \& Soliz, 2015; Docan-Morgan, 2014; Harrigan \& Braithwaite, 2010; Nelson \& Colaner, 2016). For example, research examining Korean adoptees' reunions with birth families revealed discussions played an instrumental role in adoptees' family identity cultivation. In order to make sense of their complex adoptive and family identities, adoptees often relayed messages or asked questions of their birth families (Docan- 
Morgan, 2014). Discussions between Korean adoptees and their birth family members allowed adoptees to make sense of their unique adoptive identity and overarching family identity. Although discussions between aged out foster youth and family members may revolve around different topics, these conversations are likely equally complex and may serve to solidify aged out foster youths' family identities.

Research has also revealed higher degrees of difference among family members may result in more difficult identity-building conversations (Harrigan \& Braithwaite, 2010). Indeed, research has illuminated that maintaining an open line of communication is important and necessary for family identity development. Specifically, research has shown high degrees of conversation orientation (i.e., family communication orientation which emphasizes family members' willingness and desire to engage in an open and freeflowing dialogue) in families positively predicted shared family identity between foster parent and child (Nelson \& Colaner, 2016). This study illuminates the importance of open discussions in foster families and the positive impact an open communication environment can have on cultivating a family identity. In the context of aged out foster youth, there may be a significant amount of difference between the foster youth and their family members. This may include, but is not limited to: shared genes, geographical location, social class, race, or education. Given these potential differences, discussions may allow aged out foster youth to better make sense of their family situation and identity. Importantly, discussions may vary in breadth and depth and may be based on past, present, or future circumstances.

Narrating. The internal boundary management strategy of narrating refers to the storytelling that occurs in the family as a means of creating family cohesion (Galvin, 
2006). Research has revealed family identity is created, maintained, and negotiated through family storytelling (Docan-Morgan, 2014; Galvin, 2006; Harrigan, 2010; Koenig Kellas, 2005; McAdams, 1993; Stone, 2004). In fact, theorizing on communicated narrative sense-making (CNSM) argues people communicate to make sense of their relationships, identities, lived experiences, and difficulties through storytelling (Koenig Kellas \& Horstman, 2015). Of the three storytelling foci in CNSM theorizing, the focus of the current study centers on retrospective storytelling (i.e., aged out foster youths' recollections of family stories and storytelling processes). Importantly, research has revealed families formed through difference often engage in more complex storytelling (Galvin, 2006). For example, research has revealed that international adoption stories and stories told at birth family reunions were often complex yet necessary for building familial identity (Docan-Morgan, 2014; Harrigan, 2010). These studies demonstrate the importance of storytelling in creating and sustaining family identity.

Studies examining the role of storytelling in foster families are just beginning to emerge. For example, recent research has indicated foster parents often tell foster entrance narratives (FENs) to their foster child upon the child's entrance into the home (Nelson \& Horstman, 2017). Findings revealed FENs affected and reflected family identity and functioning in so far that the story themes of untold (i.e., do not tell entrance narrative to child), better off (i.e., child is better off because he/she is distanced from past situation, hurt, or people), birth parent learning (i.e., birth parents can learn to be better parents), and temporary (i.e., the child's place in the foster family is impermanent) were associated with relational closeness and child adjustment (Nelson \& Horstman, 2017). These findings confirm storytelling is often a powerful indicator of family functioning. 
However, the link between storytelling and identity in the foster context ought to be more closely examined. As a result, the present study seeks to understand how aged out foster youth utilize storytelling to create and sustain a family identity.

Ritualizing. Lastly, ritualizing refers to the enactment of family identity via celebrations and ordinary routines (Galvin, 2006, 2014). Research has revealed ritualizing can help to manage uncertainty (Colaner \& Kranstuber, 2010), can include both one-time and recurring events (Docan-Morgan, 2014), and can be used to celebrate differing social identities within families, such as race or a child's adoptive status (Colaner \& Kranstuber, 2010; Nelson \& Colaner, 2018). Although nearly all families enact rituals, families formed through difference often have difficulty deciding what rituals should be pertinent to the current family dynamic and which rituals should be retained based on family members' past experiences (Galvin, 2006). For example, Nelson and Colaner (2017) interviewed parents who adopted transracially and found many parents felt it was critical to incorporate rituals specific to the child's cultural background as a way to foster a unique family identity. Concerning aged out foster youth and the voluntary nature of family ties, it may be the case that certain youth will want to retain a host of past rituals whereas others may seek to create new family rituals and simultaneously distance themselves from potentially adverse former routines. Depending on whom aged out foster youth define as family, it is plausible the rituals which bind the family now are the very rituals enacted in the past. On the other hand, it is plausible new family rituals and routines have surfaced and serve to solidify the current family identity. Beyond the internal boundary management strategies Galvin (2006) set forth, it is also plausible aged out foster youth utilize other, unique strategies to create and sustain a 
family identity in light of the voluntary nature of their familial status. In fact, past research has revealed, outside of Galvin's (2006) internal and external strategies, contextspecific strategies often emerge in diverse family forms (Nelson \& Colaner, 2018). For example, normalizing (i.e., emphasizing normalcy in terms of family process and functioning) is one strategy that has emerged in past research examining transracial adoptive families, co-mothering families, and families where a child has an autism diagnosis (see Hays \& Colaner, 2016; Nelson \& Colaner, 2018; Suter, Seurer, Webb, Grewe, \& Koenig Kellas, 2015). Moreover, Nelson \& Colaner (2018) discovered that transracial adoptive parents often utilize the strategy of praising (i.e., positively remarking and/or commenting on the adopted child's physical appearance) to reinforce the child's unique ethnic identity in light of their family identity. These studies speak to the potentiality of aged out foster youth also employing unique discursive strategies to create and sustain a family identity. Therefore, in addition to Galvin's (2006) internal boundary management strategies, it is plausible aged out foster youth will utilize contextspecific strategies to create and sustain their family identity.

Taken together, the internal boundary management strategies of naming, discussing, narrating, and ritualizing (Galvin, 2006) can illuminate the ways in which aged out foster youth and their family ingroup members construct and sustain a family identity in light of the voluntary and ambiguous nature of family ties. Beyond these strategies, it is plausible aged out foster youth use other, context-specific, communication strategies to create and maintain a family identity with family ingroup members. Thus, the third research question is articulated: 
RQ3: How, if at all, do aged out foster youth use internal boundary management strategies and context-specific strategies to construct and maintain family identity with family ingroup members?

\section{Disengaging Family}

Although Galvin (2006) has identified distinct internal boundary management practices families utilize to create and sustain a family identity, how family members use discourse to estrange from family members has just recently emerged in family communication research (see Carr et al., 2015; Scharp, 2014; Scharp \& Thomas, 2016; Scharp et al., 2015; Scharp, 2017). The present study attempts to add to this growing body of research by illuminating how aged out foster youth estrange from people they once considered family (e.g., biological family members, foster family members, mentors, peers, etc.). In so doing, the process of family estrangement for aged out foster youth will be examined, and the communicative components of family estrangement will be explored. First, understanding how family estrangement has been conceptualized in previous research can provide a springboard for understanding how aged out foster youth may describe and process their own family estrangement experiences.

\section{Conceptualizing Family Estrangement}

According to Agllias (2013a), family estrangement is the physical or emotional distancing between at least two family members. Physical family estrangement is best understood as contact cessation whereas emotional family estrangement is when parties "have infrequent, perfunctory, and often uncomfortable contact" (Agllias, 2013a, p. 1). Research has further indicated family estrangement is best understood as a process that can be engaged purposefully or aimlessly (Agllias, 2013a; Scharp, 2014). Purposeful 
estrangement involves making a conscious choice to estrange whereas aimless estrangement mimics ambiguous loss in terms of being unclear, traumatic, and confusing (Boss, 2010; Carr et al., 2015). Scharp (2016) identified the three primary approaches to defining family estrangement: (1) psychological (i.e., emotional cutoff, decrease in emotional closeness, and loss of affection), (2) communicative (i.e., purposeful lack of communication, decreasing interdependence, limited interactions), and (3) legal (i.e., rejection of parent by law; focus is on post-divorce parent-child relationships).

Research has further revealed family reasons for family estrangement vary considerably, and include the following: expressing entitlement (Carr et al., 2015), going to war (Boss, 2010), enduring maltreatment and abuse (Dattilio \& Nichols, 2011; Drozd \& Olesen, 2004; Kelly \& Johnston, 2001; Scharp et al., 2015), feeling unsupported (Carr et al., 2015), getting divorced (Dattilio \& Nichols, 2011), having different values (Gilligan, Suitor, \& Pillemer, 2015), being alienated (Friedlander \& Walters, 2010; Jaffe, Asbourne, \& Mamo, 2010), not liking another (Hess, 2000), economic hardship (Kim, 2006), being physically distanced (Kim, 2006; Warshak, 2010), and/or drug use (Winters, Stinchfield, Lee \& Latimer, 2008).

These studies reveal that how researchers conceptualize and approach estrangement in any given study may vary greatly. Research has further indicated that individuals' reasons for family estrangement are equally as complex. Thus, understanding how family estrangement is conceptualized and situated within previous family communication research as well as the present study is vital to assess.

Defining family estrangement communicatively. Family estrangement has long gone under-investigated from a communicative perspective (Baxter, 2014b; Galvin, 
2014; Scharp, 2014). Despite family estrangement being an inherently communicative process (i.e., communication is central to the family estrangement process), only in the past few years have family communication scholars begun researching and defining family estrangement (see Carr et al., 2015; Scharp, 2014, 2017; Scharp et al., 2015; Scharp \& Thomas, 2016). In Carr et al's (2015) study, family estrangement is defined as a lack of communication between parent and child. However, as Scharp (2014) argued, defining family estrangement as a lack of communication between family members oversimplifies the multifaceted process of estrangement and fails to take into account the complex communicative practices individuals must enact to create and maintain distance from family members. Instead, Scharp (2017) defined family estrangement as "a process where at least one family member seeks to distance himself or herself (i.e., limit interaction and decrease interdependence) because of an ongoing negative relationship" (p. 2). Importantly, Scharp (2017) also posits that family estrangement exists along a continuum, which is comprised of eight distancing continua (i.e., communication quality, communication quantity, physical distance, presence/absence of emotion, positive/negative affect, reconciliation/desire to be a family, role reciprocity, and taking legal action). Overall, this continuum recognizes family estrangement as a process and gives voice to the important component of communication throughout the family estrangement process.

For purposes of the current study, Scharp's (2017) conceptualization of family estrangement - as a distancing process existing along a continuum - will be utilized. Thus, family estrangement is acknowledged as a unique and complex distancing process. Put another way, distancing processes cannot always be classified as family estrangement 
(e.g., alienation and marginalization are two additional distancing processes), but family estrangement is always a distancing process. Thus, in terms of a conceptual hierarchical order, at the top is distancing processes, of which family estrangement falls under. In the same token, family estrangement is a higher order process to identity deconstruction. Put simply, the deconstruction of family identity is one aspect of the family estrangement process among many (e.g., managing uncertainty) (Scharp, 2017). Importantly, thirdparty intervention will not be considered family estrangement. For example, when the state removes a foster child from their family of origin that relationship should not automatically be classified as an estranged family relationship. Rather, in line with Scharp's (2017) definition of family estrangement, the foster child would have to deliberately seek to create and maintain distance from that family member - a level of agency must be enacted on the part of the individual to estrange from a specific person. Moreover, family estrangement will not be considered bound to biological family relationships. Rather, the conceptualization of family estrangement in the current study affords the opportunity for individuals to identify any relationship considered family, for any period of time throughout one's life, as an estranged relationship. Now that the distinctions between distancing, family estrangement, and identity deconstruction have been explicated, it is important to examine how aged out foster youth might engage the family estrangement process.

Aged out foster youths' family estrangement experiences. Context is important to consider when attempting to make sense of the family estrangement process. Considering research on family estrangement from a communication perspective has primarily looked at biological parent-child relationships (see Carr et al., 2015; Scharp, 
2014; Scharp et al., 2015; Scharp \& Thomas, 2016), it is imperative to give voice to the experience of family estrangement in more complex contexts (Scharp, 2014; 2017). One context that fits this call is aged out foster youth. Aged out foster youth are unique in so far that they have had at least two families throughout their lives, although many foster children transition from home to home or into and out of the system regularly (Reilly, 2002). Because of this, aged out foster youths' family estrangement experiences may be complex and highly variable given that, upon aging out, these youth: (1) must communicatively reconcile who is family in light of the voluntary nature of all previous familial relationships, (2) may seek or require social support which could infringe on their desire to estrange from certain family members, and (3) might wish to estrange from family members but do not possess the resources to create and sustain distance. Arguably, we must first examine who aged out foster youth define as estranged family members and why aged out foster youth estrange from these particular family members. This foundational knowledge is important for understanding how aged out foster youth approach the family estrangement process as well as the potentially diverse ways in which family estrangement is characterized and experienced at a broader level. Thus, research question four is posed:

RQ4a: Who do aged out foster youth define as estranged family members?

RQ4b: For what reasons do aged out foster youth estrange from family members?

\section{Family Communication Embedded in Family Estrangement}

In light of recognizing the importance of communication in creating and sustaining familial relationships, it is imperative to further explore how family communication is affected by and reflected in the family estrangement process. As 
Baxter (2014) and Galvin (2014) explain, in addition to utilizing communication to construct relationships with others, individuals also utilize communication to deconstruct relationships with others. In other words, it takes communicative work to achieve and maintain identity deconstruction. Although the importance of communication in the family estrangement process has been articulated (see Baxter, 2014; Galvin, 2014; Scharp, 2017), the specific communicative processes that serve to deconstruct familial ties have been addressed minimally in the field of family communication (Galvin, 2014). While family communication scholars may understand deconstructive processes through examining divorce and legal terminations, much less is known about how individuals communicatively deconstruct family identity (Baxter, 2014b; Hess, 2000). Thus, how individuals discursively negotiate family ties and communicate in ways to deconstruct family identity is imperative to assess. In what follows, a discussion of communicative deconstruction strategies will be applied to aged out foster youth.

Deconstructing family identity. As Galvin (2014) explains, individuals may enact communicative deconstruction strategies as a means of removing individuals from their understanding of family (i.e., estranging from family). These deconstructive strategies involve "deliberate, patterned behaviors evidencing a clear intent to dismantle the relationship" and include both verbal and nonverbal discourse (Galvin, 2014, p. 30). Some strategies may involve direct rejection messages that signal a person is no longer part of the family while other strategies may involve maintaining distance in the form of limiting communication and or face-to-face interactions (Galvin, 2014). In response to Galvin's (2014) call for family communication researchers to look more closely at how we use communication to create distance between ourselves and others, Scharp (2014) 
examined young adults' family estrangement narratives and contended children both accomplished and maintained distance communicatively. As Galvin (2014) predicted, Scharp's work confirmed that both direct rejection messages and utilizing more indirect strategies help individuals to maintain distance. For example, in order to accomplish distance, participants often reported engaging in declarative practices whereby they would tell their parent they wished to end the relationship or provided parents with an ultimatum (Scharp, 2014). This finding is characteristic of a direct rejection message. Scharp (2014) also found that some participants reported they maintained distance by not attending family holidays and events - which is characteristic of keeping communication at a minimum and avoiding face-to-face interaction as a distancing strategy. Taken together, these examples highlight the potentiality for different approaches to family estrangement to be utilized. In light of these findings, it may be the case that aged out foster youth utilize direct rejection messages and/or attempt to limit face-to-face contact when communicatively deconstructing family identity.

Beyond Scharp's (2014) examination of distancing strategies, Galvin and Braithwaite (2014) hypothesized that individuals may utilize four internal boundary management strategies to deconstruct their family identity: naming, discussing, narrating, and deritualizing. All but one (i.e., deritualizing) are the exact same strategies individuals utilize to create and sustain a family identity, in name (Galvin, 2006). Therefore, the strategies individuals employ to construct and deconstruct family identity are not all that different from each other in name although they are quite different in practice (i.e., each strategy has the potential to either construct or deconstruct family identity). Although Galvin and Braithwaite (2014) did not elaborate upon how these 
strategies may manifest in interactions, given what we know about how these strategies construct and maintain family identity, we can conjecture their place in family estrangement theorizing. Thus, in what follows, a discussion of each proposed identity deconstruction strategy will be explicated and applied to aged out foster youth.

Naming. Naming is a powerful indicator of family identity (Galvin, 2006). Naming can imply a relationship is either close or distant and is one way individuals may clue a family member into their perception of the relationship. For example, should an aged out foster child refer to his biological mother as "Susan," it could signal he does not perceive the relationship is close enough to call her "mom." In fact, research has revealed that stripping a parent from their title as "mother" or "father" and replacing it with a first name can signify a lack of closeness and increased distance (Scharp, 2017). Scharp's (2017) research also revealed some adult children would change their name to solidify their identity as a person separate from the family. For example, changing their last name from "Williams" to "Jacobs." In so doing, the child's membership in the Williams family was no longer evident. Upon aging out, it may be the case that some foster youth: (a) use address terms when referring to others to signal they are not considered a part of their family ingroup, (b) change their own name to signal they are no longer a part of the family, (c) employ both tactics, or (d) employ unique tactics that have yet to be uncovered. Thus, it is worth exploring how aged out foster youth utilize the discursive practice of naming to deconstruct family identity.

Discussing. Research has shown that in order to construct a family identity it is often the case family members engage in identity-building talk or discussions (Galvin, 2006). Thus, when examining the strategy of discussing as it pertains to family identity 
deconstruction, it is likely individuals disengage in identity-building talk as a means of establishing they no longer wish to share a family membership with another. The very nature of discussing lends support for direct rejection messages (see Galvin, 2014). In fact, previous research has found that children often directly tell parents the relationship is over or offer an ultimatum (Scharp, 2014). In these cases, discussing serves an important function and ought to be considered identity-deconstruction talk. Thus, in the present study, it is plausible aged out foster youth: (a) disengage in identity-building talk, (b) engage in identity-deconstruction talk, (c) employ both tactics, or (d) employ unique tactics that have yet to be uncovered. Consequently, it is worth assessing how aged out foster youth utilize discussing to deconstruct family identity.

Narrating. Narrating is also an important signifier of family identity and cohesion (Galvin, 2006). In fact, stories can create boundaries around who is considered family and who is not (Nelson \& Horstman, 2017). In this vein, the way that we create and share stories can provide insight into our views of relational others. While research has indicated children often share their family estrangement story to help themselves and others make sense of relationship dissolution (Scharp et al., 2015), examining how the boundary management strategy of narrating operates internally to deconstruct family identity has yet to be examined. For aged out foster youth, it may be the case that they utilize narrating to recount the family estrangement story to the estranged family member. For example, should the person an individual has estranged from come into contact with the individual, it is possible that individual will re-tell the relationship dissolution story as a way to maintain family identity deconstruction. In these instances, aged out foster youth would be utilizing a direct rejection message by specifically giving 
voice, through storytelling, to the original reasons that prompted the family estrangement. Indeed, assessing how the internal discursive strategy of narrating may contribute to our understandings of family identity deconstruction is vital to assess.

Deritualizing. Lastly, whereas ritualizing refers to the enactment of family via everyday rituals, routines, celebrations, and holidays (Galvin, 2006), deritualizing refers to a lack of participation in family rituals, routines, celebrations, and/or holidays. It may be the case that some individuals will simply stay away and not attend to family rituals, some may make excuses for their absence from family rituals, and others might directly communicate they will not be attending. Because routines and rituals are often an important part of family processes and functioning, by not attending to special or routine rituals individuals are actively choosing not to enact family. Instead, they are opting to deconstruct that family identity by not fulfilling roles typical of family ingroup members. For aged out foster youth, by actively avoiding get-togethers and family events their desire to deconstruct family ties may become clear to the relational other. Importantly, it is worth examining if and how exactly aged out foster youth employ the internal boundary management strategy of deritualizing to deconstruct family identity.

Similar to how aged out youth may utilize context-specific strategies to create and sustain a family identity (see Nelson \& Colaner, 2018), it is plausible youth may also utilize context-specific strategies to deconstruct a family identity. Therefore, in order to formally assess the utilization of Galvin and Braithwaite's (2014) internal boundary management strategies, as well as context-specific strategies to deconstruct family identity, the fifth research question is posed: 
RQ5: How, if at all, do aged out foster youth use internal boundary management strategies and context-specific strategies to deconstruct family identity?

Family estrangement impacts. Beyond assessing how aged out foster communicatively deconstruct their family identity, it is important to explore how the family estrangement process has worked out for aged out foster youth. Because reasons for family estrangement vary considerably, they often trigger a variety of different emotions. To date, research has revealed estrangement triggers grief (Agllias, 2013b), confusion (Boss, 2010), and/or hurt (Carr et al., 2015; Dattillio \& Nichols, 2011). As these studies demonstrate, people tend to experience a wide range of, primarily negative, emotions throughout the family estrangement process. Importantly, then, is assessing how aged out foster youth describe the impacts of family estrangement. In a similar vein, understanding the emotions aged out foster youth experience (i.e., both positive and/or negative) throughout the family identity deconstruction process can lend important insight into how they may be adapting (both positively and/or negatively) to the family estrangement. Thus, in order to explore family estrangement impacts, the final research question is set forth:

RQ6: How do aged out foster youth describe the impacts of family estrangement?

\section{Conclusion}

Grounded in social identity (Tajfel \& Turner, 1986), social constructionism (Berger \& Luckmann, 1967; Gergen, 1985), and discourse-dependence (Galvin, 2006) theorizing, the current study seeks to better understand the communicative experiences and complexities associated with aging out of the foster care system. The current study is guided by four primary goals: (1) to understand how aged out foster youth define 
"family," family ingroup members, and family outgroup members, (2) to examine how aged out foster youth make sense of home, (3) to explore the communication strategies aged out foster youth utilize to create and sustain a family identity with family ingroup members, and (4) to illuminate the complex characteristics and communication processes associated with the family estrangement process (i.e., who are defined as estranged family members, reasons for family estrangement, communication strategies utilized to deconstruct family identity, and impacts of family estrangement).

First, it is imperative family communication scholars begin to understand the ways in which aged out foster youth define "family," family ingroup members, and family outgroup members. Upon aging out, foster youth have agency in identifying and enacting familial group distinctions. Thus, in light of family becoming ambiguous and voluntary upon aging out of foster care, it is important to examine how aged out foster youth define "family" and conceptualize family ingroup and outgroup members. Findings addressing these unique considerations have the potential to shape family communication research, theory, and practice.

Second, the present study seeks to understand how former foster youth make sense of home. By evaluating what "home" means, we can better speak to the meanings aged out foster youth ascribe to "home." In so doing, we can better understand how aged out foster youth may cultivate "home" before, during, and after exiting care. This knowledge could prove fruitful when attempting to establish "home" for youth who are aging out of foster care.

Third, it is important to expose the discursive strategies aged out foster youth utilize to construct and maintain a family identity with family ingroup members. 
Regardless of the way in which aged out foster youth define family, they must communicatively construct family ties for there are no legal ties, relationships are voluntary and ambiguous, and there may be no biological connection (Braithwaite et al., 2010; Galvin, 2006). Results may lend insight into the communicative nuances and complexities associated with constructing and maintaining a family identity among aged out foster youth.

Lastly, when aged out foster youth do not perceive a family status, they are likely experiencing some degree of family estrangement from those who were once considered family. To this end, there are likely distinct communication strategies aged out foster youth utilize to deconstruct family identity. In order to better understand aged out foster youth's experiences of family estrangement, it is first worth looking at who aged out foster youth define as estranged family members and for what reasons aged out foster youth estrange from these family members. By asking aged out foster youth to reflect on the characteristics of their own family estrangement experiences, we can better understand the potentially diverse ways in which estrangement is characterized and experienced. Second, by examining the communicative strategies aged out foster youth employ to create and sustain distance, specific communication tactics they utilize to satisfy a specific degree of distance will be illuminated and can further shed light on the characteristics and experience of family estrangement. Finally, examining the impacts of family estrangement from aged out foster youths' perspectives can offer important insights for both current family estrangement theorizing as well as practical applications for other aged out foster youth as well as professionals who work directly (i.e., case workers, mentors, therapists, and practitioners) with aged out foster youth who are 
transitioning out of care. Ultimately, examining the impacts of family estrangement may lend important insights into how aged out foster youth reconcile relationships and adapt during the aging out process.

In order to address these overarching goals, the current study was guided by the following research questions:

RQ1a: How do aged out foster youth define "family?"

RQ1b: Who do aged out foster youth define as family ingroup and family outgroup members?

RQ2: How do aged out foster youth make sense of "home?"

RQ3: How, if at all, do aged out foster youth use internal boundary management strategies and context-specific strategies to construct and maintain family identity with family ingroup members?

RQ4a: Who do aged out foster youth define as estranged family members? RQ4b: For what reasons do aged out foster youth estrange from family members? RQ5: How, if at all, do aged out foster youth use internal boundary management strategies and context-specific strategies to deconstruct family identity?

RQ6: How do aged out foster youth describe the impacts of family estrangement?

Overall, the present study seeks to shed light on the communicative experiences and complexities associated with aging out of the foster care system. Results from the current study will serve to evaluate and extend current theorizing on family communication, discourse-dependence, social identity, and family estrangement. Practical implications stemming from the results of the current study will also be assessed. Because aging out of foster care often results in challenges that must be navigated, understanding how 
communication is affected by and reflected in the lived experiences of aged out foster youth may lend insight into how, why, and to what end they may go about cultivating healthy family relationships and abandoning destructive family relationships upon transitioning out of care. 


\section{Chapter 3: Methodology}

The overarching goal of the current study is to better understand the communicative experiences and complexities associated with aging out of the foster care system. In order to achieve this goal, this study was approached from the interpretive paradigm and utilized qualitative methods. Data was collected using in-depth, qualitative interviews with youth who have aged out of the United States foster care system within the past ten years.

In this chapter, I begin with an explanation of my rational for the proposed research methodology. In this section I explicate the assumptions of the interpretive paradigm and simultaneously apply the interpretive paradigm to the goals of the current study. I also discuss how my philosophical commitments inform the overarching research process. Next, I describe participant eligibility, recruitment, and demographics. From here, I explain how in-depth, semi-structured interviews served as my data collection method. I then discuss how the data was analyzed with a specific focus on inductive and deductive thematic analysis procedures. This chapter ends with a discussion of the validation techniques I utilized in the current study.

\section{Rationale for Research Methodology}

This section begins with a detailed discussion of the assumptions of the interpretive paradigm and an application of the interpretive paradigm to the goals of the current study. Within this discussion, a description of how my own philosophical commitments inform the present study is explicated.

\section{Assumptions and Application of the Interpretive Paradigm}


Mumby (1997) explains interpretivism represents a discourse of understanding, such that language is the tool by which we create shared meanings and construct reality. Interpretivism rejects a single, objective view of reality and, instead, contends the social world consists of multiple realities (Mumby, 1997). Therefore, interpretivist researchers attempt to understand the language and web of meaning that characterize a group of people (Baxter \& Babbie, 2004), including those who may be silenced or understudied (Creswell, 2007), by focusing on similarities in personal experiences.

The interpretive paradigm is appropriate for the current study for three primary reasons. First, the current study is grounded in social constructionism such that understanding how aged out foster youth socially construct and deconstruct familial identity as well as home represents the underlying goals of this study. Interpretivists contend we socially construct our realities (Baxter \& Babbie, 2004; Mumby, 1997) and constitute our relationships through communication (Baxter, 2004). In other words, our social world is constructed in and through our communication with others (Baxter, 2004). Thus, examining how aged out foster youth constitute family and home through their communication simultaneously represents a constitutive and interpretive approach. Second, how aged out foster youth make sense of family, home, and family estrangement is another focal point of the present study and, thus, an interpretive approach is suitable considering interpretivists seek to understand meaning-making among groups of individuals (Baxter \& Babbie, 2004). Lastly, because aged out foster youth represent an understudied population (see Nelson, 2014; Nelson \& Horstman, 2017; Patrick \& Galvin, 2012), an interpretive approach can help give voice to the understudied experiences of 
aged out foster youth (Creswell, 2007). In what follows, I discuss my philosophical commitments as they pertain to the scope and goals of the present study.

Ontologically, interpretivists seek to understand how realities are produced, maintained, and altered in communication (Mumby, 1997). Thus, interpretivists tend to focus on how the world is socially constructed (Baxter \& Babbie, 2004). In the current study, how aged out foster youth socially construct family and home life was gauged. Epistemologically, interpretivists are intersubjective, meaning the researcher and participants co-create understandings such that the researcher is not distant from, but rather enmeshed in, the research process (Creswell, 2007; Mumby, 1997). For example, in the current study, it was my role to interpret the responses I received from my participants. In this regard, we co-created the understandings that emerged from participants' experiences. Interpretivists' axiology is rooted in reflexive engagement, wherein both the researcher's and participants' own values, experiences, and thoughts are considered throughout the research process (Mumby, 1997). In this regard, during the research process I recognized that my own experiences, values, and thoughts likely influenced interview procedures and my interpretation of the findings. Methodologically, the way in which interpretivists ask and answer questions is rooted in qualitative research (e.g., interviews, focus groups) and their praxis is to understand participants' meanings (i.e., truth with a lowercase " $\mathrm{t}$ ") (Mumby, 1997). Consequently, the current study utilized in-depth, semi-structured interviews to better understand aged out foster youths' experiences of family, home, and estrangement.

Concerning the link between interpretive research and theory, Braithwaite and Baxter (2006) argue that interpretivist theories focus on meaning-making. Therefore, 
theories are used as sensitizing devices and are put into conversation with the meanings that emerge from the data (Braithwaite \& Baxter, 2006). In other words, the goal of interpretive research is not to test theory, but rather to engage the theory in conversation with the meanings and interpretations that emerge from the data. In the current study, social constructionism, social identity theory, and discourse-dependence theorizing are put into conversation with the meanings that emerged from the data.

Taken together, interpretive researchers seek to understand how participants make meaning of their own lived experiences in their own words (Baxter \& Babbie, 2004; Braithwaite \& Baxter, 2006; Creswell, 2007; Mumby, 1997). Strengths of the interpretive paradigm include the opportunity to build rapport with participants, the ability for sensitive topics to be discussed with the often open-ended question format, the in-depth nature of interpretive work, and the ability to give understudied and silenced populations a voice and outlet to share their experiences (Baxter \& Babbie, 2004; Creswell, 2007). With these strengths in mind, the interpretive paradigm was in line with the goals of the present study and illuminated the complex experiences of aged out foster youth in a detailed and rich manner.

\section{Research Participants}

This section discusses the criteria individuals needed to meet in order to be eligible to participate, participant recruitment procedures, and participant demographics.

\section{Participant Eligibility and Recruitment}

Individuals needed to meet the following criteria to participate in this study: (1) be at least 18 years of age and (2) have aged out of the United States foster care system within the past 10 years. After obtaining IRB approval, participants were recruited via 
Facebook and through snowball sampling techniques (i.e., networking sampling; word of mouth). Specifically, my recruitment script (see Appendix B) was posted on aged out foster youth Facebook groups and pages after receiving permission from site administrators, when necessary. From here, snowball sampling techniques were utilized such that individuals in my network and recruited participants were asked to share my recruitment script with people they knew who may be qualified and interested in participating in this study.

\section{Participant Demographics}

Participants (see Table 1) were 30 individuals who aged out of the United States foster care system within the past 10 years $(M=4.9$ years, $S D=3.7)$. Participants identified as female $(n=22,73.3 \%)$, male $(n=7,23.3 \%)$, and transgender $(n=1,3.3 \%)$, with ages ranging from 19 to 30 years old $(M=24.1, S D=3.7)$. Most participants identified as Black $(n=10,33.3 \%)$, with nine identifying as bi-racial $(30.0 \%)$, seven as White $(23.3 \%)$, two as Hispanic (6.6\%), and two as multi-racial (6.6\%). Participants spent between two and 20 years in the foster care system $(M=9.7, S D=5.9)$ and reported experiencing three to 154 placements while in care $(M=14.8, S D=28.1)$. Participants' relationship status varied, with 20 indicating they were single $(66.6 \%)$, six indicating they were in a romantic relationship (20.0\%), three indicating they were married (10.0\%), and one indicating they were divorced (3.3\%). Highest level of educational attainment also varied, with 15 reporting they completed some college $(50.0 \%)$, seven reporting a Bachelor's degree (23.3\%), three reporting a Master's degree (10.0\%), two reporting an Associate's degree (6.6\%), one reporting a high school diploma (3.3\%), one reporting some high school (3.3\%), and one reporting a Doctor of 
Philosophy degree (3.3\%). When asked about their current living situation, 17 participants were renting an apartment, townhouse, or home (56.6\%), five owned their own home (16.6\%), two were staying in transitional housing (6.6\%), two were staying with host families $(6.6 \%)$, two resided in student housing $(6.6 \%)$, and two reported being homeless (6.6\%). Participants' average monthly income was $\$ 1,920.00$.

\section{Data Collection}

Participants informed me of their interest in participating in this study by emailing, calling, texting, or following a link to a brief online survey through Qualtrics (see Appendix C) where participants were asked to provide their name and contact information. Participants who opted to take the brief Qualtrics survey were contacted via their preferred method to schedule an interview. All other participants received responses via the method in which they initiated contact (i.e., email, phone call, or text).

\section{Interviewing}

To better understand the experiences of aged out foster youth, in-depth, semistructured interviews were conducted (Baxter \& Babbie, 2004). The goal of each interview was to extract rich descriptions and narratives in order to better understand the experiences of aged out foster youth. Specifically, given the present study's focus on exploring the complex ways family identity and home is communicatively (de)constructed, negotiated, and enacted among aged out foster youth, in-depth interviewing was an appropriate data collection method. In-depth interviewing helped to ensure the expressive and evocative descriptions deemed necessary for studies of this purpose and nature (Baxter \& Babbie, 2004). In addition to an in-depth focus, a semistructured approach to interviewing allowed me to adapt the interview questions to the 
perspectives and needs of each participant (Baxter \& Babbie, 2004).

Prior to the interview beginning, participants were informed of the parameters of the study and had to provide verbal consent that they met the required qualifications and wished to participate in the study (see Appendix A). Then, interview questions were posed to gauge aged out foster youths' uniquely rich experiences and interactions (see Appendix D). Specifically, questions gauging RQ1a-b and RQ3 were asked first, followed by questions informing RQ2, RQ4a-b, RQ5, and RQ6. All questions were asked to each participant although participants were informed they had the right to refuse to answer any question.

In total, 30 interviews were conducted. All interviews took place over the phone and ranged from 47 to 117 minutes. Data collection continued until no new insights were produced from the data, implying saturation had been reached (Corbin \& Strauss, 2008). Specifically, when participants' accounts of their experiences became repetitive and no new categories or themes seemed to be emerging in relation to each of the six research questions, it appeared saturation had been reached. This occurred after approximately the twentieth interview. However, in order to verify saturation had been achieved, ten more interviews were conducted and transcribed. These additional interviews added to the overall richness of the data and provided further accounts to draw from to tell the story of the data. Interviews were audio-recorded and transcribed verbatim, resulting in 538 pages of single-spaced text. Each participant received a \$20 Amazon e-gift card via email upon completion of the interview.

\section{Data Analysis}


The current study's research questions required the utilization of two methods of data analysis. RQ1a-b, RQ2, RQ4a-b, and RQ6 focused on aged out foster youths' communicative constructions of "family," family ingroups, family outgroups, home, and family estrangement and, consequently, were appropriate for inductive thematic analysis. RQ3 and RQ5 focused on the specific communication strategies aged out foster youth utilized to construct and deconstruct family identity. RQ3 draws from Galvin's (2006) discourse-dependence strategies whereas RQ5 draws from Galvin and Braithwaite's (2014) deconstruction strategies. Thus, deductive thematic analysis was utilized to explore these research questions. These two methods of data analysis are detailed below.

\section{Inductive Thematic Analysis (RQ1a-b, RQ2, RQ4a-b, \& RQ6)}

Regarding RQ1a-b (i.e., "How do aged out foster youth define 'family?”; "Who do aged out foster youth define as family ingroup and family outgroup members?"), RQ2 (i.e., "How do aged out foster youth make sense of 'home?"”), and RQ4a-b (i.e., "Who do aged out foster youth define as estranged family members?"; "For what reasons do aged out foster youth estrange from family members?") and RQ6 (i.e., "How do aged out foster youth describe the impact of family estrangement?") inductive analysis was used to allow themes to emerge from the data (Bulmer, 1979). Specifically, Braun \& Clarke's (2006) six steps for thematic analysis was utilized. First, I familiarized myself with the data by thoroughly reading the transcripts multiple times, recording ideas, and taking notes. In the second step, I began generating initial codes whereby "interesting features of the data" were identified and organized into categories (Braun \& Clarke, 2006, p. 87). Next, I searched for broad themes and matched each potential theme with relevant coded data extracts. In accordance with Owen's (1984) thematic analysis techniques, to be 
considered a theme, the following criteria were applied: (a) recurrence (i.e., when the same idea or meaning was expressed), (b) repetition (i.e., when key words, phrases or sentences were repeated), and (c) forcefulness (i.e., when ideas were emphasized through vocal inflection, volume, or dramatic pauses). After identifying themes, I reviewed and refined the themes until I confirmed they accurately reflected the meanings evident in the dataset. Throughout this phase I employed the constant comparative analysis technique (Strauss \& Corbin, 1990), whereby each theme was compared with all others to determine whether themes denoted similar or different meanings. Fifth, I wrote out a detailed analysis for each individual theme and attempted to identify the "story" of each theme. Each theme was assigned a working title and subthemes were created and refined. The final step involved producing the report, which required me to choose exemplars that best captured the story of each theme.

\section{Deductive Thematic Analysis (RQ3 \& RQ5)}

Deductive thematic analysis involves starting with theory and analyzing whether a hypothesized pattern or relationship is reflected in the data (Baxter \& Babbie, 2004). Thus, in order to analyze RQ3 (i.e., "How, if at all, do aged out foster youth use internal boundary management strategies and context-specific strategies to construct and maintain family identity with family ingroup members?”), Galvin's (2006) internal boundary management strategies to construct a family identity served as the sensitizing framework. Using the internal boundary management strategies of naming, discussing, narrating, and ritualizing as a lens, the data was deductively analyzed. Additionally, in order to analyze RQ5 (i.e., "How, if at all, do aged out foster youth use internal boundary management strategies and context-specific strategies to deconstruct family identity?"), Galvin and 
Braithwaite's (2014) internal boundary management strategies to deconstruct a family identity served as the sensitizing framework. Using the internal boundary management strategies of naming, discussing, narrating, and deritualizing as a lens, the data was deductively analyzed. In order to uncover any additional, context-specific, strategies that emerged for RQ3 and RQ5, I then inductively analyzed the data by following Braun and Clarke's (2006) steps for thematic analysis, Owen's (2004) thematic analysis techniques, and the constant-comparative analysis technique (Strauss \& Corbin, 1990).

\section{Validation of Findings}

In order to speak to the credibility of the current study's findings, validation techniques were utilized. Following the recommendation set forth by Creswell (2007), three validation techniques were employed to speak to the credibility of my findings and interpretation: data conferencing, member checks, and thick descriptions.

\section{Data Conferencing}

First, I engaged in a peer verification process known as data conferencing. Data conferencing is a technique that engages the expertise of scholars in related areas of study to help assess and validate the results of qualitative work (Braithwaite, Allen, \& Moore, 2017). Three scholars with expertise in qualitative methods, foster families, family communication, social identity theorizing, discourse-dependence theorizing, and/or social constructionism participated in the data conferencing session. Prior to the session, I ensured all identifying information had been removed from the data in order to protect the anonymity of my participants. Each individual was given a document that detailed the initial findings emerging from my data analysis process.

Within the session, Braithwaite et al's (2017) steps for data conferencing were 
utilized. First, I briefed my peers on the data conferencing process and discussed my data collection procedures. I then opened the floor for comments and questions as a means of assessing the transparency of my data collection process. Next, I presented my initial findings. Specifically, I provided my peers with the title and a description each research question, followed by theme and/or subtheme titles, theme and/or subtheme descriptions, and vivid exemplars for each theme and/or subtheme. After presenting each theme I solicited feedback and answered questions. During this process I took detailed notes about the perceived clarity of theme names, theme descriptions, and exemplars presented. I also jotted down proposed alterations and critiques that arose from our discussion. After going through this process with each research question, the data conferencing session ended. In light of the feedback I received, some theme names were changed, some theme and/or sub-themes descriptions were altered, and exemplars were restructured to fit the modified themes and/or subthemes. Ultimately, the data conferencing process allowed me to clarify my initial results and represented one validation procedure utilized in the current study.

\section{Member Checks}

Member checks were also conducted to assess the validity and accuracy of the data reported in the results (Creswell, 2007). According to Creswell (2007), member checking involves contacting participants to ensure the findings in the study accurately represent their own experiences. Research has revealed member checks are an important part of establishing credibility in qualitative research (Lincoln \& Guba, 1985). At the end of each interview participants were asked whether or not they were willing to respond to an email to verify the findings of this study. All 30 participants agreed to verify the 
findings. Each participant was sent an email with a summary of the findings and was asked to indicate whether or not each theme was representative of their experience. If they did not believe a theme was representative of their experience, they were instructed to explain why that was the case. Of the 30 participants who were sent an email, 12 responded. All participants who responded confirmed the findings were representative of their experiences.

\section{Thick Descriptions}

Thick descriptions, narratives, and quotations were also used to support each theme presented. Vivid exemplars allow readers to assess whether the findings speak to similar social contexts (Lincoln \& Guba, 1985). In the current study, rich and detailed accounts of each theme were provided in order to give voice to the experiences of aged out foster youth. As part of accounting for aged out foster youths' unique experiences, additional context was provided when available. For example, if participants informed me of the nature of their relationship with their biological mother, these details were included in the exemplar in order to provide a rich and vivid account of the participant's experience. The goal in providing thick descriptions, narratives, and quotations is to examine whether the current study's findings are transferrable to other aged out foster youth. Moreover, by capturing the voices of aged out foster youth, their experiences can be better understood by readers. In this regard, detailed accounts may strengthen transferability and further speak to the validity and credibility of the findings.

\section{Summary}

The overarching goal of the present study is to understand the communicative experiences and complexities associated with aging out of the foster care system. 
Grounding this study in the interpretive paradigm and utilizing qualitative methods allowed for an in-depth understanding of aged out foster youths' lived experiences. This chapter began with an explication of the assumptions of the interpretive paradigm and an application of the interpretive paradigm to the goals of the current study. From here, a discussion of participant eligibility, recruitment, and demographics followed. Next, I detailed both my data collection (i.e., in-depth, semi-structured interviews) and data analysis (i.e., inductive and deductive thematic analysis) procedures. Finally, I described the validation strategies the current study employed to ensure the credibility of findings and interpretations. 


\section{Chapter 4: Results}

Four overarching goals guided the present study. First, I sought to understand how aged out foster youth defined "family," family ingroup members, and family outgroup members (RQ1a-b). Second, I attempted to capture the complex ways in which aged out foster youth made sense of home (RQ2). Third, I applied Galvin's (2006) discoursedependence framework to explore the internal boundary management strategies and context-specific strategies (see Nelson \& Colaner, 2018) aged out foster youth utilized to construct and maintain a family identity with family ingroup members (RQ3). Fourth, I aimed to achieve a deeper understanding of the complex characteristics and communication dynamics associated with the family estrangement process for aged out foster youth. Specifically, I explored who aged out foster youth defined as estranged family members and for what reasons aged out foster youth estranged from these family members (RQ4a-b). From here, I explored what internal boundary management strategies and context-specific strategies aged out foster youth utilized to deconstruct family identity (RQ5). Last, I assessed how aged out foster youth described the impacts of family estrangement (RQ6). Each research question was analyzed using inductive and/or deductive thematic analysis procedures. In what follows, I present each research question and discuss what themes and sub-themes emerged through my data analysis.

\section{Research Question One: Defining and Categorizing "Family"}

The first research question was comprised of two parts. The first part (RQ1a) examined how aged out foster youth defined "family," whereas the second part (RQ1b) explored who aged out foster youth defined as family ingroup and family outgroup 
members. In what follows, the themes and sub-themes animating RQ1a-b will be presented and discussed.

\section{Defining "Family" (RQ1a)}

The purpose of RQ1a was to better understand how aged out foster youth defined "family." Inductive thematic analysis revealed three primary themes animated aged out foster youths" definitions of "family." First, participants defined "family" as those who love you unconditionally. Second, participants defined "family" as those who support you. Last, participants defined "family" as more than blood. Importantly, these three themes animated participants' conceptualizations of the ideal "family" - often derived from their past experiences in foster care. In what follows, these three themes are analyzed and discussed.

As those who love you unconditionally. Participants first defined "family" as those who love you unconditionally. Showing and expressing love were vital to participants' definitions of "family." Love was positioned as bi-directional, meaning love must be both given and received in families: "I mean, and there's just that, that love there for each other" (Val, 21; denotes interview number). Positioning love as bi-directional is core to societal expectations of family. We expect family to love us and we expect to love family in return. Not only do we expect love to be given and received in families, but as a society we tend to believe that family members ought to love each other more than they love other people. Participants gave voice to this societal assumption of family through stressing that love is expected and central to family life.

Participants also emphasized that unconditional love ought to be shown through actions: "[People are family] if they have loved me and expressed their love in their 
actions" (Sasha, 14). Essentially, participants are suggesting that family means much more than simply doing things for one another and spending time together. Rather, people who are truly family will engage in activities and spend time with one another because they want to, and they love each other.

Aged out foster youth also drew from their prior experiences in foster care when positioning love as a central feature of family. For foster youth, it is not guaranteed that each and every foster home will provide unconditional love. In fact, it is not a requirement that foster parents love foster children. Rather, foster parents' primary responsibilities revolve around keeping the child safe and providing stability. Some foster parents' failure to provide love appeared to impact foster youths' expectations of "family" for years to come. As Maya put it: "I think exactly what I said with that unconditional love. In me there is this embedded fear that I won't be wanted [because of my time in foster care]... and they have continually wanted me. You know, the unconditional love" (2). Maya's account demonstrates how participants' constructions of "family" often surfaced out of a desire of what family should be, in light of their experiences in foster care. Participants desired unconditional love because it was never guaranteed given their personal experiences in the foster care system. Thus, love became vitally important to aged out foster youths' definitions of "family."

Participants went on to voice how this love was not time-bound: "They [family] love you for who you are, not for what you've gone through or what you've done in your past or even what you may do in the future" (Krista, 24). Participants positioned love as a timeless aspect of "family." Essentially, there is no line you can cross where that love would disappear - further giving credence to the notion that we expect family to love us 
more than other people and we expect to love family more than other people. Participants seemed to pull from their temporary family life experiences in foster care when positioning love as timeless, such that rather than family existing for just a reason or a season (the norm for foster families), participants desired family - and consequently love - to last for a lifetime. In this way, aged out foster youth emphasized that love was a constant and permanent function of family that should not disappear regardless of one's actions. Indeed, the idea that love is unwavering in familial relationships is both normative and expected in modern society.

Ultimately, from participants' navigation of their prior experiences in foster care emerged new understandings of how family ought to behave and what characteristics family members ought to possess. One expectation that emerged from these experiences was the belief that "family" ought to love you unconditionally. Love is not only core to societal expectations of family, but also aged out foster youths' suppositions of family. Moreover, the emphasis on unconditional love as a central feature of "family" offers initial support for the idea that "family" may center around the fulfillment of certain functions for aged out foster youth, such as showing and expressing love. An additional function of "family" that participants gave voice to was giving and receiving support.

As those who support you. Similar to unconditional love, participants positioned support as a vital function of "family." As Zoey stated: "Family for me means support and being there for someone when they really need it or when they don't need it" (13). In modern society, we expect family to be there through the good, bad, and ugly. Participants drew from their time in foster care to voice a similar expectation. Hopping from home to home, school to school, and family to family puts a serious hindrance on 
one's ability to achieve and maintain a constant support system. Thus, participants seemed to be drawing from these past experiences to suggest "family" are those that willingly jump through the hoops and transitions alongside you.

In fact, participants often discussed family as those who support you through directly referencing their time in foster care. The temporary nature of foster care directly defies societal expectations that family relationships are long-term. Thus, aged out foster youths' more temporary experiences have served to reiterate some truths about family (e.g., family ought to love and support you indefinitely) that those who did not experience foster care may take for granted. Abby gives voice to how her experiences in foster care served to reiterate the idea that family ought to support one another indefinitely:

I think that was one of the things that, when I would like act out and misbehave, they kind of just gave up, the foster parents would. It was just you know, "she's out of control, we can't handle her, let's move her." So, no one really stuck around to break down that wall. So, I suppose [family is] really just people sticking around and being there and supporting you in every aspect, good and bad.

Prior foster care experiences opened participants' eyes to what they deemed most important about "family" - people's willingness to demonstrate support throughout one's life. Consistent with societal expectations of family, participants voiced family would not give up on you or leave you behind. Instead, they offered a permanent source of support. Grace gave voice to this expectation of permanency through stating: "Well, um, they're [family] consistent first of all. Family are people I've known while I was going through various placements, they always stuck around" (18). In light of the unpredictable nature 
of foster care, family became those who offered consistency - a consistent shoulder to lean on no matter the time, situation, or geographical distance. Essentially, participants knew what it was like to live a life where consistent support was not guaranteed. Consequently, consistent support became an aspect and function of family that participants came to especially value.

"Family" was also defined as those people that showed support for you during life events where family are often expected to support you, such as holidays, birthdays, and important life milestones (e.g., graduating college, landing a new job). As Trish explained:

Family are the people who support me in my endeavors. That means whoever, whether they call me and tell me "happy birthday" or it may be someone who congratulates me on a conference that I am speaking at or a new job that I have.

Participants seemed to pull from the dominant societal discourse that suggests family presence during the holidays is a core expectation and assumption of "family." As a society we tend to think of family as those who show up for holidays, such that if people do not show up for holidays then perhaps they are not family. For aged out foster youth, presence during the holidays could never be a taken-for-granted aspect of "family," which likely led to their positioning of support during holidays and important life events as vital to "family:"

I think when it comes down to family for a foster kid, it comes down more to a support system and people that are actually going to be there for you and on the holidays and those types of things. (Adam, 25) 
Wishing and waiting for family support during the holidays was a common occurrence among participants in the current study. In fact, one participant talked about how all she ever wanted was for her mother to visit her on Christmas. She talked about how she would sit and wait while all the other girls in her group home had visits with family. Her mom never came. The fact that her mom never came directly violates the societal expectation that you spend holidays with family. In light of these (often negative) past experiences, support during holidays and important life milestones became paramount to aged out foster youths' definition of "family."

In sum, support became critical to aged out foster youths' definition of "family." Support was regarded as unconditional (i.e., constant and permanent) and often discussed in relation to past foster care experiences and expectations of family. Because anyone has the potential to fulfill participants' expectations for support, family as those who support you gives further voice to the ability of aged out foster youth to define a host of relationships as familial and demonstrates a functional approach to defining "family." By positioning family as those who fulfill vital functions of family - such as showing love and support - participants gave voice to the idea that "family" is not contingent on blood. In this way, aged out foster youth challenged the societal expectation that blood relationships are automatically family relationships.

As more than blood. Beyond defining "family" as those who fulfill the functions of expressing and receiving unconditional love and support, many participants deliberately voiced that "family" was more than blood (i.e., "family" is more than sharing genes with another). At some point in aged out foster youths' lives, biological relationships became strained. This may have been a direct result of entering care or a 
more indirect result of losing touch over the years. Whatever the case may be, at some point aged out foster youth had to rely on other people to fulfill functions of family, which served to broaden definitions of family beyond blood.

Indeed, many participants emphasized that "family" was "NOT blood, that's for sure" (Felix, 4). Felix went on to say: "I don't think blood makes you family... Because I have people that are blood and they are worthless. We don't talk, and they wouldn't do stuff for me or vice versa" (4). Rose echoed this sentiment when asked if she believed biology fit into her definition of family: "Well, I mean, they [biological parents] kind of fucked me over majorly. And it's hard to love and trust a stranger. Just because they blood doesn't make them family" (11). When participants say that family is more than blood, they are saying that blood relationships may not necessarily meet their standards of family. Rose even called her biological parents strangers, which is likely due to spending very little time with her biological parents due to being in foster care for most of her life. For Rose, and other participants, they then had to turn to other people to fulfill "family." In this way, participants extended their definition of "family" beyond blood.

Other attributes, such as caring and reliance, were also seemingly more important to participants' definition of "family" than having a blood connection: "So, what I call family... it doesn't have to be blood... it's just that they care about me and I care about them" (Ray, 28). Owen offered a similar statement: "You know, I don't think it's a blood thing. I really think it's people you count on" (17). By emphasizing qualities such as “talk," "doing stuff for each other," "love," "trust," "caring," and "reliance"- attributes blood relatives did not possess for many participants - aged out foster youth positioned these attributes (or functions of family) as more central to their definition of "family" 
than blood. Interestingly, while participants positioned family as more than blood, the very nature of them talking about blood suggests that we still have primal urges to be close to biological family members. As a society and as individuals we still tend to value our biological relationships. This could be one reason why participants still felt the need to at least give voice to blood, albeit through explaining what family may not be.

Ultimately, participants evaluated "family" in light of the expectation that blood relationships are family relationships. In this way, they simultaneously acknowledged and silenced the dominant societal discourse that blood relationships are central to experiences and definitions of "family." Participants were able to silence this dominant discourse because, in modern society, youth have more agency in identifying and abandoning family relationships. Aged out foster youth can now survive without biological family members because they can seek family out in other places. Consequently, if aged out foster youth do not feel that biological family members are satisfying their standards and expectations of family, they have more freedom to abandon these relationships. In many cases this is exactly what participants did.

Taken together, aged out foster youths' accounts speak to a valuing of function (e.g., love, support, caring) over structure (e.g., blood ties) when defining "family," such that while society's prioritization of blood was evident in participants' accounts, participants' experiences in foster care tended to shift their definition of "family" from blood to more interactional processes (i.e., showing and expressing love and support). Essentially, in light of their time in foster care, participants came to believe that family were those who acted or felt like family. Likewise, participants voiced a freedom to pick and choose family. As Chad explained, "even if you're blood family, you have to choose 
them at some point" (7). By emphasizing choice, participants affirmed they had agency in designating what and who constituted "family." The criteria aged out foster youth applied to "family" sheds further light on how aged out foster youth may make decisions about what family members occupy a family ingroup and/or family outgroup status.

\section{Categorizing "Family" (RQ1b)}

The purpose of RQ1b (i.e., "Who do aged out foster youth define as family ingroup and family outgroup members?") was to explore which family members aged out foster youth characterized as belonging in their family ingroup (i.e., who is family) and/or their family outgroup (i.e., who is not family). Below, who aged out foster youth defined as family ingroup members, family outgroup members, and liminal group members will be discussed in turn.

Family ingroup members. Stemming from aged out foster youths' definitions of "family," it comes as no surprise that aged out foster youth took an inclusive approach when defining family ingroup members. Because individuals did not necessarily have to be related by blood to be considered family, as participants explained, the door was wide open for participants to identify a wide array of individuals as belonging to their family ingroup. The following broad categories of family relationships were represented in aged out foster youths' definitions of family ingroup members: biological family members, foster family members, friends, social workers, group home workers, pets, church members, family friends, therapists, community members, teachers, and coworkers. The myriad of family relationships represented in the family ingroup category (see Table 2) suggests aged out foster youth not only choose family (e.g., friends, church members, teachers, etc.), but also take a comprehensive approach when designating who is family. 
Per aged out foster youths' definitions of "family," each and every one of these relationships discussed provided both unconditional love and support. So, while considering therapists, coworkers, or teachers as family may seem unique, it is plausible these were the individuals that stood the test of time and proved to be an important source of love and support for aged out foster youth throughout their upbringing. Ultimately, results demonstrate the agency aged out foster youth enacted when defining family ingroup members.

Family outgroup members. Similarly, in light of the way that aged out foster youth defined family (i.e., as more than blood and those who love and support you unconditionally), it makes sense that participants identified a range of individuals (e.g., biological family members, foster family members, friends, social workers) as family outgroup members (see Table 3). Essentially, because aged out foster youth are now able to be more selective with who they choose to identify as family, it opens the door for including more and more individuals as part of one's family outgroup. Thus, the inclusion of a wide array of relationships in the family outgroup category further validates the belief that relationships become voluntary upon youths' transition out of care. Importantly, the list of individuals defined as family outgroup members echoed how aged out foster youth defined "family" up front - as not necessarily blood - while still drawing upon the belief that any relationship (e.g., foster family members, friends, group home members, etc.) can be non-familial to the extent that individuals are not fulfilling family functions (e.g., loving, supporting, caring). Biological family members were most likely to be identified by aged out foster youth as family outgroup members, which further validates the notion that family may be more than blood. In what follows, two 
theories are offered that may help explain this trend in the data: the propensity to address trauma in family outgroup designations and the idea that youth may be able to rely less on biological family members now than they did in the past.

Per the first explanation offered, it may be the case that aged out foster youth were more likely to identify biological family members as family outgroup members due to experiencing trauma (prior or current) with biological family members. Youth enter foster care due to reasons of violence, abuse, and/or neglect in their family of origin. Considering participants aged out of care, we know they were not reunified with their biology family member(s). Consequently, it is plausible the reasons that prompted youth to be placed in foster care to begin with (e.g., violence, abuse, neglect) were still present in their biological families, thus resulting in aged out foster youth identifying certain biological family members as family outgroup members.

It is also plausible that aged out foster youth are giving voice to the idea that youth may be able to rely less on biological family members than they did in the past. Participants' accounts consistently demonstrated that, due to their time in care, they learned to rely on individuals outside of the biological family to fulfill family functions. Not only did they rely on others to fulfill family functions, but the functions of family arguably have changed over time. In the earliest and most primal forms of family life, youth relied on biological family members to fulfill their most basic needs: food, shelter, and protection. Youths' ability to survive was often contingent on the family unit. Essentially, people were more collectivist and group-oriented because it was necessary for survival. Over time, however, societal structures were put in place that were able to provide for youths' most basic needs, such as government assistance programs and police 
for protection. With the emergence of these societal structures came about new expectations of family. Because youths' basic needs were able to be met via societal systems and structures and they were now able to survive on their own, their expectations of family heightened. Families became much more about thriving than surviving. Arguably, then, as participants' accounts demonstrated - they sought more from their family relationships. They desired love, support, belonging, and a way to feel selffulfilled. Thus, aged out foster youth appear to be looking at the family as a unit that ought to strengthen the individual. As participants' accounts revealed, they now expected family to accept them for who they are, to support them in their individual goals, to show them unconditional love, and to promote their well-being. Consequently, if family members are not contributing positively to the self, aged out foster youth have the option to abandon those relationships. In this way, participants arguably rely less on all family members - even biological family members - than they did in the past. As a result, aged out foster youth have higher expectations for family than perhaps ever before.

Liminal group members. Results also revealed that some participants struggled to categorize family members into the discrete categories of "family ingroup" and "family outgroup." In this way, participants' ideal attributes of "family" (e.g., as those who love you unconditionally, as those who support you, and as more than blood) were put into conversation with the reality of how certain family members performed family. From participants' reconciliation of their ideal and real experiences of "family" emerged an additional family group. This family group, known as liminal group members (see Table 4), describes the group membership status of those that exist on the border between family ingroup and family outgroup. In other words, people fitting into this group are 
family (i.e., family ingroup) yet not family (i.e., family outgroup). Biological mothers were most often identified as liminal group members, followed by biological fathers, biological siblings, extended biological family members, and friends.

Pertaining to biological family members, participants gave voice to the dominant societal discourse that blood constitutes family when describing why biological family members existed on the boundary between family ingroup and outgroup, despite not fulfilling the functions often ascribed to "family" (see RQ1a). As participants consistently noted, at the end of the day they are still biological family or "technically" family (Grace, 18). As Becca explained:

Because she is my mom, that's the only reason [why I consider her family]. Because she gave birth to me and that's like a big deal in my life for me. I would always give her another chance and try to communicate with her better once she got out [of jail] ... but as of right now, no. I wouldn't consider her family, but she is my mom. (15)

Becca's account references the fact that her mother gave birth to her, which was "a big deal" in her life. At various points in her explanation, Becca referred to her mom as both family and not family. Consequently, this account offers unique insight into the tension many participants reported feeling when attempting to place family members into either the family ingroup or family outgroup category. Other participants identified family members as belonging in both the family ingroup and outgroup by referring to family members as "kind of" family:

I wouldn't consider her [biological mom], right now, my family. I guess "kind of" my family... it's a hard, nuanced thing to navigate... My mom is in family 
purgatory. Why don't we say that? Because it feels so harsh to say she isn't a part of my family, but it doesn't feel right to say she is a part of my family... I do want a relationship with my mom, but I don't want a relationship. You know, it's this constant back and forth. (Lucy, 3).

In this exemplar it becomes evident that Lucy is struggling with how to categorize the relationship she has with her biological mother. Lucy not only references her mother as "kind of" family but goes on to say her mother is in "family purgatory." The reference to "purgatory" allows us to visualize the space Lucy's mother is occupying in her mind - as both a family member and not a family member. She goes on to explain how identifying her mother as family is a "constant back and forth," which further gives credence to the idea that, at times, identifying family members as belonging into discrete categories can cause tension and conflict.

Accounts detailing the tensions inherent to defining liminal group members give credence to the idea that there may be tiers to family definitions. For example, "kind of" family is arguably a unique tier from "family." Perhaps then, individuals regarded as "kind of" family may best be labeled as "relatives," such that while participants may be related to someone, they may not be fulfilling the central functions of "family" they have come to value (i.e., providing unconditional love and support). Consequently, they are family at a different level. In this situation and at this time, "relatives" rather than "family." This finding is especially interesting because it calls us to consider the ways in which biological family relationships are positioned as voluntary - or relationships that we can choose. By labeling a biological relative as "kind of" family, participants are giving voice to the inverse of someone being "like a mother," for example, in voluntary 
kin relationships. Rather than putting relationships at a higher tier (i.e., "like a mother") to denote someone is fulfilling a role or satisfying functions typical of a mother although they may not be related by blood or law, which is normative in voluntary kin relationships, participants placed family members who occupied this liminal status at a lower tier (i.e., "kind of" family) because of their inability to perform and/or fulfill the roles expected of biological family. Importantly, the ability for individuals to shift between these different tiers of family is possible. Likely, their transition from a "relative" to "family member" status hinges on the person's ability to satisfy the conditions aged out foster youth believe are critical to "family."

In fact, participants explicitly referenced their definitions of "family" when describing how family members may teeter between a family ingroup and family outgroup status:

I mean, you know by blood, yes they're family [biological parents], but by relationship... Going back to what is family, "family" is somebody you can call and you can say "I had a bad day today," and you have a conversation. Both of my parents, my conversations with them... it's usually about my brother, it's about them, they know no intimate details about my life... they don't even know what I do. They've never been through the ups and downs of life with me, so I guess I consider them I guess my biological family, but if you're talking about an inner circle of support, no. (Wren, 22)

Participants' accounts often simultaneously referenced societal assumptions about family (e.g., family members are those who are genetically linked) and one's personal definition of "family" (e.g., as those fulfill specific functions, such as showing love and support), 
when reconciling how to categorize certain family members. Thus, while participants largely rejected the societal discourse that blood equates to "family," it appears that this discourse is still so powerful that they are not willing to fully reject or define biological family as not family. Thus, some participants ended up placing biological family members in this "gray area" of liminality.

Regarding the designation of friends as liminal group members, participants still gave voice the dominant societal discourse that families are constituted by blood. Essentially, while friends may perform functions of "family" they still do not share blood ties. In this regard, some participants struggled with identifying friends as family ingroup or family outgroup members and instead would reference friends as being "family-like." As Noah explained:

So, I think would more-so say family-like [in reference to friend who he calls "brother"]. And the reason why I am going to say family-like it because, you know, I have already explained already about how family is family to me and I hold that pretty high. I mean, I have to kind of really tell myself because I tried to look past this, but I haven't been able to because I don't think it's physically possible. My [biological] mom will always be my family - regardless if she's not here in the physical world. She is my family. My [biological] grandmother, same thing. She is my family. So, they are going to always be the closest things to me in this entire world, no matter whom I meet. So, friends, people I say are my "family," aren't really my family... so I can have that relationship like a family but at the same time it's still not going to be the same as if it was actual family. (16) 
Accounts such as these demonstrate that although individuals may reference "family" as those who fulfill specific functions (e.g., expressing love, showing support; see RQ1a results), when explicitly asked to categorize these family members as belonging to their family ingroup or outgroup participants, participants may not instinctively position them as family ingroup members. In this way, participants give voice to the potential difficulty in positioning individuals outside of the biological family as family ingroup members. Society has so deeply engrained the expectation that blood constitutes family that while aged out foster youth seem to realize that family can be more than blood, they may still struggle with placing individuals outside of the biological family into that ingroup should they still have close ties with biological family members. Thus, when these ideals collide (i.e., family as blood and family as those who support and love you unconditionally), aged out foster youth appear to be more prone to classifying non-biological family members as liminal group members. They were family yet not family.

Overall, findings revealed that categorizing ingroup and outgroup members is a largely individual process. Because there is overlap between who aged out foster youth positioned as ingroup and outgroup members, it appears that classifying family members largely comes down to personal decisions and understandings of "family." While society tends to push the idea that there is one best way to do family (i.e., family being the heterosexual, biological, in-tact family), there are scenarios where that definition does not hold up - such as in foster care - and we must seek out and create family with other individuals. The inclusivity and overlap between aged out foster youths' family ingroup and family outgroups gives voice to this idea. For certain individuals biological family members may be providing the functions of family they deem most important and for 
others they may not. Similarly, for some participants foster family members may have offered consistency in terms of love and support and thus were considered family ingroup members, whereas for others they may not. Ultimately, these results lend support for the idea that classifying ingroup and outgroup members is a distinctly individual process.

On the other hand, we can clearly see participants' navigation of the ambiguity inherent to designating family group membership through their attempts at explaining how and why family members did not entirely belong in their family ingroup or their family outgroup. From participants' reports of the "gray area" that exists in family group designations emerges a promising new classification for family members that exist in "family purgatory" or the middle-ground: liminal group members.

\section{Research Question Two: Making Sense of "Home"}

The purpose of the second research question was to better understand how aged out foster youth made sense of "home." Inductive thematic analysis revealed three primary themes animated participants' sense-making around "home:" home as self, home as a place, and home as family. Of note, most participants did not make sense of "home" solely as the self, a place, or a family. Rather, participants often intertwined these various approaches when making sense of "home." Each theme and subtheme are discussed in full below.

\section{Home as Self}

Aged out foster youths' sense-making around home first centered around home as self. Essentially, participants identified themselves as their own home, such that home belonged to and manifested inside the self: 
I've been changing the meaning of it a lot. I want home to be in my own heart, you know, because I want to love myself that much that I feel comfortable with myself to be satisfied. (Chad, 7)

Like many participants, Chad acknowledged that he sought to ignite home within his own mind and body. In this way, he positioned home as an individual experience, marked by feelings of comfort and satisfaction. Sadie described home in much the same way: "I am my home. Um, my heart and my mind and where I feel most safe is within myself"' (Sadie, 29). Sadie gave voice to the mind as a critical and powerful indicator of home, marked by a feeling of safety. Participants further echoed the idea that home was self by explicitly referencing home as a state of being associated with peace and confidence:

Yeah, I think home is um, having peace within yourself, wherever you are, like being grounded, and being safe and confident... more of a state of being and less of a place. And I think that, I mean I know a lot of that thinking comes from there wasn't a home, and I had to, you know exist in the gray area of whatever was around me, so I think I really created this, like, inner world of reminding myself of who I am and what I'm about and having peace within me wherever I go in this world. (Wren, 22)

Participants, like Wren, built upon the feeling of home as belonging in one's heart to suggest the feeling of "home" was inside of themselves and not dependent on spatial domains. In this way home traveled with the self, no matter where he/she went.

Aged out foster youth also tended to draw from their time in care to justify their sense-making around home. For example, Wren talked about this "gray area" where she existed because of not having a physical home - which ultimately prompted her to make 
sense of home as an inner world she created for herself. Indeed, not knowing where you will be in a moment's notice is quite characteristic of the foster care experience.

Consequently, through positioning home as self (i.e., "I am my home") participants may have been able to better cope with the reality that a physical space to call home may not always be guaranteed. Thus, rather than getting attached to physical spaces and/or people as "home," aged out foster youth sought to ignite home within themselves.

Overall, home as self gives further voice to the ways our societal needs have shifted and morphed throughout history. Similar to how youth may no longer rely on family solely for their survival, they may no longer consider home to serve merely as a shelter. Rather, their conceptions of family and home are becoming more complex and individualized such that now they tend to expect more from each - because they can. Now, the belief that family and home ought to fulfill higher-order needs for the individual, such as self-fulfillment, has emerged. As is demonstrated in participants' accounts, aged out foster youth expect family and home to contribute to their ability to thrive, not to survive. As such, aged out foster youth are giving voice to a more modern approach at understanding and experiencing home in the current study - as something that belongs to, manifests in, and travels with the self. Importantly, not all participants gave voice to home in this manner, suggesting that personal experiences may cause individuals to resort back to more primal definitions and expressions of "home" as a site of shelter. In the following theme, home as a place, we see both primal notions as well as more modern notions of home manifesting in participants' accounts.

\section{Home as a Place}


Participants also made sense of home by describing it as a place. Importantly, participants accounts revealed that home as a place was discussed in three distinct ways: as a site of shelter, as a site of belonging, and as a site of stability. In what follows, each subtheme is discussed.

Site of shelter. Drawing on more primal notions of home as a shelter, participants equated home to a physical place that provided for their basic needs: "[Home is] where you rest your head, it's where you have food, it's where you have clothes on your back..." (Paul, 9). As Paul, among other participants revealed, the primal urge for shelter may still be central to home life. In fact, participants talked about how they envisioned a house when asked to describe home: "I think of a house. I literally picture a house to sleep and eat and live in" (Maya, 2). Other participants gave specific reasons for imagining home as a shelter. Most of these reasons boiled down to their experiences in and out of foster care. For example, Adam explained:

I think when you turn 18 or 19 I think a home, it can even be a place you can lay your head. Because sometimes some [foster kids] are just homeless a lot... so even a place to lay your head can be a dream come true."

While Adam never experienced homelessness himself, he worked with foster youth who were both in and aging out of the foster care system. Through his work experience, he became aware of how important it was for foster youth to have a place to sleep. Home to him now was seen as more of a shelter, because even shelter can be a dream come true for foster youth.

Indeed, many participants gave voice to how prior experiences in care shaped the way they conceptualized and made sense of "home." For example, one participant talked 
about how home was stripped back to the "the basics" in light of her experiences before entering foster care. As she explained, shelter was never guaranteed. There were nights where she would sleep under a deck, on the front porch, or have to check herself into a youth shelter and hope for a bed. As a result, she became keenly aware of the importance of shelter - which draws on those more primal notions of home as providing a shelter necessary for survival.

Ultimately, as participants accounts demonstrated, we may not fully understand the value in something until we no longer have it. For some participants, a place to eat, sleep, and store clothes was not always guaranteed. Thus, shelter became the basis - or the foundation - of home. As a result, participants came to expect that bare minimum because they knew, first-hand, what it was like to live without a shelter. Consequently, equating home to higher order feelings of belonging and stability was simply not a thought that crossed these participants' minds. Rather, home as a shelter was what they came to expect and value.

Site of belonging. Participants also described home as a place that offered a sense of belonging, which gives voice to both more primal and modern notions of home. Home as a site of belonging is primal in that it still privileges the structure of the home. Home as a site of belonging is modern in that it assigns a specific attribute (belongingness) to a physical structure that, without its presence, would cease to be "home." In the past, this attribute would not have been required to call a place "home" because home was simply a shelter. Participants give voice to this intermingling of more historical and modern approaches to home through equating home to a place they could call their own. For Rose, this was her room: 
Mainly it's just my room again. It's like... home is where I am me and my stuff looks like me and everything around me is me. You know? I have my favorite things on the walls... my posters I like, my movies... you know? (11)

For many participants the ability to put things up on the walls, store things, and look around and have everything feel like them were all important aspects of belonging, which is in stark contrast to the trash bag days of foster care. While in foster care, participants would be required to store what limited possessions they had in a trash bag and would take that bag with them from home to home. Certainly, it was difficult to feel a sense of belonging when participants looked around and felt as if nothing truly belonged to them. As one participant explained:

Home is supposed to be a place where we belong, and in some cases we never really feel like we belong. We feel like we are outsiders and we will never be good enough to belong. (Faith, 26)

Through reflecting on their time in care, participants restructured their beliefs about home from merely a structure to also a place they felt like they could truly belong. No more trash bags and no more transitions - they could settle in and begin creating memories. As Kayla stated:

A "home" in my sense is... where you have memories, you have rooms that you go into and it has all your decorations, the smell of the house, the vibes are great, you know, everything about it makes you feel like you're in your safe haven. So that's what home means to me. (Kayla, 23)

Undoubtedly, positive memories are associated with a feeling of belonging. Beyond referencing the smell of the house, decorations, vibes, and safety in relation to belonging, 
participants often talked about the specific aspects of the home that they missed the most and the memories that still tied them to specific places. As Faith explained:

We had Christmas there, we did Thanksgiving dinner, me and my brother fought like cats and dogs, we got yelled at, we got whoopins in that house, we got potty trained in that house... [laughing] Everything a little child experiences was all in that house! I drive by that house today and I sit outside of it and I just look at it. It was put up for foreclosure, so I can never claim it unless I buy it. It's just the memories... they give me peace. I do miss it. I miss where I grew up and I miss stuff like that. (26)

The description of home as a site of belonging set forth by Faith was reiterated by many participants. Home was where participants "did family," a space that they could envision, that they missed as they grew older, and that they associated with the good, bad, and indifferent aspects of childhood. Participants frequently reminisced about these places as sites of belonging - places they truly felt they could always call home. Consequently, home became not only a shelter, but also a place they felt they could belong.

Site of stability. Aged out foster youth also described home as a site of stability, drawing once again from both primal and more modern notions of family and home life. Throughout history youth have come to expect that we can rely on family and home to provide a sense of stability. For foster youth, this expectation was directly challenged by their entrance into care, such that biological family members were seemingly unfit and/or unable to provide a stable family and home life. However, the societal expectation and primal notion that biological family and home do provide stability still prevailed in some 
participants' accounts. Even after entering into foster care, some participants still perceived the home they grew up in as a site of stability. As Carmen explained:

My family grew up for five generations on the same piece of property and um, it's pretty much everyone, they believe that they will always come back. It's kind of like the homestead, the home base, no matter where you go in the world you're gonna come back to that place cause you know it's, you know it's gonna be there.

Participants, such as Carmen, frequently described home as a place that was unwavering and stable. For other participants, home as a site of stability did not have to be connected to the biological family, demonstrating a more modern take on family and home life (i.e., we can create family and home without biological family members). In fact, some participants described home as a site of stability through referencing the instability of home before entering foster care - when living with biological family. Lucy described it like this:

It [the time before entering foster care] makes you realize how important it is that you have the security that you're going to have a place to sleep. You know, I never would know until I came back and the doors were locked. I realized home should be guaranteed and it's really jarring when it's not. (3)

Here we are introduced to the idea that while home was regarded as a site of stability connected to biological family members in the past, now aged out foster youth have more freedom to define and create home with people outside of the family of origin. So, while stability as a primal notion still prevails, the way in which it can be achieved and maintained is much more modern. No longer is home as a site of stability solely tied to 
the biological family. In fact, for many aged out foster youth, home as a site of stability is achieved precisely where biological family are not. For many, this stability emerged in foster homes. For example, in referencing his conception of home during foster care, Todd stated: "Home would be kind of like a place that you can rely on as a constant... like to go back to" (8). In line with the goals of foster care, foster homes are expected to provide stability. Thus, while foster care violates the very foundations of family and home life (i.e., not long-term connections; not a permanent and unwavering place to call home), in modern society we do not care as much about these foundations. Thus, as participants explained, any home can fulfill the function of stability - even foster homes.

Overall, participants seemed to draw upon their experiences before, during, and after foster care when making sense of home as a site of stability. While some participants stuck to more primal ascriptions of home as a site of stability through directly referencing biological family members and the family homestead, other participants' account gave voice to a modernization of home as a site of stability through voicing that stability could be achieved in any family structure and any household. In this way, the notion of stability as being central to "home" still prevailed, although it was conceptualized and experienced in diverse ways among participants in the current study.

\section{Home as Family}

Last, aged out foster youth described home as family. For some participants in the current study, family was a critical aspect of home:

I think home is where the family resides and so to me, it's kind of like weird, it's interconnected in a sense. Obviously, family is different. Family is like people, home is like a mixture of people, a place, and an object. (Kayla, 23) 
Kayla's take on "home" sheds light on participants' propensity to recognize the interconnected nature of home and family, while still acknowledging that differences between the two might exist. However, many participants expressed that home was not just one aspect of family, it literally ceased to exist without the presence of family. As Lucy explained: “I would probably say for me I wouldn't call a place home if it didn't have family there. I feel like they are interconnected" (3). Participants frequently equated home with family and would refer to them as "interconnected" or "one in the same." Owen even took it one step further to differentiate the way he defined home from the way he assumed other people defined home:

I view them [family and home] as one in the same. For example, if parents decided to move and they became homeless I think you can still go home wherever they are at, you know, and be part of that family. So, I think they really are one unit. You know, most people view home as a structure, but I think it's people. It doesn't have to be, like, parents. It can be somebody you view as a sister or a cousin... (17)

As participants' accounts demonstrated, home as family is not limited to the parent-child relationship. Consistent with participants' prior definitions of "family," home could be achieved with a host of family members, Participants' accounts further gave voice to the idea that family as home is ever-present, even in situations of homelessness: "I think if you have a family that wherever your family is, that's home" (Becca, 15). Essentially, rather than describing home "as where the heart is," participants described home "as wherever family is." 
Of the many implications stemming from participants' positioning of home as family, I believe the one that is perhaps most paramount to the current study is determining how home as family might shape aged out foster youths' perceptions and experiences of homelessness. Given many participants discussed family and home as "one in the same" or "interconnected," it begs the following question: if you do not have family do you have home? Interestingly, a situation such as this may require aged out foster youth to reconsider the ways in which they make sense of home, such that they may have to turn to more primal (i.e., home as a shelter) or more modern (i.e., home as self) conceptualizations of home. On the contrary, because we as a society are freer now more than ever to define and identify family for ourselves, it may be the case that aged out foster youth would seek out familial connections they may have not considered previously to achieve "home." Regardless of how this scenario might play out, what we do know is that some aged out foster youth have come to view family and home as one in the same. If they can establish a sense of family, it appears a sense of home will inevitably follow.

\section{Research Question Three: Constructing and Maintaining Family Identity}

The purpose of the third research question was to examine how aged out foster youth created and maintained family identity via family communication. Specifically, how aged out foster youth utilized internal boundary management strategies (see Galvin, 2006) and context-specific strategies (see Nelson \& Colaner, 2018) to construct and maintain familial identity was assessed. Five themes were embedded in aged out foster youths' discourse: naming, discussing, narrating, ritualizing, and normalizing.

\section{Naming}


Data revealed naming was one internal boundary management strategy

participants utilized with family ingroup members to build and maintain a family identity. Aged out foster youth offered three distinct approaches to naming (i.e., how and why they chose to name family ingroup members). First, participants explained that naming reflects the fulfillment of roles. Second, participants discussed how naming reflects the biological relationship. Third, participants elaborated on how nicknaming reflects close bonds.

Naming reflects the fulfillment of roles. Participants discussed their naming decisions in light of the role(s) individuals fulfilled in their lives. Consequently, participants demonstrated naming in terms of role fulfillment was one way to create and maintain family identity. Participants explained how they referred to people who fulfilled the roles of a mother - for example - as "mom." As Felix noted:

I have always called her "mom" because she is my mom... I would see my mom working a job and doing whatever she could to take care of us. I always looked at Mom as that she would do whatever she has to do to make sure that I am going to eat, drink, sleep. She has always been "mom" to me. Even after I got older and didn't live with her she was still my mom. I didn't ever want to call her anything else. (4)

Participants, such as Felix, often talked about the roles certain individuals would fulfill that earned them a specific title. For Felix, because his biological mom would take care of him (i.e., make sure he was going to eat, drink, and sleep) she would always be “mom." Participants would often offer straightforward definitions of what it meant to 
fulfill a certain role before describing how they named someone in light of the role they fulfilled:

Well, a mother by a definition is NOT someone who gives birth to you. It's someone who is there when you are sick, when you were misbehaving at school, when you got sent home from school with chicken pox, you know? When I got caught smoking cigarettes at school... you know. It's that person who struggles with you, it's not just someone who gives birth to you. That's why I call her [biological aunt] my mom. (Kelly, 30)

For Kelly, among many others, there was a clear acknowledgment that a "mom" was not automatically a family ingroup member because they gave birth to you (see family as more than blood). Rather, they had to go on to fulfill the functions of a "mom" (e.g., someone who picked you up when you were sick, struggled with you, etc.) in order to earn that title. Consequently, any number of people could become "mom" to participants, representing an inclusive approach to naming. Moreover, given participants' time in care, it is plausible that many individuals aged out foster youth encountered (both biological, foster, and otherwise) earned these titles as a result of their actions.

Beyond naming biological family members, participants talked about how they would name friends based off of the roles they fulfilled in their lives. For example, Sasha reflected on her naming decisions of her two friends who she referred to as her "brother" and "sister:"

With my brother [friend], I call him brother because he is like a few months older than me. I looked to him as an older brother and a protector in a sense. I also annoy him like a kid sister who would get on their big brother's or big sister's 
nerves. With me and Stella (friend), I call her sister because I tell her all the secrets I would tell my sister that only her and I know. (14)

In this exemplar, Sasha provided specific reasons for calling her friends "brother" and "sister," respectively. Her brother fulfilled the role of protector and her sister fulfilled the role of secret-keeper. These are both roles we normally ascribe to biological sibling relationships, but for Sasha her friends fulfilled these roles and thus were named in ways that reflected these roles.

Naming around the fulfillment of specific roles also centered around the expectations of certain familial designations (e.g., what "mothers should do") As Adam explained:

We say well "that's my auntie," "that my pops," "that's my father..." I think a lot of that comes with preconceived notions and expectations of what people in those relationship roles do. Even like what brother and sisters do. Like what they're supposed to do, how they're supposed to act, those types of things. (25) Participants consistently articulated that names reflected the fulfillment of specific roles, not necessarily how someone might be biologically connected to you. Participants talked about how they would realize what certain family members "should do" and would assign titles to both biological and non-biological family ingroup members based on whether or not they fulfilled the expectations attached to a certain role. In this way, aged out foster youth were engaging in a reflective process of naming: participants gave names because of the role individuals were fulfilling and, in turn, the role was solidified and reinforced because of the name. This finding builds upon RQ1a, which illuminated how aged out foster youth often identified "family" as those who fulfilled specific functions 
(e.g., caring, supporting, loving). It became clear that participants often relied on the same definition - as family being those who fulfill specific functions - when naming family ingroup members.

Naming reflects the biological relationship. Participants further gave voice to the idea that although individuals might fulfill specific familial roles, at the end of the day family titles (e.g., "mom," "dad," "sister") are reserved for and reflect biological relationships. In other words, participants' naming decisions revolved around what title an individual "literally" possessed, regardless of whether or not they fulfilled functions associated with that particular role. For example, regardless of someone's fulfillment of the "mother" role, participants would talk about how the name "mother" was still reserved for their biological mother:

The relationship with the woman that was my prior placement, my very last placement, I kind of go back and forth calling her mother and by her first name just because it never, it never really sat well with me calling her mom or momma just because I kind of already had that word reserved for my [biological] mother, so over the years slowly started calling her mother every now and then but for the most part I called her by her first name. (Carmen, 5)

Essentially, participants acknowledged that certain individuals - in Carmen's case, her foster mother - might fulfill specific functions of a "mother," but the name "mother" was reserved for her biological mother. Participants also talked about how, despite the lack of a connection to a biological family member, they would still reserve titles (e.g., "mother," "father," "aunt,") for biological relationships: 
Yeah. I call him Pops, but I don’t really call him Dad or father... the reason why is because even though I don't have the strongest bond with my biological father, I still consider that man, honestly my father. (Adam, 25)

Participants, like Adam, gave voice to the enduring nature of blood ties through discussing how naming decisions, in large part, revolved around biological indicators of family. Other participants specifically talked about not wanting to replace or hurt the feelings of biological family members, even if they were not fulfilling the roles associated with their title:

I think because I never wanted to hurt my mom's feelings. Even though she was... I mean, now I am kind of coming to understand addiction a little bit. But I never wanted to replace my mom... I always just wanted her to be better... I mean, you only have one mom. It's weird because it's like a love-hate thing. I always want to protect her and I love her but then I realize she didn't do what she was supposed to do as a mom. Yeah, I have never wanted to replace her so that's why I never called anyone else mom. (Eva, 12)

As Eva notes, despite the fact her mother did not fulfill the role of "mother" due to her addiction, she never wanted to replace her mother or hurt her feelings. Rather, she felt like she needed to protect her mother. Because of this, she made a conscious choice not to name or call anyone else "mom." Participants consistently reported they made naming decisions for many of the same reasons - to "show respect," "protect," and/or "not replace" a biological family member.

Overall, some participants' naming decisions were based off of the belief that certain titles were reserved for and reflected biological family relationships. This 
approach to naming is likely reflective of participants' time in foster care. The idea that one day participants may be reunited with biological family members was once very plausible. In fact, the primary goal of foster care is to eventually reunite the biological family and child. In this way, assigning "biological names" (e.g., "mom," "dad," "brother," etc.) to others may have seemed risky or unconventional to foster youth. Now, years later, these titles still remain reserved for biological family members. On the other hand, aged out foster youth may perceive biological names differently than the way they are positioned in broader society. For example, "mom" may be a derogatory name to aged out foster youth, implying that positive associations with biological names may have been replaced with negative connotations and associations. Thus, these names were perhaps more indicative of a distant relationship as opposed to a close relationship and, consequently, were avoided by aged out foster youth when naming family ingroup members.

Nicknaming reflects close bonds. Participants also touched on the importance they placed on nicknaming. Nicknames signified close and enduring bonds between family members. For example, Ray talked about the significance of giving and receiving nicknames within his family (i.e., individuals he works with that he considers family). $\mathrm{He}$ explained: "So we all have nicknames. So, if someone does not know our nicknames then we aren't close" (Ray, 28). For many participants, including Ray, both assigning and knowing nicknames were indicative of family cohesion. Extended interactions led to the formation of these nicknames, ultimately signaling a degree of closeness. Thus, nicknaming (and knowing nicknames) was an important way participants evaluated the closeness of a bond with another. As Zoey stated: 
I guess when it [giving and receiving nicknames] started to happen, it just made me feel more connected to them. Because I think when I turned 18 or 19 is when I started to be reunified with my siblings a little bit more, my older ones, and the relationship was a little distant. But now it feels more close-knitted and I think it's because we shared a lot of nicknames and stuff back and forth. Like they had nicknames for me when I was little, it just felt more connected that I was able to give them nicknames too. (13)

Zoey talks about how, after giving and receiving nicknames, she was able to feel close to her siblings again. Participants frequently discussed how nicknaming allowed them to feel connected and close to people they identified as family.

Overall, as a society, we tend to not give just anyone a nickname. Rather, we are more likely to give and accept nicknames from those we have established a close relationship with over time. Participants' accounts demonstrate how nicknaming manifested over time and denoted more intimate relationships. Though being able to trace the past, present, and future of the relationship, nicknames emerged as a way to identify one's inner circle. Consequently, nicknaming emerged as one way participants built and maintained family identity with others.

\section{Discussing}

Data from the current study revealed that aged out foster youth also relied on discussing to build and maintain family identity. Participants' accounts of discussing coalesced into two unique sub-themes: being able to be open without judgment and being able to process the past, present, and future. As the naming of these sub-themes suggests, 
participants gave voice to very specific functions of discussing when illuminating how discussing created a close and enduring bond between family members.

Being able to be open without judgment. Participants referenced topics of conversation that they would only share with people they considered family members, thus signifying the importance of the family bond. Participants also reiterated how discussions, regardless of topic, should be judgement-free in families. In this way, discussing functions in such a way that family members can be open with each other without the fear of being judged. As Adam explained:

People that I can talk to about a lot of personal type stuff, really speaks numbers in a sense. You know, like relationship-type life, holiday-type experiences, what you're doing in your future, to me that's about family. Also, like where you share different secrets sometimes when you talk about secretive type things and the people you trust that with, that's like family. To me you can go talk to them about anything you want... I'm going to tell you like this, if you have someone that you can talk to about stuff you don't want to talk to other people about, those are the people that's like your family. As long as they don't judge on those types of things, especially if you think about things that might be secretive or things you wouldn't talk in public about, that's normally what makes people close. (25) In this excerpt, Adam reveals that when building and maintaining a family identity through discussing, you should be free to talk about anything - even secrets - without being judged. Participants consistently gave voice to this function of discussing. As Becca put it: "[With family] you can just be yourself and say anything that really comes out your mouth. I know they aren't going to judge me for anything or whatever" (15). 
Becca's experience here, again, touches on the function of discussing as being able to be open without facing judgement. She describes how she feels she can truly be herself, no matter the topic of conversation, with family. Faith's experience echoes that of Adam and Becca, while focusing more on the discussions she has with a friend (who she considers family) about therapy appointments and feeling suicidal:

I talk about the motions that I go through... my therapy appointments which I really don't discuss... I don't really discuss emotional things either but with them I am just fully open. I tell them how I feel. I don't sugar-coat it. I tell them exactly how I am doing. So recently I felt suicidal for the first time in my life. I mean, NEVER had I experienced this. So, I called my friend at 3 in the morning and she answered and asked me what was wrong... so we met up that following Saturday and she prayed for me. We had a long discussion and for me to be able to go to someone and tell them I feel that way without them being judgmental, I think that story is freaking amazing... it's utterly awesome! (26)

Ultimately, participants' accounts revealed that discussing creates and maintains family identity when aged out foster youth are able to be fully open without facing judgment. The additional layer of "not facing judgment" appeared to stem from aged out foster youths' fears of being moved from home to home in foster care. For example, one participant recalled how she refused to come out as a lesbian to her foster mother out of fear that her foster mother would tell her to pack her bags. She referenced this story to demonstrate how her foster mother actually accepted her sexuality and, consequently, became family. In this way, discussing as a judgement-free practice echoes participants' earlier sentiment about home being a place you can be yourself, not have to worry, and 
belong. Discussing, without fear of judgment, served a family identity-building function for aged out foster youth.

Being able to process the past, present, and future. Participants also talked about the importance of being able to process their past, present, and/or future in their discussions with family members. For example, Dawn talks about how she can discuss the good and bad times as well as current and past affairs with family ingroup members:

We talk about the past. We remember what we've been through, good times and bad times. I don't know why, I don't know if we haven't seen each other in years, but every time, even over the phone. Every time when I talk with the family that I had named, we always bring up the past, even with my best friend that I consider a sister. You know, we bring up the old days, and it's always bringing up the past. That's what we always talk about. Or we'll talk about things, you know, that's momentary, that's in the moment. You know, we see somebody pass by, we just talk about stuff that's either in the moment or we'll just talk about the past, and it always starts with, "Remember when ..." (27)

Talking with family members allowed participants to process their past. When participants felt as though they could talk freely about the past and present, as well as good things and bad things going on in their lives, they reported feeling closer to family ingroup members. Consequently, these actions helped build and maintain family identity with those they considered "family." Eva talked candidly about how discussions about her past, present, and future were reserved for only those she considered family - her sisters: 
Growing up in foster care you sort of learn not to say everything that's going on in adults' lives. We are private, but we talk about my mom, what her future looks like, and how it fits in with our lives. I talk about relationship stuff with my sisters, our futures, and sometimes I don't really feel comfortable with showing off my dreams and the different things I want to do with other people... but I talk to my sisters all the time about different things I want to do once I get into my career and finish my master's program and different things like that. Kind of like not being afraid to share, I guess. (12)

Many participants, like Eva, talked about how their time in foster care shaped discussions in their family such that being able to discuss the critical aspects of one's life (i.e., the past, present, and future) spoke to the enduring bond they felt toward people they considered family.

Ultimately, participants argued that being able to discuss their past, present, and future was integral to the creation of a shared family identity. By positioning discussions as enduring in family relationships, participants are speaking to the broader societal expectation that family relationships are long-term. This is interesting because for individuals in foster care, relationships may only exist for a blip in time. Thus, participants appear to be drawing from their experience of "temporary family" to explain that those relationships that extend beyond temporary - marked by candid discussions about the most critical aspects of one's past, present, and future - are those that become familial. Consequently, aged out foster youth gave voice to the societal expectation that family members ought to occupy a distinct place in our past, present, and future. Family ought to stand the test of time. 
Taken together, by positioning discussing as the fulfillment of certain functions (i.e., being able to be open without judgement; being able to process the past, present, and future) to build and maintain a family identity, aged out foster youth set forth clear expectations for family communication. Participants' accounts extend our current understandings of the discursive practice of discussing by illuminating how the fulfillment of certain functions while discussing creates and maintains family identity.

\section{Narrating}

Narrating was another prominent discursive strategy aged out foster youth utilized to build and maintain family identity. Similar to discussing, narrating also served two unique functions: acknowledging a shared history and reclaiming the past.

Acknowledging a shared history. Participants first explained how narrating fulfilled the function of acknowledging a shared history. Aged out foster youth used storytelling to reflect close bonds between themselves and those who knew them during their time in foster care. In other words, storytelling fulfilled the function of acknowledging a shared history and reflected family identity. As Becca explained:

They [biological siblings] were there. It was good times. Like, someone who actually knows you, because when you grow up in foster care and you aren't around family, not a lot of people know you. You aren't used to having that. When you think about it, it's a good feeling. Stories make you feel good, you remember the good times. Like "man, I wish things would have turned out differently, but hey, look where we are at now." (15)

As Becca stated, she felt like storytelling with her siblings was important because those people "actually" knew her. Being able to acknowledge shared experiences, through 
storytelling, during their time in care reflected the bond that existed between family members across time. Aged out foster youth frequently noted how they would reminisce about the past as a way to reflect the closeness they felt to people they considered family: With my old friends from back home it's just like reminiscing about things like, uh, they were really supportive of me when I was going through various parts of my foster family when I got removed. I still got to go to the same school, so they knew what was going on you know. (Grace, 18).

For many participants, like Grace, these family members were there - through the transitions between homes and, for some, into and out of care. Telling stories about the past solidified the unwavering nature of the bond aged out foster youth felt toward family ingroup members. Thus, acknowledging the past ultimately served the function of reflecting how family identity stood the test of time. Storytelling reflected a consistent and enduring bond.

For some participants, there was no shared history in light of their transition into care. In these instances, aged out foster youth worked to re-ignite a prior bond with family members through storytelling. In this way, storytelling affected family identity construction through reclaiming the past.

Reclaiming the past. Participants also discussed storytelling as a way for them to learn about their past and make up for lost time. Stories represented how aged out foster youth reclaimed the past with biological family members after being in the foster care system. Essentially, storytelling fulfilled a function that a lack of shared upbringing did not afford for many participants. By reclaiming the past with biological family members, 
aged out foster youth constructed a family identity. Thus, narrating affected family identity. As Carmen explained:

Well it's [storytelling] important to me, I can't say for the rest of them, but um I think for me and my siblings it's just because we had such a rocky upbringing that we didn't, we had culture, but we also were exposed to so many other cultures that um we kind of lost our identity somewhere along the way. So, whenever we reconnect with my biological mom, it was more important for us to get back to those roots to kind of figure out where we come from, who we are... so we can know where we're going. And I guess in a sense it just has a lot to do with knowing who you are, so that's why it's important to us. (5)

Participants, like Carmen, noted a bond between themselves and biological family members was brought to life through the process of storytelling. As Carmen said, she was able to "reconnect" and "get back to those roots" with her biological mother. Because aged out foster youth are often not raised by biological family members, they tended to miss out on vital experiences that served to construct and solidify family identity. As Zoey revealed:

It's just a memory that I don't recall so it's like nice knowing that my family has stories of me that they can tell me that I don't remember. It just makes it feel like I'm not so different from other kids. Being in foster care, I didn't hear that story. So, people are like, "Oh this story my mom told or this story my dad told me when I was little. I don't remember it." I didn't have that, but now I do. Just I guess- and like hearing stories, like I hear the stories repetitively, but I just like hearing them anyway just to know what it was like when I was little. (13) 
Aged out foster youth, like Zoey, talked their family identity into being with biological family members through the process of storytelling. Often participants would reference how they did not hear "their story" during foster care. Thus, telling and hearing stories constructed a family identity with biological family members and allowed aged out foster youth to reclaim their past.

Taken together, narrating both reflected and affected family identity among aged out foster youth. Stories were a way participants could maintain family identity (i.e., acknowledging shared history) as well as a way participants could (re)construct family identity (i.e., reclaiming the past). The complexities inherent to the foster care system, in terms of transitioning from home to home as well as into and out of care, give credence to these two distinct approaches. For those who were consistently in participants' lives, stories were a way to acknowledge shared history. For those who aged out foster youth may have been separated from for some time - such as biological family members stories were a way to reignite the past and reclaim a shared history. Both approaches served to create and maintain a family identity for aged out foster youth and those they identified as family ingroup members.

\section{Ritualizing}

Participants also utilized the discursive practice of ritualizing to create and maintain family identity with family ingroup members. Aged out foster youth discussed ritualizing in terms of holidays as well as more everyday routines. These approaches to ritualizing represent two sub-themes: holiday ritualizing and everyday ritualizing.

Holiday ritualizing. Many participants talked about the importance of holiday ritualizing - or enacting rituals centered around specific holidays. In U.S. culture, 
holidays bring families together. For aged out foster youth, the holidays also meant family time:

Holidays mean family time, you know? Even though I see them pretty much on an everyday basis it's, you know, getting together for the holidays... in a sense just proving that we're still gonna be together, you know that we're still going to be there for one another, no matter what. (Carmen, 5)

As participants noted, holidays served to remind individuals of the important of family. Thus, consistent with societal expectations of family, spending time with family on the holidays crystallized the family identity. Another participant, Wren, talked about how she would spend the holidays with her brother and niece. She explained that holidays kept her grounded and reminded her of who she was:

Yeah, so I'm a creature of habit, and those, those rituals or the time together I think, we talk about being grounded... I think it grounds me, and reminds me, kind of, but, you know I work um, my job is very stressful, so when I'm removed from my job, I kind of remember who I am, without all that stress. (22) By commenting that holidays helped remind her of "who she was," Wren gave voice to the idea that ritualizing not just affirms the broader family identity, but also one's place within the family. In U.S. culture, holidays are a time to reconnect with our pasts - we tell family stories, see the people we love, and catch up on each other's lives. For aged out foster youth, this may be particularly important for they may finally feel they have a family in which they belong. They can engage in these "family behaviors" during the holidays now, perhaps unlike they could in the past - when family was seemingly always in-flux. In fact, participants directly referenced their own definitions of "family" by 
talking about the functions that family served during holidays (e.g., supporting, loving). Todd reflected on how he would spend Christmas with his friends and mom and described what those rituals meant to him:

I mean, it's just kind of our thing. Yeah, I mean... I don't really know how to describe it. It's just OUR thing. No one else does it like we do. You know, it's a constant... every time that I see whether my best friend or my sister, it's something that I can rely on to be the same. The routines, the rituals... can rely on to be the same. (8)

Specifically, Todd speaks to the notion that family are those you can rely on (see RQ1a), not just for support, but also for upholding traditions. He described his Christmas rituals as something that were unique to his family (i.e., "it's just OUR thing") that he could rely on to stay the same. In this way, holiday ritualizing appeared to build off of participants' definition of family through providing a glimpse into how family identity was solidified through specific actions. Essentially, rituals were one way that aged out foster youth performed family with family ingroup members. On emotionally-charged days, such as holidays, participants were performing family and simultaneously solidifying the family identity.

Everyday ritualizing. Beyond holiday ritualizing, participants often talked about the importance of everyday ritualizing to build family identity. Everyday ritualizing refers to engaging and enacting daily routines as a means of solidifying the family identity. Participants referenced everyday rituals that included playing games, bingewatching shows, and eating ice cream before bed. Participants not only talked about the 
rituals in and of themselves, but also went on to describe the impacts they had on their perception of the family. As Owen explained:

We binge watch shows. So, for example, Shameless was a series and we would watch that. It's a way to kind of connect and build that relationship, you know, because I think it adds to the memories of creating that relationship. (17)

For Owen, like other participants, everyday rituals created memories which served to build and maintain their family identity. Aged out foster youth also noted how everyday rituals have become more important to them due to their time in foster care. For example, Paul talked about how his family would "go fishing a lot," "go out to the race tracks to watch horse races," "go out to the movies," and "eat dinner as a family" (9). He went on to explain why he valued these everyday rituals so much:

I never got any of that [everyday rituals] when I was growing up. I had to grow up really fast on my own. I had to learn everything on my own. I had to take care of myself. And so I never got a childhood, even before I went into CPS. And so I never did family events. I never lived with "family-family." So, to actually get to participate in this stuff... I don't know, it just makes things feel good. (Paul, 9) As Paul described, the everyday rituals enacted with his current family filled the void of never feeling like he had "family-family." In this sense, everyday rituals allowed participants to create and build a family identity - an experience many reported not having when they were growing up in foster care. Building this family identity through everyday ritualizing made participants feel "good" and many reported that their lives "wouldn't be the same without them" (Faith, 26). Indeed, everyday ritualizing took many 
different forms for participants, but one impact remained constant: these rituals allowed them to feel as if they belonged in the family.

Taken together, everyday ritualizing reiterates that notion that the little stuff we do in families is important to building a family identity. Experiencing the inevitable ups and downs of family life together creates family. The being there and doing life together makes people family. In this way, doing family together is the small stuff. By partaking in these everyday activities, individuals became embedded in the family system. Everyday rituals provided aged out foster youth with memories as well as a sense of inclusivity. Ultimately, everyday ritualizing served to create and maintain family identity between aged out foster youth and those they identified as family ingroup members.

\section{Normalizing}

Data from the current study indicated normalizing was a commonly utilized discursive strategy among aged out foster youth. Because aged out foster youth are discourse-dependent, normalizing helped them to reify their family identity. In fact, aged out foster youth often stressed the normalcy of their family dynamic, regardless of the potential structural variations. As Becca explained: "We're just pretty ordinary and simple. We just talk and laugh and listen to music. That's pretty much it" (15). This account demonstrates how participants would often talk about certain behaviors as "normal" family behaviors they would engage in with family ingroup members - such as talking, laughing, and listening to music. Carmen put it like this:

We just mainly talk about family and our family matters as far as, we try not to bring up the past, um, just because we all know it, we all kind of acknowledged it, but we also have decided to move on from it so that's not, you know a big factor 
into what we, what we continue in our lives. But I believe we're just as normal as any other family. (5)

In this excerpt Carmen acknowledges that her family has always looked different from other families throughout her life - due to her being in foster care - but at the end of the day she believed her family was "just as normal as any other family." By voicing their families were just "like any other family," participants emphasized the discursive strategy of normalizing and simultaneously de-emphasized the ways in which their past may not have been the most normal (e.g., having multiple families; transitioning from home to home; hopping schools) due to participants' time in care.

Beyond indicating their family was no different than any other family, participants often discussed the "normal" family behaviors they engaged in with family members. As Eva posited: "We just are like a normal family... we like to pick on each other" (12). Even yet, participants normalized actions associated with specific familial roles: "You know, we [two friends she considers family] get into arguments just like any other siblings do!" (Sasha, 14). Overall, results revealed that aged out foster youth declared their family as normal, and in so doing, reified familial bonds. Aged out foster youth also utilized normalizing to de-emphasize the ways in which their pasts may have not been the most normal. Public declarations of normalcy helped aged out foster youth create and maintain a family identity with family ingroup members.

\section{Research Question Four: The Faces of and Reasons for Family Estrangement}

The fourth research question was comprised of two parts. The first part (i.e., RQ4a) examined who aged out foster defined as estranged family members, whereas the second part (RQ4b) explored the reasons aged out foster youth estranged from family 
members. Family estrangement was positioned as an active and purposeful process among participants. Aged out foster youth estranged from specific family members for specific reasons. In what follows, the themes and sub-themes animating RQ4a-b are presented and discussed.

\section{Faces of Family Estrangement (RQ4a)}

The purpose of RQ4a was to explore who aged out foster youth defined as estranged family members. All participants reported estranging from someone they once considered family (see Table 5). Importantly, many of the individuals that participants reported estranging from were also identified as family outgroup members, but not all. The inconsistencies between these two lists is likely to due to the way these questions were posed to participants. Participants were asked who they did not consider to be a part of their family for the family outgroup question, whereas for the faces of family estrangement question they were asked to identify someone they used to feel like family with - or society expected them to family with - that they have actively distanced themselves from or eliminated as family. Thus, the family outgroup list could very well be individuals that aged out foster youth never thought of as family. This could be due to a lack of shared upbringing, little contact, or their failure to fulfill family functions. However, the individuals on the family estrangement list were individuals that participants actively eliminated as family. These were people that they consciously and deliberately moved from the family ingroup to the family outgroup category. 25 out of 30 participants discussed their estrangement from a biological family member, while four discussed estranging from foster family members and one from a best friend. 
As these numbers reveal, most participants discussed estranging from biological family members. We even see some aunts, sisters, and cousins in the mix here, indicating that some people discussed more peripheral members of their biological family. Even yet, some people identified non-biological individuals as estranged, such as foster aunts, foster siblings, mentors, and best friends. Indeed, the fact that a diverse range of individuals were identified as estranged family members may be indicative of the fact that aged out foster youth have a broader bank of individuals to draw from when thinking about how family estrangement might manifest, in light of their time spent with different families before, during, and after foster care.

While family estrangement extends beyond biological family relationships, participants were most likely to identify biological family members as estranged. Because foster care disrupted the bond between biological family members and aged out foster youth, it may be the case that estranging from these family members seemed more plausible. Due to entering into care, foster youth realized they had the ability to pull family from elsewhere (e.g., foster families, mentors, friends, social workers). Consequently, biological family members were no longer aged out foster youths' only option for fulfilling the functions that they believed were vital to "family," such as demonstrating love and support. Rather, participants came to realize that these functions of family could be fulfilled by others and, consequently, estranged from biological family members who could not or did not meet their expectations of "family."

It is also plausible this trend is due to the primal connection youth tend to feel toward individuals with whom they share blood, such that when asked to identify an estranged family member aged out foster youth may have instinctively thought about 
biological family members. Moreover, because of these primal connections, participants may have felt as though this is what family estrangement truly is, operating under the assumption that being distanced from a biological family member ("real" family) is the only way to be estranged. Consequently, they may have focused their attention on a biological family member.

Another factor contributing to the decision to estrange from biological family members may be directly tied to the idea that youth can expect more of biological family members now than they could in the past. As the data revealed, aged out foster youth ultimately expected family to help them become their best selves. For example, participants wanted unconditional love, unwavering support, and the ability to be open about anything without facing judgment in their family relationships. As a result, should biological family members not be satisfying some or all of participants' individual needs, they sought to distance themselves. In this way, higher expectations of family equate to a higher likelihood of family estrangement. A combination of factors is likely at play, but these ideas offer a springboard for understanding why aged out foster youth may have been most likely to report estranging from biological family members.

On the other hand, some participants discussed non-biological family members. For these participants, it is likely they created alternative definitions of family due to their time in the foster care system. In this way, they likely bonded with non-biological family members and came to consider them family, then something happened that defied their expectations and standards of family, so they felt the need to estrange. It is also possible that the voluntary kin bond (i.e., bonds we typically see as voluntary, such as foster family members, mentors, and friends) was never as strong as the biological bond. Thus, 
while considered "family" at one point in time, non-biological ties may have been seemingly easier to dissolve and perhaps required less of a reason to do so.

Ultimately, because aged out foster youth have more agency in identifying and enacting family in light of their time in care, participants now have a wider array of individuals to draw from when thinking about and discussing family estrangement. Simply put, the faces of family estrangement are diversifying. Aged out foster youth reported estranging from biological family members beyond biological parents (i.e., the entire biological family, half-sisters, brothers, aunts, uncles, cousins, and grandmothers) as well as foster family members and friends they considered family. As participants' accounts demonstrate, there may be more to family estrangement story than we once thought. Exploring the reasons for family estrangement as well as how participants communicatively deconstructed family identity and described the impacts of family estrangement further contribute to the family estrangement narrative put forth by participants.

\section{Reasons for Family Estrangement (RQ4b)}

The purpose of RQ4b was to explore the reasons that aged out foster youth estranged from family members. Participants noted a variety reasons for why they estranged from family members. Thus, RQ4b provides a deeper understanding of both the intricacies of each case (see Table 5) as well as a broader, more holistic assessment of the reasons aged out foster youth estranged from family members. Specifically, aged out foster youths' reasons for estranging from family members fit into the following categories: physical actions, personal attributes, and lack of social support. Each 
category speaks to the broader notion of defying standards of family and will be analyzed in relation to the changing functions and expectations of family.

Physical actions. Participants' accounts consistently revealed that family members' physical actions played a role in their decision to estrange. Physical actions, in order of most to least cited, took a variety of forms and included abuse (i.e., physical abuse, sexual abuse, psychological abuse, harassment, verbal abuse, emotional abuse, and drug abuse), promiscuity, betrayal, moving away, and stealing. Taken together, behaviors within the broader category of physical actions were most commonly cited as reasons for family estrangement among aged out foster youth in the current study. By engaging in these physical actions, estranged family members defied participants' standards for family.

As was previously discussed, the standards for family have been increasing exponentially over time, such that youth now appear to expect much more of family than they did in the past. In more primal versions of family, physical actions (e.g., abuse, stealing) would have been tolerated because the family group was still necessary for survival. However, in modern society, youth no longer rely on family as their sole source of survival. They can both be safe and thrive without family - and, in some cases, may be better able to be safe and thrive without certain family members. Essentially, rather than viewing family as integral to survival, participants are giving voice to family as a pathway to self-actualization. Because of this, participants felt more willing and able to abandon family relationships that defied their expectations of family (e.g., family members do not abuse one another) and appeared to be negatively impacting the self (e.g., family member's abuse is causing me harm). In this way, the individual appears to 
be becoming more important than the family. Because of this, aged out foster youth are more able and willing to estrange from family members for reasons of physical actions if they ultimately believe that family estrangement can positively impact the self.

Personal attributes. Data also indicated that aged out foster youth would estrange because of family members' personal attributes. Personal attributes centered around estranged family members' personalities. The most commonly cited personal attribute that led to aged out foster youth wanting to estrange was family members' negative personalities, followed by selfishness, pretentiousness, toxicity, anger, narcissism, instability, and mental health issues. Personal attributes as reasons for family estrangement, again, speak to the notion that estranged family members were defying participants' standards for family members. In light of not meeting their standards of "family" in terms of personal attributes, aged out foster youth reported estranging from these family members.

Estranging from family members due to personal attributes also reflects the changing standards and expectations of family. Similar to how youth would have likely been more tolerant of physical actions in more primal versions of family life, they likely would have been more tolerant of one's personal attributes. What this category suggests is that youth are becoming more and more selective when it comes to identifying family. When a family member defies our expectations, by being selfish or having a negative personality, youth are more readily able and willing to say goodbye because families are now for thriving, not for surviving. Ultimately, then, if aged out foster youth believe a family member's personal attributes are threatening the self, they are more prone to abandon the relationship altogether. Essentially, aged out foster youths' account of 
estranging for reasons of personal attributes gives voice to the idea that they have more agency now, then ever before, to break up with family members.

Lack of social support. Participants' reasons for family estrangement also touched on the lack of social support they felt from family members. Lack of social support was described as, literally, a lack of social support. Other ways participants gave voice to a lack of social support as the reason for family estrangement included: lack of caring, blaming, and lack of acceptance. As RQ1a illuminated, aged out foster youth defined "family" as those who support you. By not supporting participants, estranged family members were disregarding participants' standards of "family." Thus, participants sought to estrange from these individuals. Estranging due to a lack of social support gives further credence to the idea that youth not only have higher expectations of family than they did in the past, but that social support is no longer tied to specific family members. Rather, youth can seek out and achieve social support from others should family members - even biological family members - not be fulfilling this central function of family. In this way, aged out foster youth are more likely to estrange from family members if they appear to be threatening their own ability to live their best lives and become their best selves. Thus, they are re-defining family as those that allow them to thrive rather than survive. For aged out foster youth, when family members appeared to be hurting their personal ability to thrive they sought to estrange.

Overall, each category of reasons for family estrangement that emerged (i.e., physical actions, personal attributes, and lack of social support), speaks to the broader notion of defying the increasingly higher expectations and standards of how family members ought to "do family." Participants' accounts consistently demonstrated that, 
because they are less reliant on family members now than in the past, they are becoming more critical of family members. Moreover, as their concern for the self becomes more and more central to family life, their tolerance for family members' negative actions and attributes is decreasing. Thus, in light of these results, it appears that family estrangement may be more likely and possible now than it has ever been before.

\section{Research Question Five: Deconstructing Family Identity}

The purpose of the fifth research question was to explore if and how aged out foster youth utilized the internal boundary management strategies proposed by Galvin and Braithwaite (2014) and/or context-specific strategies (see Nelson \& Colaner, 2018) to deconstruct family identity. Five themes were embedded in aged out foster youths' discourse: naming, discussing, deritualizing, silencing, and disassociating.

\section{Naming}

Participants positioned naming as one way they would communicatively deconstruct a familial bond between themselves and estranged family members. Data revealed aged out foster youth approached naming in two primary ways: naming as conditional and renaming.

Naming as conditional. Participants positioned naming as conditional through stressing the biological aspect of names as a way to emphasize relationships were defined by biology only. In other words, naming was utilized as a way to signify the relationship existed in biological terms only. As Maya put it: "I refer to her as my BIOLOGICAL [emphasis] sister" (2). As Maya's account demonstrates, she would emphasize the "biological" aspect of "biological sister" to denote a degree of distance. Essentially, rather than referring to their biological family members as "sister," "mom," or "dad," for 
example, participants discussed being deliberate about calling these individuals "biological sister," "biological mom," or "biological dad." In this way, the "biological" addition served to signify a degree of distance for many participants.

Participants often discussed how they went "through several phases" of naming but have settled on names like "bio mom," "biological mom," or "biological dad" (Chad, 7; Paul, 9; Val, 21). The fact many participants discussed changing the way they named estranged family members may signify the differing degrees of distance they felt toward these family members over time. At the current point in time, however, participants elaborated on the importance of the condition "biological" when naming to designate distance between themselves and the estranged family member. Saying "biological" to deconstruct family identity is an interesting implication, indeed, as it goes directly against the taken-for-granted assumption that biological relationships represent close relationships. Findings from the current study flip this idea on its head and position the use of "biological" when naming as being indicative of a distant relationship.

Indeed, a condition approach to naming is particularly fascinating because society tends to view the biological bond as non-voluntary - a connection that is constant, unwavering, and expected. Thus, emphasizing "biological" or "bio" as a way to indicate a degree of distance violates the assumption of closeness associated with the biological family structure. Importantly, members of adoptive and foster families often talk about family members as "biological," "adoptive," or "foster" as a way to detail the nature of their relationship with specific family members. Thus, terms such as "biological" or "foster" may not always be utilized to indicate a degree of distance. However, in the current study, participants added the "biological" component to names to emphasize a 
degree of distance and disengagement - which serves to attach a different meaning to "biological" which was derived from the way "biological" was discussed and detailed in aged out foster youths' accounts of naming. Thus, conditional naming was utilized as a way to deconstruct identity with estranged family members.

Renaming. Aged out foster youth also engaged in the process of renaming estranged family members as a way to deconstruct family identity. Participants approached renaming in two distinct ways: negating family terms and changing own name.

Negating family terms. Data revealed that participants would often rename family members through negating family terms. In other words, participants would alter titles to reflect roles and/or strip titles from names altogether as a way to signify a degree of distance. Interestingly, participants reported naming by the fulfillment of roles to both construct and deconstruct family identity in the current study. The key difference being that naming by role reflected close and enduring bonds when constructing family identity whereas naming by role reflected distant and deteriorating bonds when deconstructing family identity. For example, Kayla referred to her biological mother as "egg donor" or "bitch:"

Even in therapy, I talk to my therapist about this shit. She goes "mother" and I go, "nope that is my egg donor [referring to biological mom]." That's literally what I refer to her as because that's what she was. She let me chill in her belly for nine months, but now it is what it is. I don't really have much conversation about her. So, if it's just my friends, I'm like "oh fuck that bitch blah blah blah.” But like, 
that's like literally where it is... "bitch" or "egg donor." I literally don't have any respect for her. (23)

By referring to her biological mom as "egg donor" or "bitch," Kayla is engaging in the process of renaming to acknowledge what she perceived to be the only roles her biological mother filled in her life. For example, by saying her mother let her "chill in her belly for nine months" she is directly calling out the only role she felt her mother actually satisfied (i.e., egg donor). Kayla was not the only participant that would call her mom "egg donor," as Val noted: "there was this phase where I called her donor" (21). Val went on to talk about how with her biological mother it was "never 100\% bad shit," but there were times when the bad was so bad that she would rename her mother to reflect her actions. In these situations, she would call her biological mother "donor." As is demonstrated in this account, shifts in the relationship were reflected in the names aged out foster youth assigned to family members. In so doing, family identity was deconstructed through renaming family members to reflect "distant" roles.

Participants also discussed renaming family members as a way to give voice to their absence of fulfilling a familial role. For example, Noah talks about how he has renamed his foster aunt "Ms. Lou" because she failed to fulfill the role of "aunt":

I mean, when I see her I will just call her Ms. Lou... just by her first name. I mean just because I don't view her as that "aunt" type of relationship. She, I don't know, she's just not... she doesn't resemble to me as an Aunt. She has done things to where I know family members wouldn't do that to you. So, I wouldn't consider her as my aunt. I wish it was different but I'm not gonna just sit there and be fake 
or anything like that. I'm going to tell it like it is. I am a blunt person so I'm not going to say something I don't mean. (16)

Noah, like many other participants, talked about how individuals they sought to estrange from did not fulfill the roles they expected family members to fill. In Noah's case, his foster aunt had done things to him (i.e., stolen money from him) which he did not believe a family member would do. In this way, Ms. Lou was not fulfilling the role of aunt and thus he decided to rename her "Lou." Noah deconstructed family identity by renaming his foster aunt "Ms. Lou" in light of the roles she failed to fulfill (i.e., aunt) in his life. This is in contrast to naming as an identity construction strategy, in that participants would often assign a title that reflected a closer role. For example, instead of calling a mentor their "mentor", they might refer to this person as "dad."

Participants also noted how they would have to explain their renaming decision to the estranged family member. Sadie talked about how she renamed her mother because she was not fulfilling the role of "mother." She had to justify this choice:

I actually had to tell her in my last conversation, because she just like does [these things sometimes] like "I'm your mother, your mother, your mom" and I have to tell her, "you are my biological mother but I need you to understand that you have not been involved in my life in these last 2 or 3 years and I am really sorry if this is hurtful but I don't feel comfortable calling you mother or mom" so I call her by her [first] name. (29)

Participants frequently reported having to explain to estranged family members that they were not fulfilling the role they expected of a certain title (e.g., a mom ought to be involved in my life; a dad ought to show compassion and love). Thus, they would rename 
the estranged family member in direct response to their failure of meeting their standards of what a "mother," "father," or "sister" ought to do. In this way, naming decisions had to be justified. Similar to how participants felt the need to justify calling someone "mom" or "dad," they too had to justify their reasons for choosing not to use these more intimate titles. Ultimately, by renaming individuals due to their failure to fulfill the family role associated with their title, aged out foster youth deconstructed family identity with those they identified as estranged family members.

Participants also explained they would rename family members through stripping family terms altogether. Essentially, participants would deny or eliminate their relationship with another through negating family terms. As Krista explained:

People will be like "Hi, have you heard from your sister?" And I'm like "Who? I don't have a sister. What are you talking about?" They would say "Lindsey." And then I would go "Oh that girl ain't my sister. (24)

By explicitly denying the existence of a familial bond between her and her sister Lindsey - via negating family terms, Krista deconstructed family identity between her and Lindsey. Even yet, participants would often note renaming through negating family terms was a definitive way they deconstructed family identity. As Wren stated:

Stripping her [biological mom] of the title "mom" is just this act of like, not defiance, but just like I don't, you know... you don't deserve this. It's just like a final jab of being like "you're nothing to me," you know? (22)

Many participants talked about how negating family terms was a final send-off for the relationship. Indeed, in society, names are an important indicator of closeness. Names connect us with others and make family connections intelligible to both family insiders 
and outsiders. Thus, negating family terms via altering titles to reflect roles and/or stripping titles from names altogether was a deliberate act of distancing. Ultimately, names reflected the perceptions aged out foster youth held of the nature of the relationship - that it had changed and, in some cases, was no longer. Thus, by negating family terms, participants engaged in the discursive practice of renaming as a way to deconstruct family identity.

Changing own name. Results further indicated that aged out foster youth also engaged in the process of renaming to deconstruct family identity by legally changing their own name and/or changing the pronunciation of their name to de-identify with their biological family's culture. Chad reflected on his decision to legally change his name to distance himself from his biological family:

I have, I changed my name legally already and my last name isn't the same as it used to be... I didn't consider myself in the same unit as them and I didn't relate to them on a lot of deeper levels. I still find it hard to relate to people about these struggles. But I definitely couldn't fit myself into their family even when I tried to... I also didn't like it [last name] and they would group me into things I didn't want to be a part of and there were really negative about things. They just generally, like, weren't being good people. And I was like: “No, no, no, no, no. Don't say I am one of you if you're going to be doing this shitty stuff! Stop it. Leave me alone."

As Chad explained, he did not consider himself in the same "unit" as his biological family. He did not like to be grouped in with what he described as their "negativity" and "shitty stuff" and thus legally changed his name to distance himself from his biological 
family. Chad's experience speaks to that of many other participants, whereby changing their own name was a finite way to deconstruct family identity.

Participants also gave voice to changing the pronunciation of their name in order to de-identify with their birth family's culture. For example, Owen talked about how rather than legally changing his name - he altered the pronunciation of his name.

Specifically, he talked about how his name, when pronounced, connected him to the cultural identity of his birth family. Thus, in order to deconstruct family identity with birth family members he altered the pronunciation of his name to distance himself from the cultural identity of his birth family.

The changing of participants' own name is both important and interesting. In our culture, names are important and powerful in families. Names not only bind families across generations and cultures, but also carry patriarchal notions as typically only women change names. In the current study, name changes occurred across all genders. Consequently, aged out foster youths' changing of their own name allowed individuals of all genders to reclaim power through de-identifying from their family and culture of origin. In this way, through changing their name, participants were able to construct and project a new identity separate from the trauma and hurt likely rooted in past experiences with biological family members.

Ultimately, both actions (i.e., legally changing their own name and changing the pronunciation of their own name), served to create distance between participants and biological estranged family members. Thus, changing own name was an important discursive strategy aged out foster youth would employ to deconstruct family identity with estranged family members. 


\section{Discussing}

Data indicated that aged out foster youth engaged in the internal boundary management strategy of discussing to deconstruct family identity. Participants stressed the importance of discussing the parameters of the estrangement as a way to secure distance between themselves and the estranged family member:

Whenever I had to move him out of my house, I said: "Look man, you'll always be like a brother to me. I love you in a sense where you'll always be like a brother, but I cannot be around you personally or physically and have a personal type of relationship with you any longer. If you ever need anything, if you ever just down and out or need some guidance or need something in a business standpoint, just let me know and I'll be happy to assist you." That's how I made it. I made it perfectly clear what I was doing. I extended love toward him and knowing the fact that he didn't have anybody, I was still doing those things for him because I just love him, but personally like I said, I told him I can't have a personal relationship with him any longer. (Adam, 25)

Setting parameters was one way that participants' reassumed power over their relationships and lives. By laying out clear relational and communication expectations to estranged family members, aged out foster youth took control of the nature of the relationship.

While many participants offered similar parameters in their discussions with estranged family members, some aged out foster youth made it clear that the relationship was over, for good: "I told her, 'You know what, you can do you, but I can't do this anymore. We're done. We're done"' (Ray, 28). Noah offered a similar account: "I told 
her right then and there like, "I don't want to talk to you anymore. You're really not a family member to me and I don't want to be associated with you. I'm good" (16). For Ray and Noah, among many other participants, the discussing involved a deliberate recognition that the relationship was over, and they did not consider them a family member any longer. This is important for just as we must talk our relationships into existence, we too must talk them out of existence. For participants in the current study, a direct and deliberate approach offered a certain degree of clarity and closure to the estranged family member. In this way, participants came to realize that spelling out the changing nature of the relationship through their discussions with estranged family members was both important and, at times, necessary.

Participants accounts also revealed they would communicatively reiterate the changing status of their family identity. As Trish explained: "I essentially told her that she wasn't a part of my life and I don't need anybody like that in my life and so right now... well, I call it being divorced... being divorced from my sister" (10). Trish reiterated the changing status of her family identity by identifying her and her sister's relationship as "divorced," which served to emphasize the separated nature of the relationship. In this way, aged out foster youth assigned recognizable terms to a potentially complex situation. Because people tend to understand divorce, positioning a relationship as "divorced" may have allowed participants to better explain their thoughts and feelings about the relationship to the estranged family member.

No matter the approach (i.e., setting parameters, emphasizing the end of the relationship, and/or reiterating the changing status of their family identity), discussing was one way participants reconfigured the relationship and talked a new relationship (and 
expectations) into existence. Just as individuals talk their relationships into being, they also must talk their relationships out of being. Individuals navigate all relationships through talk - both those they seek to maintain and those they seek to abandon. As individuals there is an innate desire to address the changing status of our relationships, such that estrangement requires discussions. For participants in the current study, discussions offered clarity and closure, ultimately serving as a way to "break up" with family members. Beyond utilizing the discursive strategy of discussing to deconstruct family identity at broader levels, participants consistently voiced how important it was for them to limit conversations in order to maintain a desired level of distance. Thus, the subtheme of limiting conversations emerged.

Limiting conversations. Participants also reported limiting conversations, in both length and scope, to maintain a desired level of distance between themselves and estranged family members. In this way, participants regulated closeness by regulating disclosures, such that they decreased closeness through limiting conversations. As Sadie put it: “Like if I went around my family I didn't really speak to her [biological mother]. If she said 'hello' and I felt like I wanted to say 'hello" I would, but otherwise it wasn't really hard at all [to not talk to her]" (29). Overall, participants' accounts of limiting conversations demonstrates how aged out foster youth were able to maintain a position of power through positioning communication as a choice. Participants ultimately contended that the conversation, should it take place at all, would be limited. In this way, participants assumed power over the parameters of the discussion such that limiting conversations was one way aged out foster youth demonstrated the seriousness of their desire to estrange from certain family members. 
Participants also specifically referenced the fact they would not talk about personal things with the estranged family member anymore: "Yeah. Like I speak, like, once I see her [biological aunt] ... but it's nothing personal, like, I don't speak like that" (Liz, 20). As Liz explains, the conversation between her and her biological aunt was limited in that it was narrow in scope. When it comes to family discussions, the assumption exists that the closer you are with someone the more in-depth the discussions will be. Thus, by purposefully avoiding deep conversations, participants demonstrated an awareness of the fact that surface level conversations defy expectations of family. Thus, participants recognized that limiting conversations, in both length and scope, was one way they could signal and maintain a desired level of distance from estranged family members.

Taken together, aged out foster youth reported engaging in the discursive practice of discussing to deconstruct family identity and maintain a desired level of distance from estranged family members. Because communication is the vehicle of family life, altering communication through limiting conversations significantly altered the status of the relationship. Thus, through utilizing direct approaches (i.e., setting parameters, emphasizing the end of the relationship, and/or reiterating the changing status of their family identity) and arguably less direct approaches (i.e., limiting conversations) participants engaged in the communicative work necessary to establish and maintain a desired degree of distance from estranged family members.

\section{Deritualizing}

Aged out foster youth positioned deritualizing as a discursive strategy they frequently utilized to deconstruct family identity with estranged family members. Similar 
to how aged out foster youth engaged in the practice of ritualizing, participants deritualized by avoiding holidays as well as more mundane rituals. Knowing that rituals are central to family life, many participants deliberately removed themselves from situations that could be perceived as an attempt to build and maintain family identity. For example, Lucy reflected on how the more mundane rituals between her and her biological mother no longer took place:

I mean before we would try to talk every Sunday or around major holidays we would have coffee together. Sometimes I would ask her [biological mom] to come up to help with something school related, like moving my stuff or just come visit to say "Hi." You know, that stuff is gone. (Lucy, 3)

By emphasizing mundane rituals were no longer happening, participants were making it clear that the relationship was on the fritz. Chad talked about how he no longer went to his family's church every Sunday: “Um, I did not go to my family’s church because I was afraid of running into them" (7). As this account demonstrates, participants took it as far as changing their own routines and rituals to signify they no longer wanted to be bonded to estranged family members.

Beyond avoiding mundane rituals and routines, participants also talked about how they would deliberately avoid family holidays and celebrations. Some participants reported being blunt about their desire to avoid certain family members around rituals, such as Faith, who described her deritualizing behaviors like this: "I pretty much... well, I got invited to something and they said 'Hey, you wanna go? Jeff's gonna be there.' And I was like, 'No. I don't wanna go!'” (26). Participants, like Faith, would be straightforward with their reasons for not attending. Other participants reported making up excuses for 
missing family functions, such as Noah: "So, um, many family gatherings, many family BBQs, holidays... birthdays, beach trips, all of those. The excuse would always be one thing: that I had work. So, it would be the same thing every single time" (16). As Noah explained, he would often offer the same excuses for why he could not attend the many family events he missed.

Because spending time with family during the holidays is a hallmark in our society, the fact that participants would deliberately avoid these events is telling of the changing nature of their relationships with estranged family members. Whether participants reported being blunt about their reasons for not attending or reported making excuses for not going - one constant remained: participants would avoid family holidays and rituals. The act of avoiding family members directly defies our assumptions of the closeness inherent to family relationships. Thus, by avoiding the holidays and rituals, participants were knowingly and actively deconstructing the family identity that once existed between themselves and the estranged family member.

Participants also talked about, should they have made the choice to attend family holidays or rituals, how they would still actively avoid the estranged family member. As Eva explained:

So, say everyone is there for something, like a party, and she was going outside in the front to hang out with the kids I would go the opposite way. [laughing] Or like if she was sitting on one end of the table I was sitting on the opposite end of the table. If she was staying, I was going. If someone wants to go to the store and she is going to the store, I would stay home. Like I would just make decisions to not have her so close in my space. (12) 
By actively avoiding the estranged family member at holidays and events, participants were engaging in the practice of deritualizing. For Eva, changing the ritual of "being inseparable at family gatherings" to "avoiding each other at family gatherings" was central to the identity deconstruction process. Attending yet avoiding was a useful tactic for aged out foster youth to still engage with family ingroup members while creating and sustaining distance from family outgroup members.

Even yet, many participants referenced the future through stating the person whom they estranged from would not be invited to future rituals, such as their own wedding:

No. She [ex-friend] is not even going to be invited to my wedding. Hmm hmm. No. If I cut you off, I cut you off. And it takes a lot for me to cut you off, I only cut two people off in my life. And she is one of them. (Becca, 15) As many participants explained, one way to solidify the deconstruction of the family identity was to shun the estranged family member from future rituals. Felix also talked about how he did not know if he would even go to his biological uncle's funeral, should he pass away:

If he [biological uncle] were to die I would probably go to his funeral but I am not going to cry or anything, ya know? Maybe I wouldn't even go to his funeral... who knows? (Felix, 4)

By excluding estranged family members from future rituals and/or removing oneself from future rituals, aged out foster youth gave voice to the potentially timeless nature of family estrangement. 
Overall, the internal boundary management practice of deritualizing speaks to the broader idea of defying family standards. It is expected that family members attend weddings, make contact at church, attend family members' funerals, and join in on the annual family BBQ. However, aged out foster youth deliberately violated these standards of family as a way to signal distance. Interestingly, participants gave voice to the defying of standards when discussing their reasons for family estrangement, such that participants estranged from family members because they failed to meet their standards of "family." When it comes to deritualizing, however, participants were the ones who deliberately defied standards of "family" as a way to deconstruct family identity. Thus, standards are not only central to why aged out foster youth estrange family members, but also how they estrange from family members - in this case, through deritualizing. Thus, participants created distance between themselves and estranged family members by intentionally violating the standards of what family members do.

\section{Silencing}

Silencing represents the first context-specific strategy to emerge inductively from participants' family estrangement experiences. Silencing is a process whereby individuals attempt to cease communication and actively reject interaction requests as a means of deconstructing family identity. Some participants referred to this practice as "avoiding" while others referred to this discursive strategy as "blocking" and/or "ignoring." However, all of these terms encompass the broader idea of silencing the relationship via disengaging and distancing oneself from the estranged family member. Silencing defies the societal expectation that family members regularly communicate with one another. Therefore, rather than engaging family to build family identity, participants silenced 
family to deconstruct family identity. Participants' experiences ultimately revealed that silence spoke louder than words. As Carmen explained:

I think my silence pretty much did enough in the end. Um, the avoidance and him being aware that I'm avoiding him and not wanting to communicate with him or see him, I think that spoke louder than screaming at him and telling him how much I despised what he did. (5)

Participants often referenced silencing as their preferred way to deconstruct family identity. For example, Carmen was sexually, psychologically, and physically abused by her biological uncle. Rather than having to face someone who engaged in those actions, she felt it was ultimately better for her to avoid him. In this way, silencing appeared to be rooted in participants' reasons for family estrangement. Becca, who estranged from her best friend due to her negative personality and lack of caring, similarly explained:

I deep down believe, and no one can tell me differently, that actions speak louder than words. I don't have to tell you that I am not your friend or that I am not talking to you. You will know because I am not going to. So, you are going to get the hint. I don't feel like I have to explain myself to you. You were not a good friend to me, so you are no longer family to me. So, yeah. I have nothing to say to her, pretty much. (15)

As participants' accounts demonstrate, a lot of times they did not feel the need to explain themselves or their actions. Thus, silencing emerged as what they perceived to be one of the "better" or "clearest" ways to signify the ending of the relationship. As participants expressed, why should they spend their time explaining themselves when they (i.e., estranged family member) were not a good family member? Results suggest that 
participants felt less of a need to talk about the family estrangement if they perceived the estranged family member did one of the worst things in their book. For some individuals, like Carmen, this was physical actions. For other participants, like Becca, it was personal attributes. This is telling because it demonstrates how higher expectations of family manifest directly into the way we address and communicate with family members who exhibit negative behaviors or possess negative traits. Aged out foster youth who estranged for physical action reasons (e.g., abuse, stealing) appeared to be no more or less likely to engage in silencing than those who estranged for reasons of personal attributes (e.g., negative personality, selfishness) or lack of social support. What this demonstrates is that silencing was a discursive strategy employed by all. Participants may feel just as passionate about not communicating with estranged family members - regardless of the reason for the estrangement - if the person directly defied their own personal expectations of family.

Participants also frequently discussed how they would ignore or block both phone calls and requests from estranged family members on social media. As social media becomes increasingly inextricable from family life, it comes as no surprise that participants had to engage in silencing via social media as well. Grace talked about how she blocked her foster sister on Facebook because she could not deal with her anymore: "Um I just shut the door on her [foster sister]. I just like, I pretty much cut her off. I blocked her on Facebook. I was like eh, I can't deal with it. You know?” Grace, like many participants, did not want to deal with the individuals they defined as estranged family members. As Krista put it: 
But yep, deleted her [half-sister] from every social media platform I've had. Facebook, Twitter, Instagram; deleted. Blocked. No phone number. I don't change my phone number, I just have blocked her from calling me. So, she gets voicemail if she tries to call me. (24)

Even if the estranged family member were to make an effort to connect, their requests would be silenced: “She like makes these Facebooks, I just block her. I don't give her the time of day. Block. Block. Block. Delete. Delete. Block” (Kayla, 23). By silencing their phone calls and social media requests, participants were making it clear that they no longer wished to be associated with the estranged family member.

Participants also talked about how they would enact the silent treatment around estranged family members at celebrations and family events. This directly defies the assumption that not only do we spend holidays with family, but we converse with families at these events. Sadie talked about how her mother came to her graduation despite her wishes. Rather than having to talk to her to un-invite her, she resorted to simply not talking with her at her graduation:

Um, she was at my high school graduation because my social worker invited her against my wishes. She was also at my college graduation at my invitation, but there was just some understanding that she could be there physically but like weren't to speak. Um, so I didn't speak to her. She was there, and I saw her, but we didn't speak. (29)

In this way, participants could tolerate being in the presence of the estranged family member, but it was always understood that they would not be speaking. As Dawn echoed: 
The other get-togethers, barbecues, family birthdays and stuff where she always goes, you know, she'll come, but like I said, she don't mess with me like that. That bond is not there no more. I won't talk to her, no. No, we just won't talk, we'll pass each other up. (27).

As many participants noted, the mere presence of an estranged family member would not deter them from seeing family ingroup members. Rather, through silencing, participants could deconstruct family identity with family outgroup members while still constructing family identity with family ingroup members. Overall, by engaging in silencing, aged out foster youth actively deconstructed family identity with estranged family members.

Overall, silencing as an identity deconstruction strategy demonstrates how individuals may seek to reduce the amount of contact between themselves and the estranged family member as a way to achieve a desired degree of relational distance. Reducing meaningful contact directly defies the societal expectations and assumptions that family members regularly communicate. Interestingly, social media was a primary component in the silencing process. Specifically, participants discussed how they would block or delete the estranged family member on various social media sites (e.g., Facebook, Snapchat, Twitter, Instagram). This gives voice to the heightened expectations that individuals not only talk with family members in person, but they are expected to actively engage with family over social media. Thus, the act of deleting or blocking estranged family members was one way that participants enacted the discursive strategy of silencing to deconstruct family identity and simultaneously reduce meaningful contact.

\section{Disassociating}


Beyond silencing, an additional context-specific discursive strategy emerged:

disassociating. Disassociating is a discursive strategy that is best understood as rejecting and/or denying familial ties to deconstruct family identity with a relational other.

Participants in the current study engaged in disassociating through using deception to distance themselves from family members and/or altering their physical appearance. As Krista explained:

I lived within five minutes of a brother and when people hear that our last names are the same it's like, "Are you related to him?" I say "No." I'm like, "Nope. I don't know that man." I know exactly who he is, I am related to him, but I tell people I'm not. (24)

Participants would disassociate with estranged family members by denying a familial connection. In this way, they worked to deconstruct family identity by voicing the estranged family member was not related to them. Denying the existence of the relationship is powerful because names are often a source of pride in families. Names affect and reflect family cohesion. Consequently, by stating that an estranged family member was not related to them participants were actively talking themselves out of the larger family group. Other participants would pretend their parents were dead or say they were adopted:

Geesh, if I'm quite honest I pretend they [biological parents] are dead... Like if I was talking to you and you were my coworker and you asked how many siblings I said I would be truthful and say, "seven siblings." Now as you ask more I would say “Oh, I was adopted" ... even though I was never adopted, that's what I say. I 
really pretend they don't exist. I've never, never told anybody about my parents... my biological parents. (Owen, 17)

Going so far as to say your parents were dead or that you were adopted is really quite extreme and emphasizes just how passionate participants in the current study were about separating themselves from estranged family members. Ultimately, by denying the existence of estranged family members as family, participants were essentially talking the relationship out of being and, consequently, deconstructing family identity.

Participants also reported altering their physical appearance as a way to disassociate with estranged family members. Jill talked about how she and her brother distanced themselves from their biological father by getting tattoos and piercings that went against his culture:

And yeah, so none of them [tribe members] have piercings or tattoos or anything like that. So, their tribe, they don't do piercings. So, my brother has his ears pierced and I have all kinds of piercings and tattoos... but nothing really visible because I am a nursing major. But like, we have piercings and tattoos and stuff so we don't even follow their culture at all. (6)

Essentially, participants reported deliberately taking action in terms of altering their physical appearance as a way to distance themselves from estranged family members. Albeit rooted in more traditional notions of family life, looking like family is still valued in our society. Thus, by deliberately taking action to alter their physical appearance, participants were directly defying this societal assumption of families. Beyond defying this assumption, participants would often talk about how looking like an estranged family 
member produced annoyance or frustration. Chad explained how he would get annoyed when he looked in the mirror and saw his father:

I think that I would see him too much when I looked at myself, and I still do. But it's kind of different... I still see that, and I still get annoyed... I feel like the longer I am by myself, because I am transitioning, I still have some features left over that look like him but the ones I have obtained newly make me look different now, so I don't feel like I look him... (7)

Altering appearances was not only an act of defiance but was also a way aged out foster youth de-identified with estranged family members. The elimination of physical indicators of a familial bond was the underlying goal for many participants. By changing their physical appearance, it was one final way to emphasize the devaluation they felt toward the biological family member. Looking like one another is often valued in families. As soon as a child is born the "who does he/she/they look like?" conversation begins and continues throughout individuals' lives. For aged out foster youth, when living with foster family members, it was likely the case that they did not look like their

family. However, when it comes to biological family members, the physical indicators of a familial connection may still be evident. Thus, disassociating via altering physical appearances appears to be uniquely tied to estranged biological family relationships.

Taken together, from denying the existence of a familial bond to taking steps to physically de-identify, participants enacted the discursive strategy of disassociating to deconstruct internal feelings of family identity with estranged family members.

\section{Research Question Six: Impacts of Family Estrangement}


The purpose of the sixth research question was to gain a deeper understanding of the impacts of family estrangement. Specifically, RQ6 (i.e., "How do aged out foster youth describe the impacts of family estrangement?") was posed as a way for aged out foster youth to elaborate on the impacts of family estrangement in their own lives. Inductive thematic analysis revealed two themes emerged with respect to family estrangement impacts: emotional implications and self-improvement. These themes and corresponding sub-themes are discussed below.

\section{Emotional Implications}

Aged out foster youth first described the impacts of family estrangement in terms of emotional implications. Emotional implications are best understood as what aged out foster youths' emotional responses have been to the family estrangement. From participants' accounts, the following sub-themes emerged: positive affect, negative affect, and mixed affect.

Positive affect. Participants often discussed their emotional response to family estrangement as positive, whereby they described experiencing positive affect as a result of the estrangement. The primary emotions that participants gave voice to were happiness, relief, peacefulness, and freedom. Participants frequently discussed how much happier they were now as a result of the family estrangement. As Abby put it:

I'm an adult and, I don't you know, I really don't have to deal with her [biological mother] ... I'm happy with where I am; I'm happy with the situation [family estrangement] and I would not change it at all. (1)

In fact, participants often talked about being happier than they had ever been: "Oh yeah! Being where I am now is probably the happiest I have ever been... because it's like no one 
is watching me... no one is waiting for me to fuck up" (11). By being able to estrange, aged out foster youth felt more comfortable in their own skin, demonstrating a more selffulfilling facet of family estrangement. In fact, many participants described how happy they were that they could put their own needs first. As Kayla explained:

And so I definitely think by me distancing myself from her [biological mother], that I allowed myself... I've provided myself with the opportunity to truly be happy and not like, kind of like, put my dreams or my passions on hold in order to accommodate her needs. (23)

As aged out foster youth consistently noted - they felt truly happier now that they abandoned what they perceived to be a toxic family relationship. They felt a sense of agency over making the decision to estrange and ultimately chose happiness over a toxic family relationship - demonstrating the trend toward putting one's individual needs first as opposed to feeling a strong familial obligation. Family estrangement was part of participants' path to achieving their own dreams and desires, such that participants felt like they could truly move forward in their lives as happier people by estranging from family members.

Participants also noted how much more peaceful and at ease they felt as a result of the estrangement. Eva described it in terms of distancing herself from negative energy: I think my life has been so chaotic until now to where it's like I only want to be around people who are peaceful or have positive auras. So, dictating who is a part of my life and distancing myself from her [biological cousin] and all the negative energy she has contributed to my life makes me feel at peace and at ease. (12) 
By estranging from family members, aged out foster youth reported being better able to live their best lives without the negative emotions certain family members would evoke. Consequently, these participants felt free - free of worry, free of drama, and free of negativity. As Noah put it: "I feel so much better! I honestly do because, I mean, just the fact of not having any kind of drama in my life. Not having to worry about the family problems like that. Just not getting into any trouble or anything. I don't know, it's FREE. I feel FREE in a way" (16). As Noah exemplified, participants simply felt better as a result of the estrangement.

As participants accounts revealed, family estrangement appeared to be part of participants' journeys to become their best selves. By reporting that they were experiencing positive affect (e.g., happiness, relief, ease, peace) as a result of the estrangement, participants reiterated the idea that family estrangement might manifest out of concern and love for oneself. For example, if a family relationship is causing distress, for the sake of one's own happiness, it may be best to extract from that relationship. Ultimately, estrangement further validates the notion that youth may rely less on family now than they did in the past. So much so that if family seems to be hindering their ability to experience positive affect they have the ability to estrange from family members without facing as many negative ramifications as they may have in the past. Because youth rely less on family for survival, cutting one person out is now a plausible and worthwhile option. Participants reported choosing this option as a way of strengthening the self - they estranged for the sake of the self. Thus, the theme of positive affect represents the positive emotional implications stemming from aged out foster youths' choice to estrange from a family member. 
Negative affect. Participants also discussed their emotional response to family estrangement as negative, whereby they described experiencing negative affect - at times - as a result of the estrangement. The primary emotions aged out foster youth ascribed to negative affect were anger, stress, disgust, pity, guilt, sadness, and hurt. As Adam said: "You feel like you lost your best friend. I felt sad, stressed, anger, disgust, pity..." (25). Carmen went on to explain how the estrangement also triggered sorrow: "It's difficult to explain, or label really, but just sorrow, complete and utter sorrow... It like, hurt me to my soul" (5). As participants, like Adam and Carmen, noted - family estrangement was, at times, associated with a variety of negative emotions. Sometimes these emotions would culminate into feelings of guilt. As Lucy explained: "It's problematic because sometimes I really do want to talk to her and I feel really guilty because this email obviously hurt her feeling and I hate that. So, I feel really guilty about that" (3). Essentially, family estrangement appears to have the ability to shake participants to their core. They reported struggling with feelings of guilt and talked about feeling sad, stressed, or angry as a result of the estrangement. It is plausible participants' experiences of negative emotions are stemming from the societal expectation that family members ought to be close. By actively choosing not to be close to a family member, aged out foster youth may be struggling with the pressure of thinking that they should be close. As a result, they are managing a tension: estrangement as good for the self but stigmatized by society.

Moreover, at the most basic level, hurting people and feeling hurt are undesirable experiences. Aged out foster youth stressed this when positioning family estrangement as triggering negative affect. They became aware that while the estrangement may have 
been the best decision for them at a given point in time, it did not take the hurt away from the process. They not only felt hurt but felt guilty for seemingly causing hurt to estranged family members. Innately, family members want to protect and care for their own - they want to be close to family and do not want to hurt family. Thus, experiencing negative affect - for at least a time - during the family estrangement process is really quite normative given what we know about family relationships.

As part of negative affect, participants also gave voice to a feeling of wistfulness or nostalgia for what the relationship used to be, look, and feel like. They reported both missing the person they estranged from as well as missing out on the memories and activities they shared. Chad reflected on his relationship with his biological father and explained what he missed most:

We shared a lot of the same interests and we had moments when he was acting sane... when he was feeling good and everything was normal. We would connect on a visceral level. Like, through conversation. So, for example, we could only talk about certain things when he was doing well and present in the moment. Then, for example, we both like certain kinds of cars. We both like... we have certain jokes with each other. We would watch certain TV shows and movies together sometimes. There's just like certain things that only he would find funny, so there's things I wish I could show him or tell him or whatever it is. There's a lot of things where I just feel like that's missing. (7)

As Chad revealed, he missed when his biological father was "feeling good" and "everything was normal." He went on to reminisce about the TV shows they would watch, jokes they would share, and how he wished he could tell or show him things 
sometimes. Val offered a similar account: "I miss the good times, I miss the part where she wasn't high as a kite, I miss the part where we would just hang out together and stuff like that, you know?" (21). Participants, such as Chad and Val, emphasized a longing for the way things used to be, and - at times - they wished they could have the old relationship back and the activities that defined that relationship in the "good times." Participants appear to be validating the idea that families are often defined by the "small things." Those everyday acts of doing family would now be gone for participants, which led to feelings of wistfulness. Similar to a break up, while individuals may know it is what is best the self, they are still saying goodbye to future interactions with someone who was significant to them at one time. Participants accounts give voice to the idea that breaking up is never easy, especially with family members.

Aged out foster youth also talked about missing the person or the person's personality, specifically. As Faith put it: "I miss him. I miss his awkwardly kind of blunt 'I don't care if you like it or not' personality. At times I need it" (26). Faith is referencing her old foster care mentor, who she estranged from as a result of his lack of social support. Even so, she described missing her old mentor's personality and felt as though she needed that presence in her life at times. Even yet, some participants would talk about how they no longer had physical mementos to tie them to their past. Grace candidly talked about how, after estranging from her foster sister, she no longer had access to the details of her past:

It [family estrangement] means you lose connections to your past. I can't ask them [foster sister's family] about things because I don't want to talk to them. I mean, I can't even ask them for things like pictures or documents, you know? It's 
like when you grew up in care you don't really have... there's not someone who like... you don't have this giant book of memories. All your memories are scattered, and they belong to various people, you know? In order to ask them for those things you kind of have to shove your ego to the side and, you know, I'm not doing that. So, I'm missing out on things that I would like to see or have, you know? (18)

As Grace described, because of her time spent in foster care, her "memories are scattered and belong to various people." Grace's experience is indicative of so many other aged out foster youth, who reported losing access to "pictures" or "documents" as a result of the family estrangement. Thus, the act of estranging meant being willing to give up facets of one's past - people, things, and places. Because family life is often defined by these very things, participants appeared to be grappling with the enormity of family estrangement and what it would mean for their lives. Consequently, experiencing negative affect was simply part of the process for many participants. Although, ultimately, they decided it was what would be best for them personally.

Overall, participants' accounts of experiencing negative emotions (i.e., anger, sadness, guilt, pity) ties into the overarching theme of negative affect by demonstrating the family estrangement may have negative emotional implications. While some foster youth may be able to reconcile - or may never experience - negative emotions (see positive affect), it is important to give voice to those experiencing emotional struggles throughout the family estrangement process.

Mixed affect. Last, some participants reported feeling their emotions throughout the process could best be classified as both positive and negative. In this regard, they 
experienced mixed affect as a result of the family estrangement. Inductive thematic analysis revealed that participants would often talk about experiencing positive and negative affect simultaneously. As Kelly put it: "I am happier, but I will always feel sad about it. I would love to have a good relationship with her [biological sister], but we just can't” (30). Lucy echoed Kelly's account of feeling happier but followed it up with a sense of longing: "You know, I don't know. I think on some days I do feel happier and then other days I am like 'Fuck! I would be so much happier if I called my mom right now"' (3). Many participants would emphasize feeling happy and then go on to discuss a negative feeling - such as sadness, longing, or regret. Even yet, some participants would emphasize mixed affect yet ultimately derive at the position that the estrangement was the best choice for them. As Chad explained:

Sometimes I feel like, sad, because I know how I am making him feel. So that makes me feel a little guilty. But sometimes I feel like I am being righteous, and these feelings are justified... that this is okay what's happening, and it wins out any emotions because this is for the betterment of everything. (7)

Participants, like Chad, often noted that despite experiencing negative affect, at the end of the day the estrangement was "for the betterment of everything" (i.e., positive affect). In this regard, we caught a glimpse into aged out foster youths' reconciliation of the family estrangement process through their accounts of mixed affect.

The idea that many emotions are involved in the estrangement is, perhaps, not so surprising. However, mixed affect illuminated a lot about how participants were processing and making sense of their experiences. Sometimes processes, like estrangement, are not so cut and dry or black and white - there is a large gray area and 
participants are giving voice to this by describing the emotional implications of family estrangement as mixed (i.e., both positive and negative). In this way, they appear to be grappling with the idea that estrangement is for the best, but it does not mean the process is easy. Sometimes doing what is best for yourself requires the reconciliation of negative emotions - family estrangement being one process that illustrates this idea quite clearly, according to aged out foster youth.

Ultimately, understanding the complexity of emotions aged out foster youth experience as a result of family estrangement calls for a better understanding of the root of these emotions. As researchers we must ask ourselves which factors allow aged out foster youth to positively adapt to family estrangement and which factors result in negative or mixed affect. Overall, understanding the emotional implications of family estrangement begs a lot of questions, but also necessarily complicates our understanding of such a complex and nuanced process.

\section{Self-Improvement}

As a result of family estrangement, participants also voiced being able to focus on improving themselves and their lives Self-improvement coalesced into three sub-themes: demonstrating empowerment, encouraging self-care, and promoting mental health.

Family estrangement as a means of self-improvement offers further support for the idea that family estrangement may be a pathway to self-actualization. While individualism is valued in western cultures, suggesting that one way to become your best self may be to abandon your foundational group (i.e., the family) holds interesting implications for what it means to be an individual - and family member - in U.S. culture. This idea animated 
participants' accounts of estrangement as self-improvement (i.e., demonstrating empowerment, encouraging self-care, and promoting mental health), discussed below.

Demonstrating empowerment. Participants positioned family estrangement as a springboard to feeling and expressing empowerment. Aged out foster youths' estrangement from a specific family member allowed them to grow and achieve more than they imagined should they have attempted to sustain the relationship. In this way, family estrangement appeared to help aged out foster youth strive toward becoming their best selves. As Abby explained:

Yeah, I mean it was, it was like... I don't know... like it was just like I had to hold on to something and I was trying to so hard and then it was like all of a sudden I had this realization that I didn't have to anymore, I didn't have to try and force someone to have a relationship with me if they really weren't trying. It was just a big relief to know that I was the person that I am and I was comfortable with it... but there's still a lot of room to grow, and I definitely think that would have been stunted had she re-entered my life and that's just... even now, it's a relief. I mean just thinking, you know, where would I be now? (1)

Participants often noted that they did know where they would have been now should they have continued trying to mend and hold onto their relationship with an estranged family member. By estranging, participants reported being able to better grow into the person they were today. Growth demonstrated empowerment, suggesting estrangement was beneficial for the individual. Participants also reflected on the how estrangement empowered them to take control of their lives. As Eva said: 
I just feel like growing up I had no control over really anything in my life so being able to decide, like, who I want in my life, who is my family, who is included in certain things... I enjoy that. (12)

By being able to choose the relationships in her life, Eva demonstrated a sense of empowerment. Participants had control over who they wanted in their lives and who they would consider family, which echo earlier results (see RQ1) that revealed aged out foster youth not only expect more of family now, but specifically pick and choose family members that fulfill very specific functions. Thus, empowerment as an impact of family estrangement further validates the notion that estrangement can serve the individual.

Participants also talked about becoming stronger people and better being able to succeed, both important aspects of empowerment. As Grace explained: "I feel like it's made me a stronger person when it comes to dealing with issues from my past, more assertive" (18). This feeling of assertiveness was also expressed by Kelly:

I guess it was my motivation, you know what I mean? I guess people always thought that I wasn't going to succeed and get anywhere in life, so it has motivated and empowered me to keep going and succeed. (30) Essentially, distancing themselves from family members resulted in the impact of demonstrating empowerment. Findings suggest that aged out foster youth finally felt as if they had control over their own lives, as if they could succeed, and as if they could become stronger. In essence, they were able to "become their own person" as a result of the estrangement (Sadie, 29) - an empowering impact, indeed.

Ultimately, family estrangement as a form of demonstrating empowerment speaks to the broader idea that aged out foster youth have high expectations of family. They no 
longer need to rely on family for basic needs. Rather, they rely on family for contributing positively to their lives in some way. Thus, when family does not meet their own personal standards - and may in fact be harmful to the self - they are more willing and able to abandon those relationships. Participants gave further credence to this idea through positioning family estrangement as a pathway to self-care.

Encouraging self-care. Family estrangement prompted participants to engage in more self-care behaviors. Whether that was positioning themselves to not get hurt, to maintain a positive outlook on life, and/or to build relationships with others - overall the estrangement prompted aged out foster youth to focus on and take care of themselves first. Participants were able to become better selves by separating from family members that appeared to be getting in the way of them living their best life. As Carmen explained: It's been a good thing for me because I, I'm not constantly reminded. Because if he were to seek out a relationship with me, um, to try to mend things, I might, I might go against everything I've tried to be this whole time which is be peaceful about it. It might just, you know, cause some emotional um, baggage to come up, that I just really realize is better suppressed and um, so it's better that he stays out so that I can maintain um, a positive outlook on my life. And not be constantly reminded. (5)

For Carmen, it was best that her uncle stayed out of her life so that she would be able to maintain a positive outlook. Like many participants, Carmen recognized that she is doing what is best for her by continuing to maintain distance between herself and her uncle. Sasha echoed how her estrangement from her biological sister has given her a more positive outlook on life: 
I have more of a positive view on life. When I was with her I used to see the negative aspects. I was the one that always pointed out all the cons of something... even when there's a million pros and there's only 3 cons I would dig so deep into those cons. It was ridiculous. I don't see life like that anymore. (14) As a result of estranging from her sister, Sasha was able to change her outlook on life to a more positive one. Ultimately, the positive outlook that emerged from estranging from family members encouraged participants in the current study to practice more self-care.

Participants also discussed self-care in terms of being able to build relationships with other people. As Trish said: "I think it works out well because then I have my time to heal and work on other things in my life. It also leaves space for me to become close to other people" (10). Participants maintained a positive outlook by acknowledging that while there may be a void, that space can be filled with other people now. By being able to distance themselves from specific family members, participants were able to grow in their relationships with other people. This finding suggests that when family members were violating aged out foster youths' expectations and standards of "family," they sought out family elsewhere. Thus, they invested their own personal resources (e.g., time, love, support) into those relationships that they felt could offer them something in return. Consequently, should family members not be offering them the things that they valued and believed were good for themselves, they sought to estrange.

Other participants talked about self-care in terms of more daily behaviors: "I mean, I sleep good, I'm eating, I'm healthy, I work out, um, I mean... I'm going to work, I'm going to school, um, I'm traveling, I'm doing a lot things" (Liz, 20). Participants often explained how, in light of the estrangement, they were able to focus their energy on 
their own life and needs. Participants would frequently talk about being able to take better care of themselves in their day to day lives as a result of the family estrangement, suggesting that family estrangement may be a pathway to self-actualization. Participants also noted how family estrangement promoted their own mental health - another individual benefit stemming from the family estrangement process.

Promoting mental health. By distancing themselves, aged out foster youth reported being able to grow and heal as a result of the trauma and toxicity associated with the estranged family member. Participants would often describe how their mental health symptoms got better when they maintained distance between themselves and the estranged family member, which gives voice to the idea that family estrangement may positively impact the individual. Jane offered a vivid account of her own personal transformation:

I was diagnosed with post-traumatic stress disorder as a result of being with my mom. Her behavior alone was traumatic enough on top of the foster care experience to warrant that label. Since then, since getting out of the system, since moving on, since becoming an adult, going to college, getting a job, all those things... the more distance I've had from her, the more those symptoms and those feelings inside of me have started to diminish and really are even going away now that I don't have any of those behaviors in my life that I had eight years ago, 10 years ago. I can feel - visually, emotionally, and physically - just the difference of having that separation has been able to give for me. (19)

As Jane revealed, her PTSD symptoms have started to diminish as a result of the family estrangement. Thus, family estrangement may have the potential to alleviate aged out 
foster youths' PTSD symptoms, should they have them. Similarly, it is plausible family estrangement may help ease anxiety, according to some participants:

I mean, like, at one point I used to have nightmares and I used to have to take medicine for anxiety and stuff. And like since I am not in the situation anymore with all of the arguing and yelling I don't have those conditions any more. And I've noticed when I put myself back in those conditions that stuff happens again, so I just keep away from it. (6).

Beyond referencing specific mental health issues that participants associated with interacting with family members they have since estranged from, participants also talked about the impact of family estrangement on their mental health more broadly. As Val noted: "I mean, it's just a lot better on my mental and emotional health because not having to sit there and listen to her scream and yell and holler!” (21). Overall, participants would frequently attribute the lessening of mental health issues to their ability to estrange from and maintain distance from family members.

Ultimately, what these results suggest is that aged out foster youth can demand and expect more from family members than they could in the past because family members are needed less for survival. In this past, if youth did not like their family they were virtually stuck because family members were your means of survival. Youth relied on their families for food, shelter, and protection. Now government assistance programs exist that can help provide for youths' food and shelter needs, as well as police to offer protection. Consequently, youth appear to now view family members as contributing to their ability to personally thrive - as was demonstrated in participants' accounts of family and home previously. Thus, when family are not empowering aged out foster youth to 
become their best selves, they have the option to extract from these family relationships and become empowered as individual selves. Participants gave voice to this notion through describing family estrangement as a way to demonstrate empowerment, encourage self-care, and promote mental health. 


\section{Chapter 5: Discussion}

This final chapter delves into the implications stemming from the findings in the current study. Broadly, the current study's findings deepen our understanding of the communicative experiences and complexities inherent to family and home life for youth who aged out of foster care. Results revealed that aged out foster youths' complex family life experiences, in terms of transitioning from family to family and home to home while in care, ultimately shaped the way they defined family, reconciled family groups, made

sense of home, and approached family estrangement. Results indicated that how aged out foster youth constituted and experienced family and home life was inextricable from the fact that they grew up and aged out of foster care. Through the weaving together of participants' experiences emerged a promising new framework for understanding family and estrangement: family estrangement as a pathway to self-actualization. This chapter will first begin with a thorough detailing and exploration of this idea, whereby findings from the current study will be linked to extant research. Next, theoretical and practical implications will be explicated. This chapter will end with a discussion of the limitations inherent to the current study as well as directions for future research.

\section{Family Estrangement as a Potential Pathway to Self-Actualization}

Prior research has tended to rely on the voices of foster parents to understand the way that family is conceptualized and experienced (see Nelson \& Colaner, 2016; Nelson \& Horstman, 2017; Suter et al., 2014). Results from the current study offer a fresh perspective for understanding family relationships through taking into the account the perspectives of aged out foster youth. Aged out foster youths' family and foster care experiences have undoubtedly shaped them, resulting in higher expectations for and 
communication within families. This is evident in participants' definitions of family (i.e., as those who love and support you unconditionally) as well as their higher expectations for identity-building talk in families (i.e., being able to talk openly without facing judgment; being able to process their past, present, and future in conversations with family members). Thus, through tracing participants' conceptualizations and sensemaking of family and home life, it became evident that aged out foster youth expected and were able to achieve belongingness and self-esteem through family relationships. Thus, the belonging and self-esteem levels of Maslow's (1943) hierarchy of needs were at work in aged out foster youths' discussions of family and home life. Because these needs were able to be met by aged out foster youth, they were now able to strive toward self-actualization. Self-actualization is best understood as the achieving of one's full potential and complete self-fulfillment (Maslow, 1943). Aged out foster youth reported wanting to become their best selves and articulated the desire to feel empowered (i.e., self-improvement implications of family estrangement). They also wanted to surround themselves with people that would contribute positively to their personal well-being (i.e., positive affect implication of family estrangement). Thus, participants' accounts give voice to a desire to fulfill the need of self-actualization. In fact, one way to potentially achieve complete self-fulfillment that participants discussed was through distancing themselves from others who appeared to be hindering their ability to make it to the top of Maslow's (1943) pyramid. In this way, participants gave voice to family estrangement as a potential pathway to self-actualization. For some, their ability to reach their full potential appeared to be stunted due to the involvement of what they perceived to be negative family members in their lives. Thus, participants accounts give voice to the idea 
that family estrangement may remove blockages to potential self-actualization. In order to explicate this idea in full, participants' experiences will be weaved together with existing literature, beginning with a discussion of the changing conceptualizations and functions of family evident in aged out foster youths' accounts in the current study.

Traditionally, family has been defined as individuals who have shared genes, a legal connection, assumed permanence, and ongoing interdependence (Baxter \& Braithwaite, 2006; Floyd et al., 2006). Because foster care placements often cannot offer the characteristics central to more traditional definitions of family, aged out foster youth demonstrated more creativity in their own family conceptualizations. As was demonstrated in participants' accounts (i.e., family as more than blood), a lot more leeway in family definitions exists beyond blood or law. In fact, while voluntary kin is often used to signify significant attachments not bound by blood or law (Braithwaite et al., 2010; Nelson, 2013), results from the current study suggest that all family relationships - even those bound by blood or law - are becoming increasingly voluntary. Indeed, defining "family" as those who love you unconditionally and as those who support you validates the idea that patterns of interaction are more salient to aged out foster youths' definitions of family than shared genetics and/or legal recognition (Galvin, 2014; Whitchurch \& Dickson, 1999). Essentially, family members are increasingly becoming people that we choose, such that our family relationships are become increasingly voluntary. Consequently, while the idea of permanence is normally attached to biological family relationships, findings from the current study lend support for the idea that permanence can be derived from any family relationships that offers the 
functions individuals deem most important to "family" - in the current study, unconditional love and support.

Love and support were constant, permanent functions of "family" for aged out foster youth. Prior research has revealed that foster youth express a continued desire, but often unmet need, to experience the relational meanings they ascribe to "permanency." Specifically, foster youth have reported wanting to experience "real" family (Samuels, 2009). For participants in the current study, unconditional love and support appear to be the relational meanings they ascribed to "real" family and, consequently, permanence (i.e., permanent family members are those who express unconditional love and support). Moreover, love and support as "constant" echoes what scholars have long-noted as a central feature of biological family relationships - permanence (see Floyd et al., 2006). However, results revealed love and support were regarded as more permanent to definitions of "family" than blood. In this way, results indicate that when it comes to defining "family," aged out foster youth reported being able to choose blood just as they could choose love and support.

Ultimately, aged out foster youth chose family members that were able to perform family in ways that met their own expectations. This idea that individuals may evaluate family performance has been revealed in prior research examining conceptualizations of family among former foster youth (Thomas et al., 2017). Specifically, the discourse of performance emerged from former foster youths' constitutions family, whereby family were those who performed familial roles, demonstrated tolerance, and provided unconditional love (Thomas et al., 2017). Family as those who love you unconditionally and as those who support you both support and extend Thomas et al's discourse of 
performance. Participants in the current study similarly positioned unconditional love as central to their definition of "family." However, participants also identified support as a central feature of "family," which serves to extend the idea of performance to account for support that is given and received in family relationships.

The expectation that family members ought to love and support each other unconditionally has been reflected in a growing body work examining the changing expectations of marriage and parenthood (see Colaner, forthcoming; Coontz, 2004; Finkel, Cheung, Emery, Carswell, \& Larson, 2015). Importantly, the trajectory from marriage as self-expression to parenting as self-expression to family as self-expression was originally argued in Colaner's (forthcoming) research on adoption as liminality. Specifically, Colaner drew from the work of researchers tracing the history of marriage to formulate the argument that parenting - and consequently family - are becoming expressions of self-actualization. In what follows, the arguments Colaner drew from and set forth are teased out and applied to the foster care context.

In the $18^{\text {th }}$ century the desire for love and affection emerged among marital partners, referred to as the love revolution (Coontz, 2004). As part of the love revolution, higher expectations for marriages surfaced. Rather than marriage existing as a way to obtain property rights, raise capital, or construct political alliance, marriage was now about companionship and intimacy (Coontz, 2004). As a result, many people started demanding the right to divorce. They desired the freedom to move on from marital partnerships that were not providing the love that was now expected of this social structure (Coontz, 2004). A team of researchers have further contributed to this line of work through describing how Americans today have higher expectations of marriage than 
ever before (Finkel et al., 2015). These heightened expectations come with a distinct benefit and risk. The benefit is that marital partners can achieve higher levels of marital quality if they are able to satisfy each other's expectations. The risk is that these expectations are so high that the ability to fall short is more plausible (Finkel et al., 2015). As Finkel et al explain, in light of these heightened expectations, marriage has become an "all or nothing" proposition. Thus, marriage is now so much more than providing for one's basic needs - marriage is expected to contribute to marital partners' ability to obtain complete self-fulfillment.

In many ways, participants' accounts of the modern family mirror the history of marital partnerships. Aged out foster youth have higher expectations of family (i.e., family ought to love and support you unconditionally) and higher expectations of home (i.e., home ought to provide a sense of belonging and stability). Indeed, something about the family group calls upon an all or nothing status - similar to that of marriage (Finkel et al., 2015). As participants account demonstrate, family members are either entirely in and giving it all they got, or they are out. The current study's findings lend support for the "all or nothing family," evident in participants' higher expectations for family relationships and a higher likelihood of estranging from family members who cannot meet their personal expectations (i.e., providing unconditional love and support, a sense of belonging, and encouraging self-improvement). Thus, the idea that marriage may be a pathway toward self-actualization transcends to the family experience (Colaner, forthcoming). Specifically, as humans climb the pyramid of Maslow's (1943) hierarchy of needs (i.e., physiological to safety to belonging to esteem to self-actualization), aged out foster youth are able to demand more of their families. In the beginning, youth relied 
on family for their most basic needs (e.g., food, shelter, protection). Now, as a society, youth have government assistance programs to provide for food and shelter needs, as well as police to offer protection. As a result, youth no longer need to rely on family for their basic needs. Rather, as participants' accounts unveiled, they now expected family to provide a sense of belonging (i.e., love and intimacy) and contribute to their self-esteem needs (i.e., acceptance and respect from others) (see Maslow, 1943). As a result, because these lower levels of Maslow's (1943) hierarchy were able to be obtained for aged out foster youth, they now had the potential to achieve self-actualization (i.e., complete selffulfillment). Thus, the function of family is now to help aged out foster youth thrive, not to ensure they survive. Importantly, the foster care system played a pivotal role in shaping this conceptualization of family for aged out foster youth.

"Foster care is a 'system' in which state authorities intervene in family life to fulfill the public's duty to protect children" (Rymph, 2017, p. 2). Thus, concern for the child - or child welfare - is ultimately what drives both historical and modern versions of the United States foster care system. This elevates the profile of children as worthy of care and protection, such that the foster care system (as a social structure) is able to step in and take responsibility of child welfare. This shift from families to social structures ensuring survival arguably changed the standards for how family relationships ought to function. Specifically, while foster care as an institution seeks to provide a child a safe and loving home (Rymph, 2017), the foster care system intills the idea that some families may simply not be good enough because they cannot provide for even the most basic human needs (e.g., food, shelter, protection). Consequently, as foster youth age out of care they may be bringing with them a heightened concern for self. In fact, participants' 
accounts indicated that their own well-being was vitally important to them. Aged out foster youth were deliberate about the family relationships they sought to maintain and those they wished to abandon. In this way, the concern for the child that manifested in the foster care system (Rymph, 2017) appeared to shift into a concern for self as foster youth aged out and had the ability to make more family and home life decisions for themselves. As a result, participants indicated that they desired family and home life arrangements that would positively impact the self by allowing them to achieve a sense of belonging, stability, and empowerment. This was true for how they designated family (i.e., as those who would love and support the self), made sense of home (i.e., as self; as a place they felt they could belong and have stability), and approached family estrangement (i.e., as a means of becoming empowered, improving the self, and experiencing positive affect). Indeed, foster care provides a model for looking to others to fulfill functions of family - such as providing love and care (see Rymph, 2017). In this way, foster care as an institution appears to have opened participants' eyes up to the possibility of family estrangement. For aged out foster youth, through their entrance into foster care, they learned that they did not have to stay in abusive or neglectful families. Thus, foster care taught aged out foster youth that there are alternatives to biological family members. While in foster care, foster families, group homes, and/or residential care facilities were these alternatives. Upon aging out of care, alternatives become anyone aged out foster youth believe can fulfill the functions of family they deem most important - previous foster family members, co-workers, mentors, and even pets. Indeed, foster care experiences appear to have truly stretched the function of family in a society where family is no longer needed for survival. Family became a way for aged out foster youth to 
thrive (i.e., achieve a sense of belonging and fulfill self-esteem needs). The result of this changing conceptualization of family is higher expectations for family and a higher likelihood of family estrangement.

Arguably, results suggest that aged out foster youth may be more prone to estrangement for two primary reasons. First, youth increasingly care more and more about the individual, as opposed to the family, in modern society (Colaner, forthcoming). Western cultural is dominated by individualism (Colaner, forthcoming; Watson, 2012). Individualism, then, is heightened and put into hyper-drive in family estrangement. Specifically, rather than family solely providing a sense of livelihood and a genetic line (Floyd et al., 2006), aged out foster youth now expect family to positively contribute to the self. This can be seen in aged out foster youths' accounts of family as providing unconditional love and support, their expectations to able to talk freely and openly without judgment in families, their expectations to be able to process past hardships in conversations with family members, and their belief that family members should accept them entirely for who they are. As a result, aged out foster youth reported estranging from family for reasons of selfishness, a negative attitude, and promiscuity. That results in quite a lot of pressure on family members, which further gives voice to the idea of family as being "all or nothing" (Finkel et al., 2015).

Second, because families do not serve as central of a role in survival as they once did, aged out foster youth give voice to the idea that family are now expected to provide higher-order feelings - such as belonging and esteem (see Maslow, 1943). In this way, individuals appear to have more ideal standards of home, family, and themselves. Evidence to this claim is supported by participants' accounts in the current study. Many 
participants voiced ideal standards of home as being a peace within themselves or a site of belonging - both of which give voice to these higher standards. Similarly, participants voiced ideal standards of family as being those that love and support you unconditionally. Arguably, by obtaining these higher standards in their family and home lives, the possibility for aged out foster youth to obtain self-fulfillment and achieve their full potential emerges. In this way, because participants' accounts give voice to family as providing belonging and self-esteem, those levels of the pyramid have been obtained. What is left is the ability to reach self-actualization - the highest level of Maslow's (1943) pyramid. Consequently, when individuals were not performing family up to their standards (see Thomas et al., 2017), aged out foster youth made the choice to leave these individuals behind for the sake of self.

By putting individual health and wellness above the preservation of the family group, participants demonstrated how family relationships are contingent upon family members' ability to appeal to individual needs. In this way, family exists for the self. A compelling example centers on one participants' account who argued their dog was their family, but their biological mother was not. The dog was able to fulfill the functions of family (e.g., happiness, love, comfort) deemed most important by this participant whereas the biological mother was not. Consequently, the biological mother was identified as a family outgroup member whereas the dog was identified as a family ingroup member. Thus, the sacrificial role that parents tended to take on appears to no longer be of primary concern, such that parents can still be rejected despite the sacrifices they may have made throughout aged out foster youths' upbringing. Essentially, if family members cannot provide the functions of family that aged out foster youth deem as most important - love, 
care, and belonging for participants in the current study - then they may be cut out. In a similar token, if family members appear to be infringing on one's ability to become their best selves (i.e., evident in participants' accounts of family estrangement as contributing to self-improvement) - via physical actions, personal attributes, or failure to provide social support - they too may be cut out. Ultimately, family estrangement appeared to be one way that participants could remove blockages to potential self-actualization. Thus, it is perhaps unsurprising that participants described the impacts of family estrangement as primarily positive.

Although participants reported experiencing negative affect - marked by feelings such as guilt or sadness - they ultimately contended that family estrangement was the best thing they could do for themselves. Family estrangement allowed aged out foster youth to demonstrate empowerment, encouraged self-care, and promoted their mental health. Ultimately then, family estrangement opened up the door for the potential of selfactualization - to become their best selves and live their best lives because they did not have certain people in their way. Indeed, more agency in family designations equates to more agency to abandon those relationships that appear to be getting in the way of one's own attainment of self-actualization. Essentially, participants appeared to be asking themselves: what can/did you do for me? If the answer did not satisfy their personal needs and standards, that person was distanced. Indeed, the fact that so many participants attributed their own self-improvement to family estrangement speaks volumes about the many potential positive implications of family identity deconstruction - and family estrangement, more broadly. Demonstrating empowerment, encouraging self-care, and promoting mental health as a result of family estrangement holds interesting implications 
in terms of the factors that promote youths' ability to demonstrate positive adaptation to difficult life experiences upon aging out of care (see Courtney et al., 2016; Courtney \& Hughes-Heuring, 2005; Cunningham \& Diversi, 2013). While it is important to reiterate the qualitative nature of this study (i.e., generalization is neither the goal nor a possibility), findings suggests that future research ought to assess the degree to which family estrangement may predict outcomes associated with aged out foster youths' selfimprovement - such as individual empowerment, self-care, self-esteem, mental health, and life satisfaction.

Moreover, while society tends to think of children as products of parents (Colaner, forthcoming), the current study illuminated how adult children are making a name for themselves by shaking up previous held notions of what it means to be family, have home, and estrange from family. Ultimately, results revealed that the expression of family appears to be changing. Because of the social systems that now exist in our society to provide for youths' most basic needs, aged out foster youth are able to expect exponentially more from family members. Specifically, aged out foster youth now expect family to provide a sense of belonging, demonstrate intimacy, and contribute positively to the self. Consequently, when family members are unable to meet these expectations, aged out foster youth positioned family estrangement as a viable solution. Importantly, while the experiences of aged out foster youth are inextricable from their family and home life experiences during care, understanding how the expression of family may be changing among other emerging adults is worthy of assessment. Thus, future research ought to examine how emerging adults are conceptualizing and making sense of family and home life. Moreover, continuing to explore family estrangement as a potential pathway to self- 
actualization represents a ripe area for future research. Specifically, examining how emerging adults talk about the reasons for family estrangement (as potentially selfserving) as well as the impact of family estrangement (as promoting self-improvement and positive affect) are two starting points that may provide additional empirical support for family estrangement as a pathway to self-actualization.

\section{Implications for Discourse-Dependence Theorizing}

Findings advance discourse-dependence theorizing by expanding knowledge about how and potentially why aged out foster youth utilize internal boundary management strategies to both construct and deconstruct family identity. First, identity construction contributions will be discussed. Then, implications stemming from the assessment and evaluation of aged out foster youths' utilization of deconstruction strategies are presented.

Heightened standards for identity-building talk. Discourse serves as the vehicle by which family identity is constructed, negotiated, and maintained (Galvin, 2006). In the current study, aged out foster youth utilized naming, discussing, narrating, ritualizing, and normalizing to construct and maintain family identity. While each of these strategies has been validated and explicated in prior research (see Colaner \& Kranstuber, 2010; Docan-Morgan, 2014; Docan-Morgan, 2017; Galvin, 2006; Harrigan, 2010; Harrigan \& Braithwaite, 2010; Hays \& Colaner, 2016; Nelson \& Colaner, 2018;

Suter, 2012; Suter et al., 2015), results lend unique insight into the idiosyncratic nature of discourse-dependence strategies. Namely, each internal boundary management strategy was discussed in a very specific way among aged out foster youth - giving voice to the uniqueness of this diverse family structure while still speaking more broadly to 
previously established identity construction strategies. Specifically, results suggest that aged out foster youth not only utilize strategies to construct family identity (Galvin, 2006), but that higher standards for "family" equate to higher expectations for identitybuilding talk. By discussing the functions of internal boundary management strategies, participants gave voice to these heightened standards. Specifically, identity constructions strategies were not just affecting and reflecting family membership, they were creating and impacting the self. Thus, not only is discourse the vehicle by which individuals construct and maintain family identity (Galvin, 2006), but family communication may be a vehicle toward self-actualization. In what follows, how higher standards for identitybuilding talk in families coalesced into specific functions that may allow aged out foster youth to strive toward self-actualization are presented.

Although participants' higher standards for identity-building talk were evident in each discursive strategy utilized in the current study, the three strategies that provided the most compelling examples of identity-building talk as a potential pathway to selfactualization included discussing, narrating, and normalizing. Participants' accounts revealed that they did not just expect families to discuss, they expected them to do it in a specific way that was, in many ways, self-serving. Discussing ultimately fulfilled the purpose of allowing aged out foster youth to process their past hardships and hopes for the future, free of judgment. By being able to process their lives and experiences in conversations with others, aged out foster youth exemplified how discussing may be a pathway toward individual self-actualization. Participants' accounts of narrating indicated much the same. Storytelling allowed aged out foster youth to process their often-complex histories and better understand their roots. Thus, participants were not 
solely sharing stories as a way to build family identity. Rather, by attaching the functions of acknowledging a shared history and reclaiming the past to narrating, participants were creating family relationships that extended their own personhood. Aged out foster youths' discussion also exemplified how normalizing may be a pathway toward selfactualization. Prior research has revealed that crafting normalcy - through affirming life can be normal despite experiencing hardships - is one way that individuals may communicate resilience (Buzzanell, 2010). In the current study, participants engaged the discursive practice of normalizing as a way to de-emphasize how their pasts may not have been the most normal. Thus, normalizing allowed participants to reconcile past hardships they faced before, during, and after aging out of care. In so doing, normalizing appeared to serve as a way for participants to communicate resilience and strive toward self-actualization.

Overall, because we have families in communication (Baxter, 2004) and families may be a pathway to self-actualization (Colaner, forthcoming), communication must serve as the vehicle toward self-actualization. The manner in which internal boundary management strategies were discussed among participants in the current study gave voice to this higher purpose. Namely, participants attached specific functions to internal boundary management strategies, demonstrating the higher standards now placed on identity-building talk in families. Participants did not just expect families to talk to build identity; rather, they had very specific requirements for what those conversations needed to look like. These higher standards for identity-building talk in families appear to affect and reflect an individual's ability and desire to self-actualize. Future research ought to continue to explore what additional functions individuals attach to internal boundary 
management strategies. Understanding how definitions of "family" may shape discursive enactments and expectations of family identity would be a fruitful place to start. Moreover, exploring how functions underlying discursive strategies may ultimately serve the individual - in addition to the family - is both worthwhile and necessary.

Evaluating family identity deconstruction strategies. Family communication researchers have contended that individuals likely utilize discursive strategies to deconstruct family identity (Galvin, 2014; Galvin \& Braithwaite, 2014). Results from the current study offer empirical support for three internal boundary management strategies proposed by Galvin and Braithwaite (2014) to deconstruct family identity: naming, discussing, and deritualizing. Beyond these strategies, two additional context-specific strategies (see Nelson \& Colaner, 2018) emerged: silencing and disassociating. The evaluation of aged out foster youths' utilization of identity deconstruction strategies implicates discourse-dependence theorizing by providing a glimpse into how identity deconstruction strategies manifest within and shape conversations among estranged family members. Beyond offering empirical evidence for the use of identity deconstruction strategies, a trend emerged among the results in the current study: each strategy employed deliberately defied family standards.

Caughlin (2003) originally proposed the defying of family standards as a contributing factor to individual dissatisfaction with family relationships. The current study contributes to this line of work through demonstrating how individuals may take it upon themselves to deliberately defy family standards as a way to create distance between themselves and an estranged family member. In what follows, how each identity 
deconstruction strategy was utilized as a way to actively and deliberately defy family standards will be exemplified.

First, participants utilized naming to accomplish this goal. Aged out foster youth discussed positioning naming as conditional and/or renaming to deconstruct family identity. First, by stressing the "biological" aspect of the name (e.g., you are my BIOLOGICAL mom), participants' defied the standards attached to naming, such that in close familial relationships with biological family members we do not tend to call our biological family members our "biological mom," "biological aunt" or "biological brother," for example, to their faces. This approach to naming not only directly defies the societal expectations of naming biological family members, but also defies standards for family relationships more broadly (i.e., biological tends to indicate closeness whereas here it was used as a way to indicate distance). Future research ought to explore if members of other discourse-dependent families add or emphasize the biological component of a name to deconstruct family identity via defying standards.

Regarding renaming, participants first discussed renaming family members such that they altered names to reflect roles and/or stripped titles altogether. Prior research has revealed that stripping a parent from their title as "mother" or "father" and replacing it with a first name can signify a lack of closeness and increased distance (Scharp, 2017). Results from this study demonstrate how beyond switching to a first name, individuals may rename by using (often negative) roles. For example, one participant talked about how she called her biological mom "egg donor" and "bitch." Findings also extend this line of work by adding in the additional layer of erasing family terms. In close families, erasing the family terms that make our relationships intelligible is unexpected. In this 
way, participants appeared to be erasing the family identity, consciously and deliberately. Both of these approaches to renaming demonstrate how aged out foster youth directly defied the standards of family through renaming estranged family members. In close family relationships, using negative titles to refer to family members and/or erasing the family member's name altogether is not normative. However, in order to signify a degree of distance, findings give voice to the plausibility of these approaches to naming. Future research ought to continue to explore how negating family terms may be deliberately utilized as a way to deconstruct family identity by defying standards of family.

Renaming was also discussed in terms of changing one's own name. Sharing the family name bonds family members and is a powerful indicator of family identity (Galvin, 2006). Thus, by changing their name, participants were deliberately and actively defying the standard that family members keep the family name. Importantly, prior research has described the legal changing of one's own name as an act of de-legitimizing (changing names to signal distance to family outsiders), such that changing one's own name was positioned as an external boundary management strategy utilized to deconstruct family identity (Scharp, 2017). In the current study, participants focused on the impact changing one's name had internally - thus deeming changing own name as an internal discursive strategy utilized to deconstruct family identity. Thus, the discursive practice of changing one's name may operate internally, in addition to externally, to deconstruct family identity. No matter the means of changing one's own name, it directly defies the family standard that we keep family names to signal family cohesion (Galvin, 2006). 
Participants also actively defied standards of family through discussing, such that aged out foster youth approached discussing by doing precisely what close families would not: setting parameters around the relationship, emphasizing the end of the relationship, reiterating the changing status of their family identity, and limiting conversations. While most of these discussing functions do not inherently imply the deconstruction of family identity on their own (the one exception being emphasizing the end of the relationship), the culmination of these different functions suggests that participants often had to be creative in their approach to deconstructing family identity. In so doing, they enacted this strategy in four unique ways - each of which defies standards of family. For example, setting parameters and limiting conversations implies that some sort of friction in the family has resulted in the need to place boundaries around family communication, which is atypical in close and healthy family relationships. By emphasizing the end of the relationship and reiterating the changing status of the family identity, standards of family were defied because participants actively made the choice to abandon the family relationship despite the societal pressure to maintain family relationships. These approaches give further voice to the idea that not only do we talk our relationships into being (Baxter, 2004), but we also talk our relationships out of being. By deliberately defying standards of family through four distinct approaches to discussing, participants in the current study navigated their way out of relationships through talk. Future research ought to examine how members of other discourse-dependent families defy standards of discussing as a way to deconstruct family identity. Moreover, exploring whether or not the amount of directness in discussions (e.g., setting parameters as more 
direct than limiting conversations) impacts individuals' success in maintaining a deconstructed family identity is worthwhile.

Deritualizing also speaks to the broader idea of defying family standards. It is expected that family members will attend weddings, communicate at Christmas, or join in on family game night as a way to build family identity (Galvin, 2006). Thus, participants deconstructed family identity by deliberately violating the standards of what family members do (e.g., attending family holidays and partaking in family rituals). Results further contribute to this line of work by illuminating how deritualizing is not only a tactic used in the here and now, but a tactic that applies to future rituals. For example, Felix talked about how he was not going to attend his uncle's funeral, should he pass away. Prior research has revealed family estrangement is an ongoing process (Scharp, 2017). The discussion of deritualizing in the present and future lends support for this assertion. Identity deconstruction strategies may be employed over and over again given the timeless nature of the family estrangement process - potentially until the death of the estranged family member. Future research ought to continue to examine how individuals defy standards of family through ritualizing (both now and in the perceived future) as a way to actively deconstruct family identity.

Two unique, context-specific strategies to deconstruct family identity also emerged from participants' accounts. The first strategy to emerge was silencing. Through taking deliberate actions, such as ignoring calls, ignoring Facebook requests, deleting family from social media, and refusing to offer explanations for their distancing actions participants engaged in this discursive practice to reduce meaningful contact, which Scharp (2017) argues is characteristic of the family estrangement process. Silencing was 
also rooted heavily in discussions of social media. Indeed, silencing defies the family standard that family members will communicate on a regular basis - both face-to-face and over social media. Findings lend support for the inclusion of silencing as an additional identity deconstruction strategy. Future work should investigate how silencing is utilized and interpreted by individuals navigating the family estrangement process. Moreover, further exploring the ways in which social media usage may influence the deconstruction of family identity though the defying of standards, as well as the family estrangement process as a whole, is both worthwhile and necessary.

The second context-specific strategy to emerge was disassociating. Disassociating operates internally through reflecting aged out foster youths' beliefs about the status of the relationship to the estranged family member. From denying the existence of a familial bond (i.e., verbal enactment) to taking steps to physically de-identify (i.e., nonverbal enactment), participants enacted this discursive strategy. These two facets of disassociating defy standards of family because it is uncharacteristic for close family members to deny they are related to one another and/or change their appearance, so they do not look like one another. Results from the current study support the idea that disassociating ought to be considered among the internal boundary strategies individuals may utilize to deconstruct family identity. Future research ought to continue to explore the ways that disassociating may manifest, both verbally and nonverbally, among individuals navigating the family estrangement process.

Overall, not only do findings from the current study lend support and offer extensions to Galvin and Braithwaite's (2014) identity deconstruction strategy theorizing, but it positions these strategies as deliberate acts of defying family standards on the part 
of the family member seeking to estrange. Thus, the defying of family standards is not only central to why aged out foster youth estrange family members, but also how they estrange from family members. Future research ought to continue to explore how aged out foster youth may deliberately defy standards to deconstruct family identity. Importantly, this reconceptualization of family standards is not limited to the foster care context. The deliberate defying of standards may also be seen among married partners, romantic partners, siblings, and friends - to name a few. Really, the possibilities are virtually endless. The only qualification for applying this conceptualization is that individuals must be deliberately defying relational standards as a means of creating distance between themselves and a relational other. Thus, I welcome future researchers to continue to explore the ways in which family standards are not only receptively evaluated, but actively initiated to obtain relational distance.

\section{Implications for Social Identity and Intergroup Theorizing}

From the results of the current study emerged two primary implications for social identity and intergroup theorizing. First, implications pertaining to what it means to move away from the family group are presented and discussed. Next, implications pertaining to how liminal group memberships may complicate current understandings of intergroup distinctions is assessed. Both of these implications are positioned within the extant literature and serve to paint a portrait of how aged out foster youths' experiences both speak to and shape social identity and intergroup theorizing more broadly.

Reimagining the family group. As was revealed through participants' accounts, family estrangement may be a pathway to self-actualization. The desire for selfactualization also informs social identity theory and intergroup theorizing, more broadly, 
through revealing how our foundational group - the family - is being reimagined. Prior research has revealed that families are among the most central, long-lasting, and meaningful groups to which an individual belongs (Giles et al., 2010; Socha, 1999). In fact, some people are so connected to the family group that the individual and the group are one in the same, signifying a strong sense of shared family identity (Manning, 2006; Soliz \& Rittenour, 2012). Thus, by disassociating from the family group via family estrangement, participants are calling us to consider the ways in which the foundational family group is being reimagined.

This disassociation with the family group speaks to a prioritization of self over the prioritization of groups, such that individuals' concern about their own well-being seemingly now trumps their desire to maintain the family group. So, while social identity theory reflects a collectivist approach to understanding the self and others (Hogg \& Abrams, 2001), individuals who estrange appear to be taking a much more individualistic approach to understanding the self and others. In fact, prior research has revealed that we are motivated to maintain a positive social identity, such that we seek to belong in superior groups (Hogg \& Abrams, 2001). Consequently, when we belong in marginalized groups or feel our groups are being perceived negatively, we tend to employ specific tactics to uphold a positive social identity (Giles et al., 2010; Hogg \& Abrams, 2001). One of these tactics is social mobility, which occurs when an individual leaves the group in search of a more positive group (Giles et al., 2010). In the current study, this is precisely what aged out foster youth did when estranging from family members. They walked away from the family group and recreated the family ingroup so it would align with their expectations of family and personal desires. In this way, rather than 
participants being a reflection of their groups (i.e., collectivist approach to understanding the self and others, typical of intergroup theorizing), they altered their groups to create themselves in the ways they wished to be (i.e., individualistic approach to understanding the self and others, demonstrating how the family group is being reimagined). Thus, family estrangement as a potential pathway to self-actualization appears to influence how aged out foster youth understand, enact, and react to the family group as a whole. Ultimately, findings lend support for the idea that our most primal group - the family group - may not be as rigid and long-lasting as we once thought. Rather, the family group is becoming more permeable (see Giles et al., 2010).

Because of the many choices individuals have to designate and define family (see Braithwaite et al., 2010) as they see best fits their own needs, there is more agency to move away from one family group and into another (i.e., more permeability). Arguably, foster care as an institution opened participants' eyes to the idea that the family group can be permeable. Foster youth are essentially told that one family cannot provide adequately so we will seek out another family for you - further reinforcing the idea that family groups are permeable and social mobility is a valid answer when a certain family group is not fulfilling our individual needs. Thus, participants' accounts implicate ingroup theorizing through positioning social mobility as the preferred tactic for upholding a positive social identity. Because of the increasing agency to alter the family ingroup as we see best fits our individual needs, social mobility is arguably more feasible and able to be enacted. Rather than engaging in social creativity (i.e., changing outlook of group to something more positive or shifting the comparison group) or social competition (i.e., advocating, protesting, or fighting for more favorable group conditions) to uphold a 
positive family ingroup identity, which arguably take more communicative work, participants' accounts of family estrangement give voice to the social mobility preference (Giles et al, 2010). Thus, the assumption that individuals will do all they can to uphold the family ingroup is simply not validated by the results of the current study. Consequently, moving forward, family ingroup research ought to take into account individuals' increasing agency to alter the family ingroup to create themselves in the ways they wish to be and individuals' preferences for upholding a positive social identity. Results suggest social mobility may be the preferred tactic. Thus, future research ought to examine whether this assertion holds up in other family structures. Moreover, future research ought to continue to evaluate the permeability of family groups and how this permeability may be influenced by societal structures (e.g., foster care institution), family standards, family estrangement, and the desire for self-actualization.

A call for research on liminal group identities. Findings also revealed that categorizing family members into distinct groups can be difficult, such that family members may not always fit neatly into the categories of family ingroup or family outgroup. From participants' discussion of this gray area emerged a new classification of group membership: liminal group members. In what follows, a tracing of liminality in prior research as well as the current study will be unveiled, affording a more complete understanding of how liminality may shape the future of social identity and intergroup theorizing.

While scholars tend to think of family membership as concrete (Socha, 1999; Vangelisti, 2006), findings suggest that family membership may not be so easily defined. Indeed, it is interesting that family members can exist in this gray space between family 
ingroup and family outgroup, given what we know about intergroup and social identity theorizing. As it stands, current theorizing positions family member classifications as rather black and white - you are either in (i.e., ingroup) or out (i.e., outgroup) (Harwood et al., 2010). This dichotomy is not only evident in families more broadly, but also within specific social identities. For example, gender. As Nuru (2014) explained, because of the gender dichotomy, transgender individuals often experience more difficulty when negotiating their gender identity. Nuru ultimately suggests that rather than conceptualizing gender identity as a dichotomy, it would behoove researchers to explore and better understand the complexity and nuances inherent to broader social identity categories. Applying this to the family, by approaching family group membership as a dichotomy we are potentially missing out on understanding and studying those who may not fit seamlessly into the family ingroup or outgroup. The same holds true for specific social identities (e.g., race, age, gender) that may also occupy liminal spaces. In what follows, how research examining racial and cultural identity speaks to the broader conceptualization that social identities may occupy a liminal space is explored. Next, how findings from the current study further shape intergroup and social identity theorizing through explaining how family group members may be perceived as occupying a liminal family identity is explicated.

Liminality is best understood as "that which is neither this nor that, and yet is both" (Turner, 1987, p. 9). From a social identity perspective, studies have emerged that arguably address the idea of liminality. Take, for instance, the growing body of work examining transracial adoptive families. Research conducted by Vivero and Jenkins (1999) revealed that transracial adoptees may be at risk for experiencing cultural 
homelessness - whereby they do not feel they entirely belong to the cultural identity group connected to their genetic origins or those of the adoptive family. In this way, cultural homelessness is indicative of a liminal space that transracial adoptees may occupy between two distinct cultural identity groups. A related line of research on the transracial adoption paradox further speaks to the liminality of social identities. The transracial adoption paradox refers to the tension between racial group classifications, such that transracial adoptees may feel caught between their own racial identity group and the racial identity group of the adoptive family (Lee, 2003). Similarly, adoptees who feel caught between two racial identity groups arguably are navigating a liminal identity: they are neither this nor that, yet both. Beyond these empirical articles, Colaner (forthcoming) has contended that adoption is a permanent liminality, such that adoptees must communicatively navigate their identity throughout their lives due to their belonging in two families (i.e., birth family and adoptive family). As a result, adoptees occupy a liminal space between the birth family and adoptive family which "necessitates that adoptees consider their identity, their place, and their belonging" (Colaner, forthcoming, p. 3). Through these bodies of work, the potentiality for individuals to occupy a liminal space between groups and/or social identities becomes evident. Consequently, a call for social identity and intergroup theorizing to take into account the ways in which individuals may communicatively reconcile and navigate their own liminal social identities is set forth.

Beyond reconciling how group memberships may result in individuals navigating their own liminal identities, the current study affords an understanding of how individuals may reconcile the group status and identities of others as liminal. Applying Turner's 
(1987) conceptualization of liminality to the broader family group, liminal family members are neither family ingroup or family outgroup members, yet are both. This conceptualization of liminality echoes the growing body of research on border work. Suter (2014) originally positioned border work as occurring when discursive strategies to build a family identity work across borders by fulfilling both internal and external functions. Importantly, researchers have contended that not only may communication work across borders, but individuals may also represent internal and external members (Galvin \& Colaner, 2013). As Colaner and Nelson (2018) argued, naturally this complicates the internal versus external nature of family borders. Findings from the current study lend support for this assertion. Aged out foster youth carefully considered the group membership of individuals and ultimately contended they were not either/or (i.e., ingroup or outgroup) but both/and (i.e., both ingroup and outgroup) family members, resulting in liminal group member classifications. Echoing prior research, results of the current study also revealed that reconciling group membership can be fraught with tension.

Building upon Colaner et al's (2014) research that examined the tensions inherent to relational-relational identity gaps for adoptees (i.e., whereby adoptees' place in the adoptive family was at odds with adoptees' place in the birth family), findings from the current study suggest individuals may feel a similar tension when reconciling others' family group membership. Specifically, participants' positioned individuals' belonging in the family ingroup as at odds with an individuals' belonging in the family outgroup resulting in liminal group classifications. Importantly, the tensions inherent to identifying others' belonging was navigated through communication in the current study. 
Specifically, participants discussed characteristics that rendered individuals as family ingroup members (i.e., fulfilling of vital family functions associated with particular roles; shared genes) as well as other characteristics that rendered those same individuals as family outgroup members (i.e., failure to fulfill vital family functions associated with specific roles; lack of shared genes). In this way, participants positioned individuals as satisfying some of the conditions of each group, but not all. Consequently, individuals' family status was positioned as liminal - not entirely belonging to the family outgroup yet not entirely belonging to the family ingroup. Thus, continuing to evaluate how family ingroup and outgroup standards may affect liminal group member designations in future research is important and necessary.

Ultimately, continuing to view social identities and groups as existing dichotomously jeopardizes researchers' ability to better understand the nuances inherent to liminal group identities. Thus, social identity and intergroup theorizing ought to take into account liminality and how liminal group identities may be navigated through talk. This is not only true for the family identity, but other social identities that may occupy a liminal space or teeter between ingroup and outgroup classifications (e.g., race, sexual orientation, gender, age). Understanding how individuals make sense of their own as well as others' liminal identities, exploring how liminal identities are communicatively navigated, and uncovering how liminal identities may be linked to specific outcomes (e.g., communication apprehension, self-concept, communication accommodation) are three specific avenues for continuing this research trajectory.

\section{Practical Implications}

Beyond theoretical implications, a variety of practical implications emerged that 
may be helpful for professionals who may work directly with foster youth during their transition out of foster care. The desire for aged out foster youth to be active in their own family and home life decisions was made evident in participants' accounts. So while aged out foster youth demonstrate a desire for support, they want to have a voice in the conversations that impact their family and home life experiences upon transitioning out of care. In what follows, practical implications relating to granting aged out foster youth agency in identifying family, helping aged out foster youth to evaluate practical skills for evaluating family, offering family estrangement coaching, and encouraging conversations about "home" are detailed and discussed.

Granting aged out foster youth agency in identifying family. When looking at how to help establish familial connections for youth who are aging out of the foster care system, results suggest it may be important for professionals to grant aged out foster youth the agency to identify important family connections for themselves. For example, results revealed certain biological family relationships may be important to some foster youth and not to others. In the current study, eight out of 30 participants defined their biological mother as a family ingroup member and just one identified their biological father as a family ingroup member. Indeed, operating under the assumption that biological family members, especially parents, always constitute family is not supported by the experiences of the participants in the current study. Thus, it is important for professionals to have a conversation with youth who are aging out of care about who they identify as family, so they may be able to more appropriately assist in fostering familial connections for aged out foster youth during their transition out of care. Ultimately, encouraging these conversations with aged out foster youth not only addresses the need 
aged out foster youth have long-noted for more connections with individuals who can support them after aging out of care (Cunningham \& Diversi, 2013), but may also lower rates of social isolation among aged out foster youth (Courtney \& Hughes-Heuring, 2005). Thus, opening the line of communication about desired social supports early onand helping to foster these connections prior to youth aging out of care - may result in foster youth having a supportive family network that they can rely during their transition out of care.

Developing practical skills for evaluating family. Findings also suggest it may be important for professions to help aged out foster youth develop practical skills in terms of judging whether or not certain individuals will be able to satisfy their standards of family upon transitioning out of care. In the current study, aged out foster youth defined family as those people who loved you and supported you in both good times and bad, such that unconditional love and support were the specific standards they identified as central to family relationships. Thus, candid conversations about whether or not specific family members may be able to meet the standards aged out foster youth deem as most important to family relationships is important to assess. Essentially, talking through what it means to be in a healthy family relationship may help aged out foster youth make decisions about which family ties may be worth maintaining and what family ties they may be best off abandoning. Knowing this information may help foster youth avoid social support disruptions (Cunningham \& Diversi, 2013) during the inevitable ups and downs associated with aging out of the foster care system.

Offering family estrangement coaching. In light of the proposition that aged out foster youth ought to receive practical skills training in terms of judging whether or not 
family members may be able to meet and uphold their personal standards of family, it may be the case that some family members simply do not fit the bill. Consequently, aged out foster youth may decide to cut ties with certain family members. In situations such as this, it would be helpful for aged out foster youth to have professionals to help coach them through the family estrangement process - should they deem that is what may be best for them as they age out of care. Thus, findings from the current study lend initial support for the inclusion of optional family estrangement coaching as part of aged out foster youths' transition plans.

As participants' accounts revealed, navigating the family estrangement process requires tactful communication. Being able to support foster youth as they navigate the complicated relationships that emerge from foster care scenarios is both worthwhile and necessary. While many trauma-based interventions exist (see Chamberlain, 2003;

DeRosa et al., 2006; Timmer et al., 2006), it is important that counselors understand the nuances inherent to cutting ties with family members. This is where family communication scholars have something unique to offer: an understanding of how communication may guide the family estrangement process. Consequently, it would be fruitful for counselors and family communication scholars to work together to create a family estrangement coaching program for aged out foster youth.

Teaching individuals how to "break up" with family members may seem counterintuitive given what we know about the importance of social support in buffering the many potential negative implications associated with aging out of care (e.g., homelessness, social isolation, job insecurity, poverty, mental health issues) (Courtney \& Hughes-Heuring, 2005; Cunningham \& Diversi, 2013; Samuels, 2009). However, 
participants' accounts revealed that one way to foster self-improvement (i.e., demonstrate empowerment, encourage self-care, and promoting mental health) may actually be to estrange from family members. Because navigating such a complex process is difficult, it would be fruitful for counselors with experience in relationship dissolution to team up with family communication scholars with expertise in family estrangement to coach aged out foster youth through the estrangement process, should they seek this support.

Specifically, focusing on how aged out foster youth might utilize the various identity deconstruction strategies emerging from the current study's findings (i.e., naming, discussing, deritualizing, silencing, and disassociating) may be a useful place to start. Ultimately, because aged out foster youth spoke extensively about the many potential positive implications that may stem from family estrangement, with some even crediting family estrangement for their own personal well-being, offering family estrangement coaching could provide aged out foster youth with a useful tool to draw from when navigating family life upon transitioning out of care. Future research ought to continue to evaluate what an estrangement coaching program might look like and ought to further evaluate the usefulness and effectiveness of estrangement coaching for aged out foster youth before implementing a program such as this at local, national, or federal levels.

Encouraging conversations about "home." Last, the current study afforded a better understanding of what "home" meant to aged out foster youth. As was aforementioned, experiences of homelessness are common among aged out foster youth (Courtney et al., 2016; Fowler et al., 2009). Thus, understanding each individuals' ideal "home" goals could be a fruitful venture for professionals who assist in putting together 
individualized transition plans for youth aging out of care. Findings of the current study revealed that "home" was conceptualized in a variety of ways - as self, as a place, and as family. Ultimately, my hope is that professionals working with aged out foster youth can take what we have learned from participants' accounts and help youth who are currently aging out of the system identify a clear path to their personal understanding of "home." For example, for individuals who defined home as a site of stability, it would be fruitful for professionals to assist aged out foster youth in identifying and talking through places that may serve this particular purpose. Indeed, home as a site of stability may mean reconnecting and residing with biological family members, residing in a transitional living facility, or finding an apartment or house to call their own. Of course, the path to each of these goals is quite different. Talking through these various choices and helping youth identify the option that believe may be best for them may result in one less thing for foster youth to worry about upon aging out of care. Thus, rather than making assumptions about the home life that may best suit aged out foster youth upon transitioning out of care, it is important to talk through the many possibilities of "home" that may personally satisfy the preferences of each individual foster youth. Ultimately, talking about home plans early and often may help aged out foster youth be better prepared for the transition out of care and may ultimately result in fewer instances of homelessness within this population.

\section{Limitations}

While the present study provided a deepened understanding of how communication affects and reflects aged out foster youths' conceptualizations and experiences of family and home life, it is important to address the limitations inherent to 
the current study. Although not the goal of this project, it is important to note that the findings of this study are limited to the participants in the current study. As such, while the results stemming from participants' accounts may be tested and evaluated in future research, the current study's findings are not inherently generalizable to the broader population. Beyond generalizability considerations, a few other limitations concerning the sample and methodology emerged.

Regarding the sample, the current study relied on retrospective accounts from youth who aged out of foster care within the past ten years. Arguably, it would have been advantageous to recruit youth who aged out of care more recently. While the accounts participants provided in the current study were evocative, it is plausible participants would have been able to provide even richer details about their family and home life experiences should they have aged out of care more recently. Thus, future research ought to attempt to solicit the perspectives of individuals who have aged out of foster care within the past year.

Additionally, while beyond the scope of the current study, recruiting foster youth closer to the time when they age of care out may allow for unique longitudinal research opportunities. A longitudinal approach could provide interesting insights into how aged out foster youth communicate about and experience family and home life over time. Moreover, a longitudinal approach may allow for the assessment of intervention work. For example, employing the expressive writing intervention (Pennebaker, 1997) or the resilience and coping intervention (Houston et al., 2017) within the first few months after youth age out of care could lay the necessary groundwork for testing the impacts of these interventions longitudinally on various well-being outcomes for youth (e.g., life 
satisfaction, mental health, self-esteem, etc.).

It is also worth noting the discrepancy between participants' level of educational attainment and that of the broader population of aged out foster youth. In the current sample, $93.3 \%$ of participants reported completing at least some college. This is quite different from the larger aged out foster youth population, in that research has revealed just $9 \%$ of youth take college courses within the 12-18 months after leaving care (Courtney et al., 2001). As noted above, this inconsistency may be due to the assessment of youth who aged out of care within the past ten years, rather than the last 12-18 months. In other words, it is plausible some youth do not start taking college classes till some time has passed since their transition out of care.

Another reason for the discrepancy between participants' level of educational attainment and that of the broader population of aged out foster youth may be directly related to the manner in which participants were recruited. Because word of mouth was a predominant way in which participation was solicited, it is plausible that the individuals that participants recommended to participate in my study were individuals within their close social networks that they talked to on a regular basis. Should the participant spreading word of the study have a higher level of educational attainment, it is possible they referred friends who occupied similar spaces (e.g., college campus). Thus, being deliberate about recruiting aged out foster youth who represent more diverse levels of educational attainment in future research may provide further insight into aged out foster youths' communication about family and home life.

Last, regarding methodological limitations, it is important to note that all interviews took place over the phone. Being able to talk to participants face-to-face may 
have resulted in more of a willingness to self-disclose on the part of the participant. Indeed, research has revealed that the immediacy that is afforded by face-to-face interviews allows for adaptability and responsiveness on the part of the researcher which, in turn, may result in increased comfort on the part of the participant to disclose (Guba \& Lincoln, 1981). Thus, moving forward, conducting interviews face-to-face with aged out foster youth may positively impact the interview environment, resulting in even richer details being provided by foster youth about their family communication and home life experiences upon aging out of care.

\section{Directions for Future Research}

Beyond the suggestions for future research already discussed and presented in this chapter, the findings from the current study point to a few additional avenues for future research that have yet to be addressed. Below, these additional directions for future research are set forth.

First, it would be interesting to examine whether blood relationships are positioned as voluntary in other diverse family forms. While prior research has revealed that voluntary kin relationships are common (Braithwaite et al., 2010), research has yet to fully illuminate the circumstances by which blood relationships come to be considered and talked about as voluntary. Essentially, understanding whether or not the designation of "biological family as voluntary family" is unique to individuals who have been in and/or aged out foster care is worth exploring in future research. Moreover, it would be worthwhile to explore whether or not family as more than blood animates definitions of "family" in other discourse-dependent families. It is plausible this finding is unique to the foster care experience, such that foster youth feel inclined to address biological 
relationships when defining "family" in light of their time spent in the foster care system. Overall, future research ought to continue to tease out the circumstances by which biological family members constitute voluntary family relationships and "family" may be defined as more than blood.

Regarding family estrangement, a variety of additional avenues for future research emerged. First, future research ought to focus more on how social class discrepancies may impact individuals' willingness and/or success in estranging from family members. It is plausible that those with more resources (i.e., belonging to higher social class) may be more likely to estrange than those with fewer resources (i.e., belonging to lower social class). While beyond the scope of the current study, understanding how social class may impact the decision to estrange from specific family members is important to explore in future research.

Second, while the current study provided an understanding of the reasons why aged out foster youth estranged from family members, it would be worthwhile to explore whether or not specific estrangement reasons shape the identity deconstruction strategies individuals tend to utilize with estranged family members. In other words, it is possible reasons for family estrangement may prompt the use of specific strategies over others to deconstruct family identity. For example, should someone seek to estrange from a family member due to physical abuse, they may determine it is best to silence the relationship altogether. Thus, the discursive practice of silencing may be particularly helpful for navigating estrangement due to physical abuse. Of course, future research would have to assess how reasons for family estrangement may be related to the utilization of specific identity deconstruction strategies. 
Last, results from the current study open the door for examining family estrangement in more diverse contexts. While prior research has focused on the communicative experiences of family estrangement in biological parent-child relationships (see Carr et al., 2015; Scharp, 2017; Scharp et al., 2015; Scharp \& Thomas, 2016), much more research is needed on how family estrangement is communicatively negotiated in broader biological family relationships, foster family relationships, and friendships - to name a few. Moreover, it could be fruitful for future researchers to specifically solicit accounts centering around a particular estrangement reason. For example, recruiting participants who solely estranged for reasons of physical abuse may provide interesting insight into how this specific experience may be navigated through communication. Ultimately, both of these specific directions for future research could result in a better understanding of the communicative complexities and nuances inherent to particular family estrangement contexts.

\section{Conclusion}

Overall, the current study deepens our understanding of the communicative experiences and complexities inherent to family and home life for youth who aged out of foster care. An examination of how aged out foster youth defined "family," family ingroup members, family outgroup members, and liminal group members offers unique insight into the negotiation and importance of family membership in aged out foster youths' lives. An exploration of how aged out foster youth constructed and maintained a family identity with family ingroup members gives voice to the power of discourse in sustaining relationships. An investigation of the characteristics and communication processes that animated the family estrangement experiences of aged out foster youth 
speaks to the complexity, ambiguity, and impacts inherent to "breaking up" with family members. Taken together, this study afforded a necessary understanding of how aged out foster youth understand and process "family," family identity formation and deconstruction, and "home" in conversations with others. A host of interesting implications - both theoretical and practical - emerged from the findings in the current study, paving the way for future research to explore how family and home life are discussed and experienced among aged out foster youth. 


\section{References}

Ackerman, J. P. \& Dozier, M. (2005). The influence of foster parent investment on children's representations of self and attachment figures. Applied Developmental Psychology, 26, 507-520. doi:10.1016/j.appdev.2005.06.003

Adoption and Foster Care Analysis Reporting System (AFCARS) (2016). Preliminary FY 2015 Estimates as of June 2016. Adoption and Foster Care Analysis and Reporting System. Retrieved from:

https://www.acf.hhs.gov/sites/default/files/cb/afcarsreport23.pdf

Agllias, K. (2013a). Family estrangement. In Encyclopedia of Social Work. New York, NY: Oxford University Press.

Agllias, K. (2013b). The gendered experience of family estrangement in later life. Journal of Women and Social Work, 28, 309-321. doi:10.1177/0886109913495727

Allen, S. F., Pfefferbaum, B., Nitiéma, P., Pfefferbaum, R. L., Houston, J. B., McCarter III, G. S., \& Gray, S. R. (2016). Resilience and coping intervention with children and adolescents in at-risk neighborhoods. Journal of Loss and Trauma, 21, 85-98. doi:10.1080/15325024.2015.1072014

Alsop, R. (2008). The trophy kids grow up: How the millennial generation is shaking up the workplace. San Francisco, CA: Jossey-Bass

Anderson, K. N., Rueter, M. A., \& Lee, R. M. (2015). Discussions about racial and ethnic differences in internationally adoptive families: Links with family engagement, warmth, \& control. Journal of Family Communication, 15, 289-308. doi:10.1080/15267431.2015.1076420 
Andersson, G. (2009) Foster children: A longitudinal study of placements and family relationships. International Journal of Social Welfare, 18, 13-26. doi:10.1111/j.1468-2397.2008.00570.x

Baxter, L. A. (2004). Relationships as dialogues. Personal Relationships, 11, 1-22. doi:10.1111/j.1475-6811.2004.00068.x

Baxter, L. A. (2014a). Introduction to the volume. In L. A. Baxter (Ed.), Remaking Family Communicatively (pp. 3-16). New York: Peter Lang.

Baxter, L. A. (2014b). Theorizing the communicative construction of "family:" Three R's. In L. A. Baxter (Ed.), Remaking Family Communicatively (pp. 33-50). New York: Peter Lang.

Baxter, L. A., \& Babbie, E. (2004). The basics of communication research. Belmont, CA: Wadsworth.

Baxter, L. A., \& Braithwaite, D. O. (2006). Introduction: Metatheory and Theory in Family Communication Research. In D. O. Braithwaite \& L. A. Baxter (Eds.), Engaging Theories in Family Communication: Multiple perspectives (pp. 1-16). Thousand Oaks, CA: Sage.

Berger, P. L., \& Luckmann, T. (1967). The social construction of reality: A treatise in the sociology of knowledge. Garden City, NY: Anchor

Biehal, N. (2012). A sense of belonging: Meanings of family and home in long-term foster care. British Journal of Social Work, 44, 955-971. doi:10.1093/bjsw/bcs177 Blunt, A. \& Dowling, R. (2006). Home. London: Routledge. Boss, P. (2010). The trauma and complicated grief of ambiguous loss. Pastoral Psychology, 59, 137-145. doi:10.1007/s11089-009-0264-0 
Braithwaite, D. O., Allen, J., \& Moore, J. (2017). Data conferencing. In J. Matthes, R. Potter, \& C. Davis (Eds.). International Encyclopedia of Communication: Methods of Qualitative Research Methods. Wiley-Blackwell. doi:10.1002/9781118901731.iecrm0057

Braithwaite, D., Bach, B., Baxter, L., DiVerniero, R., Hammonds, J., Hosek, A., ... Wolf, B. M. (2010). Constructing family: A typology of voluntary kin. Journal of Social and Personal Relationships, 27, 388-407. doi:10.1177/0265407510361615

Braithwaite, D. O., \& Baxter, L. A. (2006). Engaging theories in family communication: Multiple perspectives. Thousand Oaks, CA: Sage.

Braun, V., \& Clarke, V. (2006). Using thematic analysis in psychology. Qualitative Research in Psychology, 3, 77-101. doi:10.1191/1478088706qp063oa

Buzzanell, P. M. (2010). Resilience: Talking, resisting, and imagining new normalcies into being. Journal of Communication, 60, 1-14. doi:10.1111/j.14602466.2010.01.469.x

Caughlin, J. P. (2003). Family communication standards: What counts as excellent family communication and how are such standards associated with family satisfaction?. Human Communication Research, 29, 5-40. doi:10.1111/j.14682958.2003.tb00830.x

Children's Bureau of the United States Department of Health and Human Services. (2017). Focus areas. Retrieved from https://www.acf.hhs.gov/cb/focusareas/foster-care

Colaner, C. W. (forthcoming). Adoption as permanent liminality: Adoption experiences and cultural parenting values. In T. Carson (Ed.) Neither here nor there: The 
many voices of liminality. Cambridge: Lutterworth Press

Colaner, C. W., Halliwell, D., \& Guignon, P. (2014). "What do you say to your mother when your mother's standing beside you?" Birth and adoptive family contributions to adoptive identity via relational identity and relational-relational identity gaps. Communication Monographs, 81, 469-494.

doi:10.1080/03637751.2014.955808

Carey, J. W. (1989). A cultural approach to communication. In Communication as culture: Essays on media and society (pp. 13-36). New York: Routledge.

Carr, K., Holman, A., Abetz, J., Koenig Kellas, J., \& Vagnoni, E. (2015). Giving voice to the silence of family estrangement: Comparing reasons of estranged parents and adult children in a nonmatched sample. Journal of Family Communication, 15, 130-140. doi:10.1080/15267431.2015.1013106

Chamberlain, P. (2003). The Oregon Multidimensional Treatment Foster Care model: Features, outcomes, and progress in dissemination. In S. Schoenwald \& S. Henggeler (Series Eds.), Moving evidence-based treatments from the laboratory into clinical practice. Cognitive and Behavioral Practice, 10, 303-312. doi:10.1016/S1077-7229(03)80048-2

Chatters, L. M., Taylor, R. J., \& Jayakody, R. (1994). Fictive kinship relations in black extended families. Journal of Comparative Family Studies, 25, 297-313.

Retrieved from http://www.jstor.org/stable/41602341

Colaner, C. W., \& Kranstuber, H. (2010). "Forever kind of wondering": Communicatively managing uncertainty in adoptive families. Journal of Family Communication, 10, 236-255. doi:10.1080/15267431003682435 
Colaner, C. W., \& Soliz, J. (2015). A communication-based approach to adoptive identity: Theoretical and empirical support. Communication Research, 44, 1-27. doi:0093650215577860..1177/0093650215577860

Collier, A., Phillips, J. L., \& Ledema, R. (2015). The meaning of home at the end of life: A video-reflexive ethnography study. Palliative Medicine, 29, 695-702. doi:10.1177/0269216315575677

Coontz, S. (2000). Historical perspectives on family diversity. In D. H. Demo, K. R. Allen \& M. A. Fine (Eds.), Handbook of Family Diversity (pp. 15-31). New York, NY: Oxford University Press.

Coontz, S. (2004). The world historical transformation of marriage. Journal of Marriage and Family, 66, 974-979. doi:10.1111/j.0022-2445.2004.00067.x

Courtney, M. E., Piliavin, I., Grogan-Kaylor, A., \& Nesmith, A. (2001). Foster youth transitions to adulthood: A longitudinal view of youth leaving care. Child Welfare, 80, 685-717. doi:0009-4021/2001/060685-33

Courtney, M.E. \& Hughes Heuring, D. (2005). The transition to adulthood for youth “aging out” of the foster care system. In D. W. Oswood, E. M. Foster, C. Flanagan, \& G. R. Ruth (Eds.), On your own without a net: The transition to adulthood for vulnerable populations (pp. 27-67). Chicago, IL: University of Chicago Press.

Courtney, M. E., Okpych, N. J., Charles, P., Mikell, D., Stevenson, B., Park, K., Kindle, B., ...Feng. H. (2016). Findings from the California Youth Transitions to Adulthood Study (CalYOUTH): Conditions of Youth at Age 19. Chicago, IL: Chapin Hall at the University of Chicago. 
Cox, T. L. (2013). Improving educational outcomes for children and youths in foster care. Children \& Schools, 35, 59-62. doi:10.1093/cs/cds040

Cunningham, M. J., \& Diversi, M. (2013). Aging out: Youths' perspectives on foster care and the transition to independence. Qualitative Social Work, 12, 587-602. doi: $10.1177 / 1473325012445833$

Dattilio, F. M., \& Nichols, M. P. (2011). Reuniting estranged family members: A cognitive-behavioral-systematic perspective. The American Journal of Family Therapy, 39, 88-99. doi:10.1080/01926187.2010.530169

Day, A., Riebschleger, J., Dworsky, A., Damashek, A., \& Fogarty, K. (2012). Maximizing educational opportunities for youth aging out of foster care by engaging youth voices in a partnership for social change. Children and Youth Services Review, 34, 1007-1014. doi:10.1016/j.childyouth.2012.02.001

Denuwelaera, M. \& Bracke, P. (2007). Support and conflict in the foster family and children's well-being: A comparison between foster and birth children. Family Relations, 56, 67-79. doi:10.1111/j.1741-3729.2007.00440.x

Depres, C. (1991). The meaning of home: Literature review and directions for future research and theoretical development. Journal of Architectural and Planning Research, 8, 96-115. Retrieved from: http://www.jstor.org/stable/43029026

DeRosa, R., Habib, M., Pelcovitz, D., Rathus, J., Sonnenklar, J., Ford, J., Sunday, S., Layne, C., Saltzman, W., Turnbull, A., Labruna, V., \& Kaplan, S. (2006). Structured Psychotherapy for Adolescents Responding to Chronic Stress (SPARCS): A Trauma-focused Guide. North Shore-Long Island Jewish Health System, Manhasset, NY. 
Docan-Morgan, S. J. (2014). "They were strangers who loved me": Discussions, narratives, and rituals during Korean adoptees' initial reunions with birth families. Journal of Family Communication, 14, 352-373.

doi:10.1080/15267431.2014.946033

Docan-Morgan, S. (2017). Korean adoptees' discursive construction of birth family and adoptive family identity through names and labels. Communication Quarterly, 65, 523-548. doi:10.1080/01463373.2017.1299192

Drozd, L. M., \& Olesen, N. W. (2004). Is it abuse, alienation, and/or estrangement? A decision tree. Journal of Child Custody, 1, 65-106. doi:10.1300/J190v01n03_05

Dworsky, A., Napolitano, L., \& Courtney, M. (2013). Homelessness during the transition from foster care to adulthood. American Journal of Public Health, 103, S318-23. doi:10.2105/AJPH.2013.301455

Easthope, H. (2004). A place called home. Housing Theory and Society, 31, 128-138. doi:0.1080/14036090410021360

Ebaugh, H. R., \& Curry, M. (2000). Fictive kin as social capital in new immigrant communities. Sociological Perspectives, 43, 189-209. doi:10.2307/1389793

Ellingsen, I. T., Stephens, P., \& Størksen, I. (2012). Congruence and incongruence in the perception of 'family' among foster parents, birth parents and their adolescent (foster) children. Child \& Family Social Work, 17, 427-437. doi:10.1111/j.13652206.2011.00796.x

Ellingsen, I.T., Shemmings, D. \& Størksen, I. (2011) The concept of 'family' among Norwegian adolescents in long-term foster care. Child and Adolescents Social Work, 28, 301-318. doi:10.1007/s10560-011-0234-0. 
Finkel, E. J., Cheung, E. O., Emery, L. F., Carswell, K. L., \& Larson, G. M. (2015). The suffocation model: Why marriage in America is becoming an all-or-nothing institution. Current Directions in Psychological Science, 24, 238-244. doi: $10.1177 / 0963721415569274$

Floyd, K., \& Morman, M. T. (2006). Introduction: On the breadth of family experience. In K. Floyd \& M. T. Morman (Eds.), Widening the family circle: New research in family communication (pp. xi-xvi). Thousand Oaks, CA: Sage.

Floyd, K., Mikkelson, A. C., \& Judd, J. (2006). Defining the family through relationships. In L. H. Turner \& R. West (Eds.), The Family Communication Sourcebook (pp. 21-39). Thousand Oaks, CA: Sage.

Fowler, P. J., Toro, P. A., \& Miles, B. W. (2009). Pathways to and from homelessness and associated psychosocial outcomes among adolescents leaving the foster care system. American Journal of Public Health, 99, 1453-1458. doi:10.2105/AJPH.2008.142547

Freundlich, M., \& Wright, L. (2003). Post-permanency services. Retrieved July 6, 2004, from Casey Family Programs Center for Resource Family Support website: http://www.casey.org/NR/rdonlyres/A96DC62B-190E-4F5CA21B984B0269C8E0/123/post_permanency_services.pdf

Friedlander, A., \& Walters, M. G. (2010). When a child rejects a parent: Tailoring the intervention to fit the problem. Family Court Review, 48, 98-111. doi:10.1111/j.1744-1617.2009.01291.x

Galvin, K. M. (2004). The family of the future: What do we face? In A. L. Vangelisti (Ed.) The Routledge Handbook of Family Communication. New York: Routledge. 
Galvin, K. M. (2006). Diversity's impact on defining the family: Discourse-dependence and identity. In L. H. Turner \& R. West (Eds.), The family communication sourcebook (pp. 3-20). Thousand Oaks, CA: Sage.

Galvin, K. M. (2014). Blood, law, and discourse: Constructing and managing family identity. In L. A. Baxter (Ed.), Remaking Family Communicatively (pp. 17-32). New York: Peter Lang.

Galvin, K. M., \& Braithwaite, D. O. (2014). Theory and research from the communication field: Discourses that constitute and reflect families. Journal of Family Theory \& Review, 6, 97-111. doi:10.1111/jftr.12030

Galvin, K., \& Colaner, C. (2013). Created through law and language: Communicative complexities of adoptive families. In K. Floyd \& M. Morman (Eds.). Widening the family circle (2 ${ }^{\text {nd }}$ ed.) (pp. 191-209). Thousand Oaks, CA: Sage.

Gardner, H. (1998) The concept of family: perceptions of adults who were in long-term out-of-home care as children. Child Welfare, 77, 681-700. PMID:9830111

Gergen, K. J. (1985). The social constructionist movement in modern psychology. American Psychologist, 40, 266-275. doi:10.1037/0003-066X.40.3.266

Gergen, K. J. (2003). Meaning in relationship. In M. Gergen \& K. J. Gergen (Eds.), Social construction: A reader (pp. 148-156). Thousand Oaks, CA: Sage.

Giles, H., Reid, S., \& Harwood, J. (Eds.). (2010). The dynamics of intergroup communication. New York: Peter Lang Publishing, Inc.

Gilligan, M., Suitor, J. J., \& Pillemer, K. (2015). Estrangement between mothers and adult children: The role of norms and values. Journal of Marriage and Family, 77, 908-920. doi:10.1111/jomf.12207 
Guba, E. G., \& Lincoln, Y. S. (1981). Effective evaluation: Improving the usefulness of evaluation results through responsive and naturalistic approaches. San Francisco, CA: Jossey-Bass.

Halliwell, D. (2016). "We didn't realize the loss until it actually happened": A phenomenological, dialogic analysis of sibling pairs' relational talk about moving apart (unpublished doctoral dissertation). University of Missouri, MO.

Harrigan, M. M. (2010). Exploring the narrative process: An analysis of the adoption stories mothers tell their internationally adopted children. Journal of Family Communication, 10, 24-39. doi:10.1080/15267430903385875

Harrigan, M. M., \& Braithwaite, D. O. (2010). Discursive struggles in families formed through visible adoption: an exploration of dialectical unity. Journal of Applied Communication Research, 38, 127-144. doi:10.1080/00909881003639536.

Harwood, J. (2006). Communication as social identity. In G. J. Shepherd, J. St. John \& T. Striphas (Eds.), Communication as .... Perspectives on Theory (pp. 84-91). Thousand Oaks, CA: Sage.

Hays, A., \& Colaner, C. (2016). Discursively constructing a family identity after an autism diagnosis: Trials, tribulations, and triumphs. Journal of Family Communication, 16, 143-159. doi:10.1080/15267431.2016.1146722

Hess, J. (2000). Maintaining nonvoluntary relationships with disliked partners: An investigation into the use of distancing behaviors. Human Communication Research, 26, 458-488. doi:10.1111/j.1468-2958.2000.tb00765.x

Hogg, M. A., \& Abrams, D. (2001). Intergroup relations: Essential readings. Philadelphia, PA: Psychology Press. 
Holtan, A., Ronning, J. A., Handegayrd, B. H., \& Sourander, A. (2005). A comparison of mental health problems in kinship and nonkinship foster care. European Child \& Adolescent Psychiatry, 14, 200-207. doi:10.1007/s00787-005-0445-z

Houston, J. B. (2015). Bouncing forward: assessing advances in community resilience assessment, intervention, and theory to guide future work. American Behavioral Scientist, 59, 175-180. doi:10.1177/0002764214550294

Houston, J.B., First, J., Spialek, M.L., Sorenson, M.E., Mills - Sandoval, T., Lockett , M., First, N.L., Nitiéma , P., Allen, S.F., \& Pfefferbaum, B. (2017). Randomized controlled trial of the resilience and coping intervention (RCI) with undergraduate university students. Journal of American College Health , 65, 1-9. doi:10.1080/07448481. 2016.1227826

Houston, J. B., Spialek, M. L., Cox, J., Greenwood, M. M., \& First, J. (2015). The centrality of communication and media in fostering community resilience: A framework for assessment and intervention. American Behavioral Scientist, 59, 270-283. doi:10.1177/0002764214548563

Jaffe, P. G., Asbourne, D., \& Mamo, A. A. (2010). Early identification and prevention of parent-child alienation: A framework for balancing risks and benefits of intervention. Family Court Review, 48, 136-152. doi:10.1111/j.17441617.2009.01294.x

Johnson, C. L. (1999). Fictive kin among oldest old African Americans in the San Francisco Bay area. Journal of Gerontology: Social Sciences, 54B, S368-S375. doi:10.1093/geronb/54B.6.S368 
Jones, L. (2012). Measuring resiliency and its predictors in recently discharged foster youth. Child and Adolescent Social Work Journal, 29, 515-533. doi:10.1007/s10560-012-0275-Z

Jones, C., \& Hackett, S. (2008). Communicative openness within adoptive families: Adoptive parents' narrative accounts of the challenges of adoption talk and the approaches used to manage these challenges. Adoption Quarterly, 10, 157-178. doi:10.1080/10926750802163238

Kelly, J. B., \& Johnston, J. R. (2001). The alienated child: A reformulation of parental alienation syndrome. Family Court Review, 39, 249-266. doi:10.1111/j.1741617.2001.tb00609.x

Kim, K. J. (2006). Parent-adolescent conflict, negative emotion, and estrangement from the family of origin. Research in Human Development, 3, 45-58. doi:10.1207/s15427617rhd0301_5

Koenig Kellas, J., \& Horstman, H. (2015). Communicated narrative sense-making: Understanding family narratives, storytelling, and the construction of meaning through a communicative lens. In L.H. Turner \& R. West (Eds.) The Sage handbook of family communication ( $2^{\text {nd }}$ ed). Thousand Oaks, CA: Sage

Lee, R. M. (2003). The transracial adoption paradox: History, research, and counseling implications of cultural socialization. The Counseling Psychologist, 31, 711-744. doi: $10.1177 / 0011000003258087$

Leeds-Hurwitz, W. (2006). Social theories: Social constructionism and symbolic interactionism. In D. O. Braithwaite \& L. A. Baxter (Eds.), Family theories in communication (pp. 229-242). Thousand Oaks, CA: Sage. 
Legault, L., Anawati, M., \& Flynn, R. (2006). Factors favoring psychological resilience among fostered young people. Children and Youth Services Review, 28, 10241038. doi:10.1016/j.childyouth.2005.10.006

Leone, P., \& Weinberg, L. (2010). Addressing the unmet educational needs of children and youth in the juvenile justice and child welfare systems. Washington, DC: Georgetown University Center for Juvenile Justice Reform.

Lincoln, Y. S., \& Guba, E. G. (1985). Naturalistic inquiry. Newbury Park, CA: Sage.

Luke, N. \& Coyne, S. M. (2008). Fostering self-esteem: exploring adult recollections on the influence of foster parents. Child and Family Social Work, 13, 402-410. doi:10.1111/j.1365-2206.2008.00565.x

Luthar, S., Cicchetti, D., \& Becker, B. (2000). The construct of resilience: A critical evaluation and guidelines for future work. Child Development, 71, 543-562. doi:10.1111/1467-8624.00164

Manning, L. D. (2006). "Presenting opportunities:" Communicatively constructing a shared family identity. International \& Intercultural Communication Annual, 29, 43-67.

Maslow, A. H. (1943). A theory of human motivation. Psychological review, 50(4), 370396. doi:10.1037/h0054346

McAdams, D. P. (1993). The stories we live by: Personal myths and the making of the self. New York, NY: Guilford.

McCarthy, B., Hagan, A., \& Martin, M. J. (2002). In and out of harm's way: Violent victimization and the social capital of fictive street families. Criminology, 40, 831-865. doi:j.1745-9125.2002.tb00975.x 
McWey, L. M., Acock, A., \& Porter, B. E. (2010). The impact of continued contact with biological parents upon the mental health of children in foster care. Children and Youth Services Review, 32, 1338-1345. doi:10.1016/j.childyouth.2010.05.003

Mumby (1997). Modernism, postmodernism, and communication studies: A rereading of an ongoing debate. Communication Theory, 7, 1-28. doi:10.1111/j.14682885.1997.tb00140.x

Munro, B., \& Munro, G. (2003). Family, definition of. In J. J. Ponzetti (Ed.), International Encyclopedia of Marriage and Family (Vol. 2). New York: Thomson.

Muraco, A. (2006). Intentional families: Fictive kin ties between cross-gender, different sexual orientation friends. Journal of Marriage \& Family, 68, 1313-1325. doi:10.1111/j.1741-3737.2006.00330.x

Myers, K. K., \& Sadaghiani, K. (2010). Millennials in the workplace: A communication perspective on millennials' organizational relationships and performance. Journal of Business and Psychology, 25, 225-238. doi:10.1007/s10869-010-9172-7

Nelson, M. K. (2013). Fictive kin, families we choose, and voluntary kin: What does the discourse tell us? Journal of Family Theory \& Review, 5, 259-281. doi:10.1111/jftr.12019

Nelson, L. R. \& Colaner, C. W. (2016). Fostering “family”: How communication sustains and functions in foster families. Paper presented at the 2016 National Communication Association Conference, Philadelphia.

Nelson, L. R. \& Colaner, C. W. (2018). Becoming a transracial family: Communicatively negotiating divergent identities in families formed through transracial adoption. 
Journal of Family Communication, 18, 51-67.

doi:10.1080/15267431.2017.1396987

Nelson, L. R. \& Horstman, H. K. (2017). Communicated meaning-making in foster families: Relationships between foster parents' entrance narratives and foster child well-being. Communication Quarterly, 65, 144-166.

doi:10.1080/01463373.2016.1215337

Nuru, A. K. (2014). Between layers: Understanding the communicative negotiation of conflicting identities by transgender individuals. Communication Studies, 65, 281297. doi: $10.1080 / 10510974.2013 .833527$

Oswald, S. H., Heil, K., \& Goldbeck, L. (2010). History of maltreatment and mental health problems in foster children: A review of literature. Journal of Pediatric Psychology, 35, 462-472. doi:10.1093/jpepsy/jsp114

Owen, W. F. (1984). Interpretive themes in relational communication. Quarterly Journal of Speech, 70, 274-287. doi:10.1080/00335638409383697

Patrick, D. \& Galvin, K. M. (2012). Family communication and the foster care experience: the next frontier. Paper presented at the 2012 National Communication Association Conference, Orlando.

Pennebaker, J. W. (1997). Writing about emotional experiences as a therapeutic process. Psychological Science, 8, 162-169. doi:10.1111/j.1467-9280.1997.tb00403.x

Ray, J. A. (2013). Family Connections: Today's young families: Successful strategies for engaging millennial parents. Childhood Education, 89, 332-334.

doi:10.1080/00094056.2013.830920 
Reilly, T. (2002). Transition from care: Status and outcomes of youth who age out of foster care. Child Welfare, 82, 727-746. doi:0009-4021/2003/060727-20

Rymph, C. (2017). Raising government children: A history of foster care and the American welfare state. Chapel Hill, NC: The University of North Carolina Press

Samuels, G. M. (2009). Ambiguous loss of home: The experience of familial (im) permanence among young adults with foster care backgrounds. Children and Youth Services Review, 31, 1229-1239. doi:10.1016/j.childyouth.2009.05.008

Scannapieco, M., Connell-Carrick, K., \& Painter, K. (2007). In their own words: Challenges facing youth aging out of foster care. Child and Adolescent Social Work Journal, 24, 423-435. doi:10.1007/s10560-007-0093-x

Scharp, K. M. (2014). (De)Constructing family: Exploring communicative practices in accomplishing and maintaining estrangement between adult children and their parents (doctoral dissertation). University of Iowa, IA.

Scharp, K. M. (2017). "You're not welcome here": A grounded theory of family distancing. Communication Research (advanced online publication). doi: $10.1177 / 0093650217715542$

Scharp, K. M., Paxman, C. G., \& Thomas, L. J. (2016). "I want to go home": Homesickness experiences and social-support-seeking practices. Environment and Behavior, 48, 1175-1197. doi:10.1177/0013916515590475

Scharp, K. M., \& Thomas, L. J. (2016). Family "bonds": Making meaning of parentchild relationships in estrangement narratives. Journal of Family Communication, 16, 32-50. doi:10.1080/15267431.2015.1111215

Scharp, K. M., Thomas, L. J., \& Paxman, C. G. (2015). "It was the straw that broke the 
camel's back": Exploring the distancing processes communicatively constructed in parent-child estrangement backstories. Journal of Family Communication, 15, 330-348. doi:10.1080/15267431.2015.1076422

Sheppard, W. N. (2012). An ecological approach to understanding physical child abuse and the impact on academics: Differences between behaviors in physically abused and nonabused children regarding parental disciplinary practices, family interaction and family events and their effects on social interaction and school success. (Unpublished doctoral dissertation). Ohio State University, $\mathrm{OH}$.

Shin, S. H. (2005). Need for and actual use of mental health service by adolescents in the child welfare system. Children and Youth Services Review, 27, 1071-1083. doi:10.1016/j.childyouth.2004.12.027

Soliz, J., \& Rittenour, C. E. (2012). Family as an intergroup arena. In H. Giles (Ed.), The Handbook of Intergroup Communication (pp. 331-343). New York: Routledge. Somerville, P. (1997). The social construction of home. Journal of Architectural and Planning Research, 14(3), 226-245. Retrieved from: http://www.jstor.org/stable/43030210

Stone, E. (2004). Black sheep and kissing cousins: How our family stories shape us. London, England: Transaction Publishers.

Strauss, A., \& Corbin, J. (1990). Basics of qualitative research: Grounded theory procedures and techniques. Newbury Park, CA: Sage.

Suter, E. A. (2008). Discursive negotiation of family identity: A study of U.S. families with adopted children from China. Journal of Family Communication, 8, 126-147. doi:10.1080/1526743070185740 
Suter, E. A. (2012). Negotiating identity and pragmatism: Parental treatment of international adoptees birth culture names, Journal of Family Communication, 12, 209-226. doi:10.1080/15267431.2012.686940

Suter, E. A. (2014). The adopted family. In L.A. Baxter (Ed.), Remaking "family" communicatively (pp. 137-155). New York, NY: Peter Lang.

Suter, E. A., \& Ballard, R. L. (2009). "How much did you pay for her?”: Decisionmaking criteria underlying adoptive parents' responses to inappropriate remarks. Journal of Family Communication, 9, 107-125. doi:10.1080/15267430902773253.

Suter, E. A., Baxter, L. A., Seurer, L. M., \& Thomas, L. J. (2014). Discursive constructions of the meaning of "family" in online narratives of foster adoptive parents. Communication Monographs, 81, 59-78.

doi:10.1080/03637751.2014.880791

Suter, E. A., Seurer, L. M., Webb, S., Grewe Jr, B., \& Koenig Kellas, J. (2015). Motherhood as contested ideological terrain: Essentialist and queer discourses of motherhood at play in female-female co-mothers' talk. Communication Monographs, 82, 458-483. doi:10.1080/03637751.2015.1024702

Tajfel, H., \& Turner, J. C. (1986). The social identity theory of intergroup behaviour. In S. Worchel \& W. G. Austin (Eds.), Psychology of Intergroup Relations (pp. 724). Chicago, IL: Nelson-Hall.

Tester, G., \& Wingfield, A. H. (2013). Moving past picket fences: The meaning of "home" for public housing residents. Sociological Forum, 28, 70-84. doi:10.1111/socf.12003 
Timmer, S. G., Llrquiza, A. I., Herschell, A. D., McGrath, J. M., Zebell, N. M., Porter, A. L., \& Vargas, E. C. (2006). Parent-child interaction therapy: Application of an empirically supported treatment to maltreated children in foster care. Child Welfare, 85, 919-939. PMID: 17305042.

Thomas, L. J., Jackl, J. A., \& Crowley, J. L. (2017). “Family?... not just blood”: Discursive constructions of "family" in adult, former foster children's narratives. Journal of Family Communication, 17, 238-253.

doi:10.1080/15267431.2017.1310728

Turner, V. (1987). Betwixt and between: The liminal period in rites of passage. In L. C. Mahdi, S. Foster, \& M. Little (Eds.), Betwixt and between: Patterns of masculine and feminine initiation (3-19). La Salle, IL.: Open Court

Turner, L. H., \& West, R. (2015). The challenge of defining "family". In L. H. Turner \& R. West (Eds.), The Sage Handbook of Family Communication (pp. 10-25). Thousand Oaks, CA: Sage.

Vangelisti, A. L. (2006). Family Communication Theories: Variations and challenges. In D. O. Braithwaite \& L. A. Baxter (Eds.), Engaging Theories in Family Communication: Multiple perspectives (pp. xi-xviii). Thousand Oaks, CA: Sage. Viadero, D. (2010). Foster children. Education Week, 29, 5.

Vivero, V. N., \& Jenkins, S. R. (1999). Existential hazards of the multicultural individual: Defining and understanding" cultural homelessness." Cultural Diversity and Ethnic Minority Psychology, 5, 6-26. doi:10.1037/1099-9809.5.1.6

Warshak, R. A. (2010). Family bridges: Using insights from social science to reconnect parents and alienated children. Family Court Review, 48, 48-80. 
doi:10.1111/j.1744-1617.2009.01288.x

Watson, B. M. (2012). Intercultural and cross cultural communication. In A. Kurylo, Inter/cultural communication: Representation and construction of culture (pp. 2545). Thousand Oaks: Sage.

Watters, E. (2003). Urban tribes: A generation redefines friendship, family, commitment. New York: Bloomsbury.

Weston, K. (1991). Families we choose. New York: Columbia University Press.

Whitchurch, G. G., \& Dickson, F. C. (1999). Family communication. In M. Sussman, S. K. Steinmetz, \& G. W. Peterson (Eds.), Handbook of marriage and the family (pp. 687-704). New York: Plenum Press.

Winters, K. C., Stinchfield, R. D., Lee, S., \& Latimer, W. W. (2008). Interplay of psychosocial factors and the long-term course of adolescents with a substance use disorder. Substance Abuse, 29(2), 107-119. doi:10.1080/08897070802093460 
Table 1. Participant demographics.

\begin{tabular}{|c|c|c|c|c|c|}
\hline Pseudonym & Gender & Race & $\begin{array}{l}\text { Current } \\
\text { Age }\end{array}$ & $\begin{array}{c}\text { Age at } \\
\text { Aging Out }\end{array}$ & $\begin{array}{l}\text { Number of } \\
\text { Placements }\end{array}$ \\
\hline Maya & $\mathrm{F}$ & White & 30 & 21 & 11 \\
\hline Lucy & $\mathrm{F}$ & Bi-racial & 21 & 21 & 9 \\
\hline Jill & $\mathrm{F}$ & Bi-racial & 19 & 19 & 4 \\
\hline Owen & M & Hispanic & 27 & 18 & 7 \\
\hline Ray & M & Black & 25 & 21 & 32 \\
\hline Sasha & $\mathrm{F}$ & Black & 28 & 18 & 6 \\
\hline Trish & $\mathrm{F}$ & Black & 27 & 18 & 4 \\
\hline Noah & M & White & 24 & 18 & 4 \\
\hline $\mathrm{Liz}$ & $\mathrm{F}$ & Multi-racial & 21 & 21 & 10 \\
\hline Felix & M & White & 28 & 18 & 5 \\
\hline Eva & $\mathrm{F}$ & Black & 23 & 18 & 7 \\
\hline Val & $\mathrm{F}$ & White & 27 & 21 & 4 \\
\hline Grace & $\mathrm{F}$ & Hispanic & 30 & 21 & 10 \\
\hline Abby & $\mathrm{F}$ & Bi-racial & 20 & 18 & 15 \\
\hline Rose & $\mathrm{F}$ & Bi-racial & 18 & 18 & 13 \\
\hline Zoey & $\mathrm{F}$ & Multi-racial & 23 & 21 & 8 \\
\hline Wren & F & White & 29 & 18 & 6 \\
\hline Kayla & $\mathrm{F}$ & Black & 21 & 21 & 53 \\
\hline Faith & $\mathrm{F}$ & Black & 22 & 18 & 7 \\
\hline Paul & M & Bi-racial & 19 & 18 & 7 \\
\hline Sadie & $\mathrm{F}$ & Black & 22 & 21 & 4 \\
\hline Chad & $\mathrm{T}$ & Bi-racial & 19 & 18 & 3 \\
\hline Dawn & $\mathrm{F}$ & Black & 26 & 18 & 13 \\
\hline Becca & $\mathrm{F}$ & Black & 20 & 18 & 4 \\
\hline Jane & $\mathrm{F}$ & Bi-racial & 25 & 18 & 9 \\
\hline Kelly & $\mathrm{F}$ & Bi-racial & 27 & 18 & 3 \\
\hline Adam & M & White & 27 & 18 & 15 \\
\hline Krista & $\mathrm{F}$ & Black & 28 & 21 & 154 \\
\hline Carmen & $\mathrm{F}$ & White & 26 & 21 & 6 \\
\hline Todd & M & Bi-racial & 21 & 18 & 11 \\
\hline
\end{tabular}

Note: $\mathrm{M}=$ male, $\mathrm{F}=$ female, $\mathrm{T}=$ transgender; Ages are reported in years 
Table 2. Family ingroup members.

\begin{tabular}{|c|c|c|}
\hline Family Ingroup Members & $n$ & $\%$ \\
\hline Friend(s) & 17 & 56.7 \\
\hline Biological Sibling(s) & 14 & 46.7 \\
\hline Biological Grandparent(s) & 9 & 30.0 \\
\hline Foster Sibling(s) & 8 & 26.7 \\
\hline Biological Mother & 8 & 26.7 \\
\hline Biological Family (broad) & 7 & 23.3 \\
\hline Foster Parent(s) & 7 & 23.3 \\
\hline Foster Care Mentor(s) & 7 & 23.3 \\
\hline Social Worker(s) & 7 & 23.3 \\
\hline Co-worker(s) & 5 & 16.7 \\
\hline Uncle(s) & 4 & 13.3 \\
\hline Church Member(s) & 4 & 13.3 \\
\hline Aunt(s) & 4 & 13.3 \\
\hline Friend's Family & 4 & 13.3 \\
\hline Cousin(s) & 2 & 6.7 \\
\hline Dog & 2 & 6.7 \\
\hline Teacher(s) & 2 & 6.7 \\
\hline Foster Family (broad) & 2 & 6.7 \\
\hline Foster Cousin(s) & 1 & 3.3 \\
\hline Therapist & 1 & 3.3 \\
\hline Boss & 1 & 3.3 \\
\hline Half-sibling(s) & 1 & 3.3 \\
\hline Sibling's Adoptive Family & 1 & 3.3 \\
\hline Biological Father & 1 & 3.3 \\
\hline Family Friend(s) & 1 & 3.3 \\
\hline Community Member(s) & 1 & 3.3 \\
\hline Romantic Partner & 1 & 3.3 \\
\hline
\end{tabular}

Note: "(broad)" signifies the entire family group was referenced 
Table 3. Family outgroup members.

\begin{tabular}{llc}
\hline Family Outgroup Members & $n$ & $\%$ \\
\hline Biological Father & 9 & 30.0 \\
Biological Mother & 6 & 20.0 \\
Biological Family (broad) & 6 & 20.0 \\
Foster Family (broad) & 5 & 16.7 \\
Aunt & 4 & 13.3 \\
Biological sibling(s) & 4 & 13.3 \\
Cousins & 4 & 13.3 \\
Uncle & 3 & 10.0 \\
Extended Relatives (broad) & 3 & 10.0 \\
Biological Grandparent(s) & 2 & 6.7 \\
Friend & 2 & 6.7 \\
Foster Siblings & 2 & 6.7 \\
Foster Parent(s) & 2 & 6.7 \\
Stepsibling(s) & 1 & 3.3 \\
Group Home Members & 1 & 3.3 \\
Foster Aunt & 1 & 3.3 \\
Social Worker & 1 & 3.3 \\
\hline Note: "(broad)" signifies the entire family group was referenced & & \\
& &
\end{tabular}


Table 4. Liminal group members.

\begin{tabular}{lcc}
\hline Liminal Group Members & $n$ & $\%$ \\
\hline Biological Mother & 10 & 33.3 \\
Biological Father & 5 & 16.7 \\
Biological Sibling(s) & 5 & 16.7 \\
Extended Relatives (broad) & 4 & 13.3 \\
Friend(s) & 2 & 6.7 \\
\hline
\end{tabular}

Note: "(broad)" signifies the entire family group was reference 
Table 5. Family estrangement profiles.

\begin{tabular}{lcc}
\hline Pseudonym & Estranged Relationship & Estrangement Attribution \\
\hline Maya & Biological Sister & Sister's Toxic Attitude \\
Lucy & Biological Mother & Mother's Selfishness \\
Jill & Biological Father & Father Caused PTSD \\
Owen & Biological Parents & Mother's Emotional Abuse / Father's Selfishness \\
Ray & Biological Sister & Sister's Anger \& Promiscuity \\
Sasha & Biological Aunt & Abuse (physical, psychological) / Lack of Caring \\
Trish & Biological Sister & Sister's Betrayal \\
Noah & Foster Aunt & Aunt's Stealing / Narcissism \\
Liz & Biological Aunt & Aunt's Lack of Acceptance \\
Felix & Biological Uncle & Uncle's Drug Abuse / Betrayal \\
Eva & Biological Cousin & Cousin's Negative Personality \\
Val & Biological Mother & Abuse (psychological) / Harassment \\
Grace & Foster Sister & Foster Sister's Blaming \\
Abby & Biological Mother & Mother's Selfishness \\
Rose & Biological Family & Family's Lack of Caring \\
Zoey & Biological Grandmother & Grandmother's Negative Personality \\
Wren & Biological Aunt & Aunt's Betrayal \\
Kayla & Biological Mother & Mother's Negativity and Lack of Support \\
Faith & Foster Care Mentor & Mentor's Lack of Social Support \\
Paul & Biological Mother & Mother's Drug Abuse / Instability \\
Sadie & Biological Mother & Abuse (verbal, physical) \\
Chad & Biological Father & Father's Mental Health Issues \\
Dawn & Biological Cousin & Cousin's Pretentiousness \\
Becca & Best Friend & Friend's Negative Personality / Lack of Caring \\
Jane & Biological Mother & Abuse (emotional, physical) \\
Kelly & Biological Sister & Pretentiousness / Negativity / Verbal Abuse \\
Adam & Foster Brother & Brother's Betrayal \\
Krista & Half-Sister & Half-sister's Blaming \\
Carmen & Biological Uncle & Abuse (sexual, psychological, physical) \\
Todd & Biological Brother & Brother Moved Away \\
\hline & &
\end{tabular}




\section{APPENDIX A: CONSENT FORM}

Project Title: Aged Out Foster Youths' Experiences of Family, Home, and Estrangement

Researchers: Leslie Nelson is a doctoral candidate in the Department of Communication at the University of Missouri where Dr. Colleen Colaner, the project advisor, is an Assistant Professor.

Purpose: $\quad$ This study involves research on how aged out foster youth define and experience family, home, and estrangement upon aging out of the foster care system. To participate in this study, you must meet the following criteria: (a) be 18 years of age or older and (b) have aged out of the United States foster care system within the past 10 years.

Time: $\quad$ Each interview should take approximately 60 minutes.

Procedure: In the interview I will ask you questions about family, home, and estrangement. The interview will be audio-recorded and should last approximately 60 minutes.

Voluntary: Your participation is voluntary. You may quit at any time and you may refuse to answer any question.

Risk: $\quad$ There is minimal risk involved with the study. There is no more risk than you would experience in your daily interactions.

Benefits: There are no direct benefits for participating in this study. Your input, however, will be valuable in understanding the experiences of aged out foster youth.

Other: $\quad$ The first 30 participants will receive a \$20 Amazon e-gift card upon completion of the interview.

Confidential: Your identity will not be revealed in transcripts, written documents, or verbal presentations of the data. The following steps will be taken to protect your identity and confidentiality: (1) identifying information will be eliminated from the interview transcripts and any reporting of the data, (2) pseudonyms (i.e., "fake" names) will be utilized in the interview transcripts and any reporting of the data, (3) you can refuse to answer any question asked, and (4) audiotapes will be kept on a password protected computer.

Contact: If you have questions, feel free to contact Leslie Nelson at leslienelson@mail.missouri.edu or 402-676-1988. You may also contact the project advisor, Dr. Colleen Colaner, at colanerc@missouri.edu. 
Questions: If you have questions about your rights, contact Campus IRB:

Office of Research

483 McReynolds Hall

Columbia, MO 65211

(573) 882-9585

Thank you for your participation!

Leslie Nelson

$\mathrm{PhD}$ Candidate

Department of Communication

University of Missouri-Columbia

leslienelson@mail.missouri.edu

402-676-1988 


\section{APPENDIX B: RECRUITMENT SCRIPT}

Hello! My name is Leslie Nelson and I am a PhD candidate at the University of Missouri. I am conducting research to learn more about aged out foster youths' experiences of family, home, and estrangement. To participate you must: (1) be 18 years of age or older and (2) have aged out of the United States foster care system within the past 10 years.

The interview may take place in-person or over the phone and should last approximately 60 minutes. The first 30 participants will receive a \$20 Amazon e-gift card. If you are interested in participating, please do one of the followings:

1. Enter your contact information at https://missouri.qualtrics.com/jfe/form/SV_8dgPVVQdjxUDfVz so I can reach out to you to schedule an interview.

2. Email me to set up a time to interview: leslienelson@mail.missouri.edu

3. Call/text me to set up a time to interview: 402-676-1988

You are also welcome to contact me via email or telephone if you have any further questions about this study!

I look forward to speaking with you!

Leslie Nelson

$\mathrm{PhD}$ Candidate

Department of Communication

University of Missouri

leslienelson@mail.missouri.edu

402-676-1988 


\section{APPENDIX C: QUALTRICS RECRUITMENT SURVEY}

Thank you for your interest in completing an interview with me! Please provide your name and preferred method(s) of contact.

1. Please provide your first name:

2. How may I contact you to schedule your interview? Note: check all that apply!

a. Email (please enter email address):

b. Phone call (please enter phone number w/ area code):

c. Text message (please enter phone number w/ area code):

Thank you! I will be in touch with you soon to schedule your interview! Please don't hesitate to call/text/email me if you have any questions (see below).

All the best,

Leslie Nelson

Doctoral Candidate

Department of Communication

University of Missouri

leslienelson@mail.missouri.edu

402-676-1988 


\section{APPENDIX D: INTERVIEW PROTOCOL}

Hi, (INSERT NAME)! Thanks again for agreeing to participate in this study! This interview should last approximately 60 minutes and will be audio-recorded. I am going to ask you some questions about your family, home, and estrangement. If at any point you do not want to answer a question that is totally fine. Are you ready to begin?

\section{Starter Questions:}

1. First, can you please confirm you are 18 years of age or older and aged out of the United States foster care system within the past 10 years?

a. How old are you currently?

b. When did you leave care? How old were you?

2. Now, can you please tell me about your experience in the foster care system?

a. How did you enter into foster care? How old were you at this time?

b. Can you describe what your transition out of care was like?

i. What were your feelings at this time?

c. How many homes (i.e., foster families/group homes/residential care) did you transition into while in care?

i. Can you please describe these homes and the people within them that are or were significant to you?

\section{Family Ingroups/Family Outgroups (RQ1)}

1. With those relationships in mind that we just talked about, I want to ask you some more specific questions about your family growing up and upon aging out of care.

a. In other words, I don't want you to focus on your own children and spouse, if that's an option. Rather, I want you to think about the family or families you grew up in and family upon aging out of care.

2. First, what does family mean to you?

a. How would you define family?

b. What do you believe makes someone family?

3. Of those people you mentioned to me when telling your story, who do you consider to be a part of your family?

a. When people ask you who your family is, what do you tell them?

i. What about biological family members? Former foster family members? Group home members? Residential care members? Social workers? Others you consider to be family, such as other aged out foster youth or friends?

b. What do you believe makes these individuals family?

c. Do these individuals also consider you to be a part of their family?

i. How do you know this? 
4. Who do you consider to NOT be a part of your family that others may expect you to be family with?

a. What about biological family members? Former foster family members? Group home members? Residential care members? Social workers? Others?

b. Why don't you consider these individuals family?

i. What characteristics make these individuals not family to you?

c. Do these individuals also consider you to not be a part of their family?

i. How do you know this?

\section{Family Identity Construction Strategies (RQ3)}

1. Now I want you to think about the stories that you tell within your family...

a. What are these stories about?

b. Can you share one of your most memorable family stories with me in detail?

i. Who are the characters? What's the plot?

c. How do the stories shared in your family make you feel like family?

2. Thinking about those who you consider to be family — what names do you use when referring to these people?

a. Probe: For example, do you call your biological/foster mother mom or something else? What about siblings? Biological/foster dad? Friends?

3. Do you talk about foster care with your family members?

a. Probe: How would you describe your family conversations about foster care?

b. Probe: Were they more open or closed? Deep or surface level?

4. What are some of your family rituals? (note: rituals are special or mundane activities that occur in your family and hold special meaning to you)

a. Probe: What are some of your family rituals around holidays?

b. Probe: Are there any other special celebrations or rituals in your family? What are these? Please explain.

c. Probe: Have there been any new family rituals since you have aged out of foster care?

5. Beyond telling stories, having discussions, using specific names, and participating in family rituals - what are some other ways that make you feel like family with family members?

a. In other words, do you do or say anything else within your family that makes you feel close?

\section{Conceptions of Home (RQ2)}

1. Now I want to ask you some questions about home. 
2. So what does home mean to you?

a. Probe: Can you please define home for me, in your own words?

i. In other words, if someone asked you to define home, what would you say?

b. Probe: Is home a feeling, place, or associated with certain people?

3. How would you describe home before you entered into foster care?

a. What about while you were in foster care?

b. What about upon aging out of foster care?

4. Where do you feel most at home?

5. Where do you feel least at home?

6. What would you say are the differences between home and family?

a. Is there a difference between home and family for you?

7. What does it mean to be homeless?

a. If you have any first-hand experience with being homeless, what is/was this experience like?

b. Can you describe what it means to be homeless and how it impacts your life?

\section{Estrangement Who/Why (RQ4)}

1. Now I want to ask you some questions about family estrangement. Specifically, I want you think of someone you used to feel like family with... or that society expected you to be family with (e.g. birth family members). In other words, I want you to think about someone you once had a connection with through blood, law, or significant voluntary kin that you have distanced yourself from and/or eliminated as family.

2. Do you feel like you are estranged (or in the process of estranging) from someone you used to feel like family with or society expected you to be family with?

a. Who is this person?

i. Note: work through who this person might be for participants in the interview.

b. Can you please describe this relationship for me?

3. Why did you estrange yourself from this person?

a. What do you believe led to this estrangement?

b. For what reason(s) did you decide to estrange from this person?

\section{Family Identity Deconstruction Strategies (RQ5)}


1. For this next series of questions, I want you to keep the estranged relationship we just talked about in mind.

2. So first, research suggests individuals sometimes use stories to estrange from people.

a. At any point have you used stories to estrange from $\mathrm{X}$ ?

b. What are these stories?

i. Please describe the characters and plot of these stories.

c. Can you describe one story to me that you believe captures your estrangement from $\mathrm{X}$ ?

d. What stories do you tell about X?

i. Are there any stories you leave X out of?

3. Now I want you to think about specific conversations you had with $\mathrm{X}$ in order to distance yourself from them.

a. What did these conversations look like? What was discussed?

b. Were these discussions ongoing or one-time events? Please explain...

4. Now I want you to think about how you distance yourself from this person in terms of rituals...

a. At any point did you stop going to family gatherings or holidays to avoid $\mathrm{X}$ ? What ones? Why?

b. What rituals, everyday or otherwise, stopped happening as a result of wanting to distance yourself from $\mathrm{X}$ ?

i. Please explain what these rituals are and how they stopped happening.

ii. Probe: did you stop participating in these rituals or would you make excuses for why you couldn't attend? Can you please give me an example?

5. How do you refer to $X$ ? What do you call $X$ ?

a. Example: biological mom is now Susan, not Mom etc.

b. How do you refer to $\mathrm{X}$ to their face?

c. How do you refer to $\mathrm{X}$ in conversations with others?

d. Did you change your name at all to create distance between you and X? If so, please explain.

i. What did you change your name to? Why?

6. What other things do you say or do, if any, to distance yourself from X?

\section{Impacts of Estrangement (RQ6)}

1. Now thinking about your estrangement from $X \ldots$

2. How did this estrangement work out for you?

a. What would you say has been the impact of estrangement for you? 
3. In what ways do you believe estrangement is beneficial?

a. Do you believe estrangement is healthy? How so?

4. In what ways do you believe estrangement is problematic?

a. Do you believe estrangement is unhealthy? How so?

5. How does this estrangement make you feel?

a. What emotions did you feel throughout the estrangement process?

b. Do you believe estrangement was a good thing for you? A bad thing? Both a good and bad thing? How so? Please explain.

c. Are you happier now that you estranged from X?

6. Would you ever consider reconciling your relationship with $X$ ? Why or why not?

7. Do you have any advice for others going through the estrangement process?

\section{Concluding Questions/Demographics}

1. As you can probably tell, I am trying to understand aged out foster youths' experiences of family, home, and estrangement. With that in mind, are there any last thoughts or information you would like to provide me with? Anything you wish I would have asked?

2. Before you go, I would like to get some demographical information from you and information I need to distribute your gift card (say only if 1 of first 30 participants).

a. Again, what is your age and how old were you when you aged out of care?

b. What is your gender?

c. How would you describe your racial/ethnic background?

d. What is the highest level of education you have completed? Are you currently in school? Part-time or full-time?

e. What is your relationship status?

f. Would you mind sharing your monthly income with me?

g. What is your current living situation?

h. How many placements did you experience while in care? (e.g., foster homes, group care, residential care, etc.)

3. Now for the gift card information....

a. First, can I get your full name (i.e., first and last name)?

b. Next, can I get a valid email address from you to send your gift card?

i. When you receive the $\$ 20$ Amazon e-gift card please respond back to me so I know you got it! 
4. Are you interested in being contacted in the future to verify the findings from the study? Basically, I will send you a summary of my findings and ask you if they ring true to your experience.

5. Would you be open to being contacted for future studies?

6. At this point the interview is concluded. Thank you for participating in this study and sharing your experiences with me! 
VITA

Leslie R. Nelson (B.A., Communication Studies, University of Nebraska, 2012; M.A., Communication, University of Missouri, 2014) is a doctoral candidate in the Department of Communication at the University of Missouri. Her research examines how communication affects and reflects diverse family forms. Specifically, her work focuses on how family communication: (1) creates, maintains, and deconstructs family identity, (2) promotes sense-making and coping during relational transitions, and (3) impacts individual and relational well-being in diverse family structures. Much of her current work seeks to advance theoretical and practical knowledge of foster family communication. Leslie's work has been published in Communication Monographs, Journal of Social and Personal Relationships, Communication Quarterly, Journal of Family Communication, and Journal of Family Theory and Review. Her research has also been supported with grants from the University of Missouri (i.e., Richard Wallace Alumni Grant, Rebecca Verser \& Alumni Graduate Support Grant, Graduate Professional Council Travel Grant, and Graduate Student Association Travel Grant). She has also served as a Research Associate for the Institute of Family Diversity and Communication during her time at Mizzou. At the University of Missouri, Leslie has helped facilitate and teach courses in Family Communication, Relational Communication, Public Speaking (including Honors), Contemporary Families and Social Issues, and Children's Communication. Leslie's commitment to teaching excellence, creativity, and innovation drove her to obtain a minor in College Teaching. She was also the recipient of the Loren Reid Outstanding Graduate Student Teacher Award in 2014 and 2017. 